\title{
INFLUÊNCIA DO VOLUME E DO FATOR DE CONFIGURAÇÃO CAVITÁRIA NAS FORÇAS GERADAS DURANTE A CONTRAÇÃO DE POLIMERIZAÇÃO DE RESINAS COMPOSTAS
}

RAFAEL FRANCISCO LIA MONDELLI 


\section{INFLUÊNCIA DO VOLUME E DO FATOR DE CONFIGURAÇÃO CAVITÁRIA NAS FORÇAS GERADAS DURANTE A CONTRAÇÃO DE POLIMERIZAÇÃO DE RESINAS COMPOSTAS}

RAFAEL FRANCISCO LIA MONDELLI

Tese apresentada à Faculdade de Odontologia de Bauru, da Universidade de São Paulo, como parte dos requisitos para a obtenção do título de Livre-docente em Odontologia, área de Dentística. 


\begin{tabular}{|l|}
\hline Mondelli, Rafael Francisco Lia Mondelli \\
M745i $\begin{array}{l}\text { Influência do volume e do fator de configuração } \\
\text { cavitária nas forças geradas durante a contração de } \\
\text { polimerização de resinas compostas / Rafael Francisco } \\
\text { Lia Mondelli -- Bauru, } 2005 .\end{array}$ \\
xxiii, 150 p. : il. ; $30 \mathrm{~cm}$. \\
Tese (Livre-docência) -- Faculdade de Odontologia \\
de Bauru. Universidade de São Paulo.
\end{tabular}

Autorizo, exclusivamente para fins acadêmicos e científicos, a reprodução total ou parcial desta tese, por processos fotocopiadores e outros meios eletrônicos.

Assinatura:

Data: 


\section{DADOS CURRICULARES}

18 de Agosto de 1966

Araraquara, São Paulo,

Brasil

Filiação

1984-1989

1989

1989-1992

1989

$1992-1996$
Nascimento

José Mondelli

Marisa Lia Mondelli

Graduação em Odontologia

Faculdade de Odontologia da Universidade Estadual Paulista "Júlio de Mesquita Filho" UNESP, Araraquara, SP.

Professor Assistente da Faculdade de Odontologia de Bauru, Departamento de Dentística, Endodontia e Materiais Dentários, da Universidade de São Paulo.

Curso de Pós Graduação em Dentística, nível Mestrado - Faculdade de Odontologia de Bauru, Universidade de São Paulo.

Sócio do G.B.P.D. - Grupo Brasileiro de Professores de Dentística.

Curso de Pós Graduação em Reabilitação Oral, nível Doutorado - Faculdade de Odontologia de Bauru, Universidade de São Paulo.

Sócio da SBPqO - Sociedade Brasileira de Pesquisas Odontológicas. 
Sócio da IADR: The International Association for Dental Research.

Concurso para provimento do cargo de Professor Doutor, em R.D.I.D.P., junto ao 1999 Departamento de Dentística, Endodontia e Materiais Dentários, da Faculdade de Odontologia de Bauru - USP.

Título de Especialista em Dentística Restauradora, reconhecido pelo CROSP.

Miniresidency in Dental Materials and Operative Dentistry, realizada na University of Minnesota School of Dentistry, EUA. 


\section{A Deus,}

Ao nosso Pai eterno, agradeço esta bênção que me permitiu almejar mais um degrau em minha carreira docente. Obrigado, Pai, por todas as oportunidades oferecidas em minha caminhada profissional e, principalmente, minha vida afetiva, permitindo que eu e a minha esposa, Maria Fernanda, construíssemos uma Família maravilhosa, brindando-nos com o dom da criação, representado pelos nossos filhos Giovanni e Rafaella. Obrigado, Pai, por sua proteção e presença constante em toda a minha existência. 


\section{Dedicatória}

À minha esposa Maria Fernanda

Dedico este trabalho à minha companheira Fernanda, por ter acreditado em nossa relação ao longo de todos estes anos de convivência. Obrigado pelo carinho, cumplicidade, pelos ensinamentos de vida, compreensão nos momentos de minha ausência, pelas experiências compartilhadas e constante dedicação a mim e, agora, também aos nossos anjos, Giovanni e Rafaella. Você é uma Esposa e Mãe maravilhosa. Continue sempre assim, meu amor!

\section{A meus filhos Giovanni e Rafaella}

Agora, que tenho vocês, com a benção de Deus, começo a entender o significado e a importância de ser um Pai de Família. Meus queridos filhos, vocês são a razão da minha vida e essência do meu ser. Não existe nada mais gratificante do que ser abençoado com um casal de filhos lindos e maravilhosos como vocês. Desculpe pela minha ausência durante a confecção deste trabalho. 


\section{Agradecimentos Especiais}

Aos meus Pais, José Mondelli e Marisa

Gostaria de agradecer todas as oportunidades na vida que vocês me proporcionaram e também à minha formação humana e profissional. Obrigado por sempre acreditarem nos meus sonhos e pelo exemplo de honestidade e humildade. Com certeza, sou o espelho desta educação e o resultado de muitos anos de ensinamentos, sacrifícios e privações que me levaram ser a pessoa e o profissional que sou hoje. Obrigado, Pai, pelos ensinamentos e pela confiança depositada. Você é minha fonte de inspiração!

Aos meus irmãos, Ricardo, Alessandro e Adriano

Pela convivência pacífica e cumplicidade demonstrada em todos estes anos de relacionamento em Família, obrigado por sempre acreditarem em mim.

Às minhas cunhadas, Maria Renata, Maria Teresa e Flávia

Agora que fazem parte da minha Família, tenho vocês como verdadeiras irmãs e amigas.

Aos meus sobrinhos, Giulia, Luca e a "neném" do Nanai e da Flávia que está a caminho

Que vocês continuem a obra de seus Pais, sempre mantendo a Família unida e em sintonia com os ensinamentos de Deus.

Aos meus sogros, Leão e Maria Marta

Obrigado por me aceitarem no berço de sua família e me fazerem sentir como um filho de vocês. Vocês são exemplos de vida e amor, servindo como luz guia no nosso caminho. 


\section{Agradecimentos}

Aos Professores da Disciplina de Dentística,

Aos amigos Aquira Ishikiriama; Carlos Eduardo Francischone; Eduardo Batista Franco; João Lúcio Coradazzi, José Carlos Pereira; José Mondelli; Maria Fidela de Lima Navarro e Maria Teresa Atta e aos demais colegas que colaboraram efetivamente com a nossa Disciplina, os quais sempre estiveram caminhando em conjunto para o engrandecimento de nosso Departamento. Obrigado pelos ensinamentos compartilhados durante todos estes anos de convivência na Disciplina de Dentística, pelas oportunidades concedidas e grande contribuição em minha formação profissional.

Aos Professores da Disciplina de Materiais Dentários

Aos professores da área de Materiais Dentários da FOB-USP, Professores Halinn, César, Paulo Amarante e Paulo Francisconi, pela convivência e ensinamentos durante estes anos de trabalho na FOB.

\section{Aos Professores da Disciplina de Endodontia}

Aos professores da área de Endodontia, Alceu, Brandão, Clóvis, Ivaldo e Norberti, pela convivência e ensinamentos durante estes anos de trabalho na FOB.

Aos Professores da Disciplina de Prótese

Obrigado pelos ensinamentos durante o curso de Doutorado em Reabilitação Oral.

Aos Professores das demais Disciplinas

Agradeço também por todos os conhecimentos transmitidos. 
- Às secretárias da área de Dentística, Ângela, Célia, Elisabeth, Eloísa, Patrícia e Rita, pelo carinho, atenção e presteza demonstrados diariamente na Dentística .

- Aos funcionários da área de Dentística, Nelson, Dito, Júnior, Karen, Zuleica, Dona Rosinha, Ziley, Maria, Mauro e demais funcionários que colaboraram com a disciplina, pela presteza e carinho com que sempre me atenderam.

- Aos funcionários do Serviço de Biblioteca da FOB-USP, pela paciência, simpatia, orientações e ensinamentos.

- Ao professor José Roberto Pereira Lauris, pela realização da análise estatística e interpretação dos resultados deste trabalho.

- Ao ex-aluno de Especialização, Hector Gregory Socias Junior pela ajuda na realização da parte experimental desta pesquisa. 


\section{Agradecimentos Institucionais}

- À Universidade de São Paulo, na pessoa do magnífico Reitor, Prof. Dr. Adolpho José Melfi; À Faculdade de Odontologia de Bauru, na pessoa de sua Diretora, Profa. Dra. Maria Fidela de Lima Navarro; Ao Hospital de Reabilitação de Anomalias Cranofaciais, na pessoa do seu Superintendente, Prof. Dr. José Alberto de Souza Freitas, nosso Tio Gastão; Ao Campus USP-Bauru, na pessoa do seu Prefeito, Prof. Dr. José Fernando Castanha Henriques; ao Presidente da Comissão de Pós-Graduação da Faculdade de Odontologia de Bauru, Prof. Dr. José Carlos Pereira; agradeço as condições e oportunidades de trabalho, assim como o especial apoio. 


\section{SUMÁRIO}

LISTA DE ABREVIATURAS, SIGLAS E SÍMBOLOS............................ xiii

LISTA DE FIGURAS .........................................................................

LISTA DE TABELAS ..................................................................

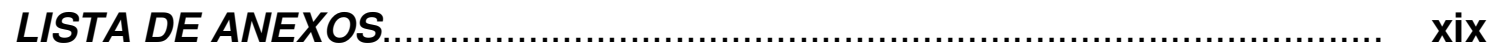

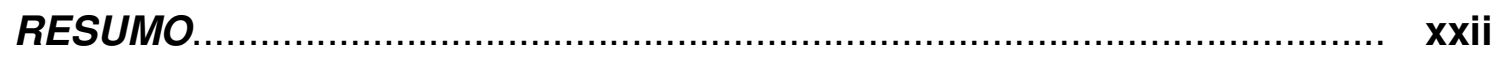

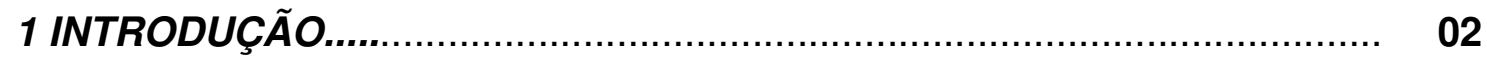

2 REVISÃO DE LITERATURA............................................................ 08

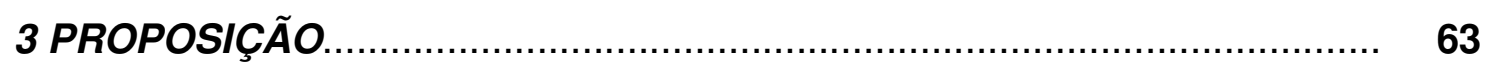

4 MATERIAIS E MÉTODO .......................................................... 65

4.1 Descrição do Método........................................................ 66

4.1.1 Determinação do volume dos incrementos de resina composta..

4.1.2 Determinação do fator de configuração cavitária (“Fator C").... 70

4.2 Influência do volume e do fator de configuração cavitária na intensidade das forças geradas durante a contração de polimerização de uma resina composta fotoativada.

4.3 Influência da variação do fator de configuração cavitária na intensidade das forças geradas durante a contração de polimerização de resinas compostas de ativação física e química.

5 RESULTADOS.

5.1 Influência do volume e do fator de configuração cavitária na intensidade das forças geradas durante a contração de polimerização de uma resina composta fotoativada.

......5.2 Influência da variação do fator de configuração cavitária na intensidade das forças geradas durante a contração de polimerização de resinas compostas de ativação física e química. 


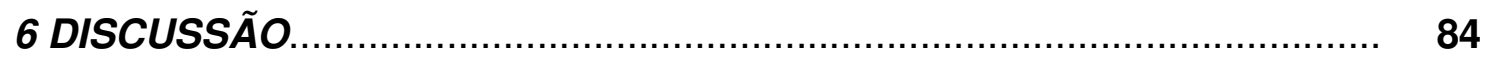

6.1 Metodologia empregada.................................................. $\quad 84$

6.2 Influência do modo de ativação das resinas compostas nas forças de contração de polimerização................................................... $\quad 87$

6.3 Geometria das bases para adesão dos compósitos.................... 91

6.4 Volume dos incrementos de resina composta........................ 94

6.5 Influência do fator de configuração cavitária na determinação das forças de contração dos compósitos............................................... $\quad 95$

7 CONCLUSÕES.

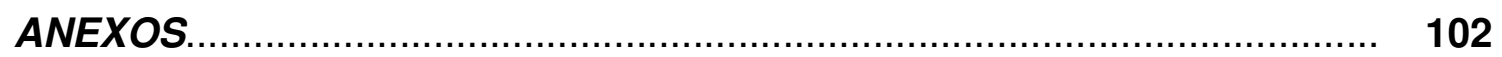

REFERÊNCIAS BIBLIOGRÁFICAS.............................................. 113

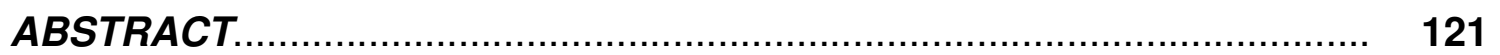




\section{LISTA DE ABREVIATURAS, SIGLAS E SÍMBOLOS}

\%: Porcentagem

$<$ : menor

$\leq$ : menor ou igual

: Graus

${ }^{\circ} \mathrm{C}$ : Graus Celsius

$\mu \mathrm{m}$ : Micrometro

\pm : Mais ou menos

"Fator C": Fator de configuração cavitária

a: Alfa

3M/ESPE: 3M do Brasil Ltda. - Produtos Dentários

ANOVA: Análise de Variância

Bis-GMA: Bisfenol Glicidil Metacrilato

Bis-EMA: Bisfenol A-etileno Metacrilato

C: Carbono

cc: Centilitro

CIV: Cimento de lonômero de Vidro

$\mathrm{cm}$ : Centímetro

$\mathrm{cm}^{2}$ : Centímetro quadrado

$\mathrm{CQ}$ : Canforoquinona

E: Energia

EGDMA: Etileno Glicol Dimetacrilato

F: Freqüência

FTIR: Fourier Transform Infrared (Espectofotômetro de Fourier)

GPa: Giga Pascal

$\mathrm{H}$ : Hora

$\mathrm{J} / \mathrm{cm}^{2}$ : Joules por centímetro quadrado

kg: Quilograma 
LED: Light Emitting Diode (Diodo Emissor de Luz) $\mathrm{mJ} / \mathrm{cm}^{2}$ : milijoules por centímetro quadrado $\mathrm{mW} / \mathrm{cm}^{2}$ : miliwats por centímetro quadrado $\mathrm{mm}$ : Milímetro $\mathrm{mm}^{2}$ : Milímetro ao quadrado $\mathrm{mm}^{3}$ : Milímetro ao cubo $\mathrm{mm} / \mathrm{MPa}$ : Milímetro por Mega Pascal $\mathrm{mm} / \mathrm{N}$ : Milímetro por Newton MSAA: Metacrilato Álcool Estireno-alil nm: Nanometro

$\mathrm{N}$ : Newton

$\mathrm{N} / \mathrm{s}$ : Newton por segundo

$\mathrm{n}$ : Número de espécimes

$\mathrm{n}^{\circ}$ : Número

s: Segundo

p: Probabilidade

TEGDMA: Trietileno Glicol Dimetacrilato UDMA: Uretano Dimetacrilato UEDMA: Uretano Etil Dimetacrilato v: Volume $\mathrm{x}$ : Indica o número de vezes 


\section{LISTA DE FIGURAS}

Figura 01 Relação das cavidades com o fator de configuração cavitária. (Fonte: FEILZER; De GEE; DAVIDSON ${ }^{34}$, 1987).

Figura 02 Gráfico demonstrando o perfil de tensão produzida pelas três resinas (esquerda) e pelos três valores de "Fator C" (direita). (Fonte: BOUSCHLINCHER; VARGAS; BOYER ${ }^{8}, 1997$ ).

Figura 03 Relação de alívio das tensões com o fator de configuração cavitária. (Fonte: SUH $\left.^{65}, 1998\right)$.

Figura 04 Fraturas em esmalte. (Fonte: SUH $\left.{ }^{65}, 1998\right)$......

Figura 05 Perfil das tensões de contração produzidos por uma resina quimicamente ativada (Silar) e uma fotoativada (Silux). (Fonte: DAUVILLIER; AARNTS; FEILZER $\left.{ }^{33}, 2000\right)$.

Figura 06 Gráfico da força de contração das resinas compostas avaliadas. (Fonte: MONDELLI; CASTAÑEDA-ESPINOSA; FRANCO ${ }^{50}, 2002$ ).

Figura 07 Curvas da força de contração da resina Z-250, em função do modo de ativação. (Fonte: AZEVEDO et al. ${ }^{5}, 2003$ ).

Figura 08 Gráfico das curvas da força de contração da resina Z-250, em função da utilização de materiais de base. (Fonte: CASTAÑEDA-ESPINOSA et al. ${ }^{15}$, 2003).

Figura 09 Esquema do dispositivo Bioman empregado na pesquisa. (Fonte: WATTS; MAROUF; AL-HINDI $\left.{ }^{73}, 2003\right)$.

Figura 10 Gráfico das curvas da força de contração $(N)$ de uma resina composta em função do tempo (s), variando a densidade de potência e o modo de ativação. (Fonte: SAKAGUCHI; WILTBANK; MURCHISON ${ }^{61}$, 2004)

Figura 11 Dispositivo empregado nos ensaios. A- resina composta (1), cilindros de vidros (2) e extensômetro (3); B- ativação com duas fontes de luz auxiliadas com um guia de posicionamento. (Fonte: CALHEIROS et al. ${ }^{13}, 2004$ )........ 
Figura 12 A- bases fixadas de forma paralela na máquina de ensaios universal Emic DL 500; B- base metálica superior acoplada ao braço móvel da máquina de ensaios através da célula de carga de $10 \mathrm{~kg}$; C- base inferior acoplada à base fixa da máquina através do dispositivo BENCOR Multi-teste; D- vista aproximada das bases metálicas.

Figura 13 Esquema dos equipamentos utilizados no teste. A- célula de carga de $10 \mathrm{~kg}$; B- bases metálicas fixadas à máquina, C- comprimento da base metálica $(6,0 \mathrm{~mm})$; D- largura da base metálica $(2,0 \mathrm{~mm})$; E- espaço ajustável entre as bases para inserção da resina composta $(1,0 \mathrm{~mm})$.

Figura 14 A- inserção e adaptação do incremento de resina composta entre as bases metálicas (1,0 mm de altura), com auxílio de espátula; B- corpo-de-prova preparado para o início do ensaio; C- fotopolimerização do incremento de resina composta com apenas uma fonte de luz.

Figura 15 Forma geométrica e dimensões do incremento (corpo-de-prova) de resina composta inserido entre as bases metálicas. A- comprimento de $6,0 \mathrm{~mm}$; Bespessura de 2,0 $\mathrm{mm}$; C- altura de 1,0 $\mathrm{mm}$.

Figura 16 Esquema das bases metálicas que foram empregadas. A- Bases metálicas retangulares de $3,0 \times 2,0 \mathrm{~mm}$; B- comprimento da base metálica $(3,0 \mathrm{~mm})$; C- largura da base metálica $(2,0 \mathrm{~mm})$; D- altura entre as bases $(2,0 \mathrm{~mm}) \mathrm{e}$ "Fator C" de 0,6; E- Bases metálicas quadradas de 2,0 x 2,0 mm; Fcomprimento da base metálica $(2,0 \mathrm{~mm})$; G- largura da base metálica $(2,0$ $\mathrm{mm})$; $\mathbf{H}-$ altura entre as bases $(3,0 \mathrm{~mm})$ e "Fator C" de 0,33

Figura 17 Forma geométrica e dimensões dos incrementos (corpos-de-prova) de resina composta inseridos entre as bases metálicas $\left(\mathrm{v}=12,0 \mathrm{~mm}^{3}\right)$. A- incremento de resina obtido a partir da base metálica de 3,0 x 2,0 mm; B- comprimento de $3,0 \mathrm{~mm}$; C- espessura de $2,0 \mathrm{~mm}$; D- altura de $2,0 \mathrm{~mm}$ e "Fator C" de 0,6; E- incremento de resina obtido a partir da base metálica de $2,0 \times 2,0 \mathrm{~mm}$; F- comprimento de $2,0 \mathrm{~mm}$; G- espessura de 2,0 mm; $\mathbf{H}$ - altura de 3,0 $\mathrm{mm}$ e "Fator C" de 0,33.

Figura 18 Gráfico das médias $(\mathrm{N})$ das forças geradas durante contração de polimerização da resina composta Z-250, em função da variação do volume e do fator de configuração cavitária. 
Figura 19 Gráfico das médias $(\mathrm{N})$ das forças geradas durante a contração de polimerização da resina composta Z-250, em função da variação do volume $\left(\mathrm{mm}^{3}\right)$

Figura 20 Gráfico das médias $(\mathrm{N})$ das forças geradas durante a contração de polimerização da resina composta Z-250, em função da variação do "Fator C",

Figura 21 Gráfico das médias $(\mathrm{N})$ das forças geradas durante a contração de polimerização da resina composta Z-250 e Concise, com volume constante de $12 \mathrm{~mm}^{3}$, em função da variação do "Fator C". 


\section{LISTA DE TABELAS}

Tabela 01 Composição básica da resina composta avaliada no experimento.

Tabela 02 Grupos avaliados em função da variação do volume e do fator de configuração cavitária da resina composta Z-250 (3M/ESPE).

Tabela 03 Composição básica das resinas compostas avaliadas no experimento

Tabela 04 Distribuição dos grupos das resinas compostas em função do modo de ativação e do fator de configuração cavitária

Tabela 05 Médias, Desvio-Padrão, Coeficiente de Variação e Análise Estatística das forças geradas durante a contração de polimerização da resina composta Z-250, em função da variação do volume e do fator de configuração cavitária.

Tabela 06 Análise de variância a um critério para comparação entre os grupos, em função do volume e do fator de configuração cavitária.

Tabela 07 Teste de Tukey para as comparações múltiplas entre os grupos

Tabela 08 Médias, Desvio-Padrão, Coeficiente de Variação e Análise Estatística das forças geradas durante a contração de polimerização das resinas compostas Z-250 e Concise, com volume constante de $12 \mathrm{~mm}^{3}$, em função da variação do fator de configuração cavitária

Tabela 09 Análise de variância a dois critérios (resina composta e "Fator C")

Tabela 10 Teste de Tukey para as comparações múltiplas entre os grupos 


\section{LISTA DE ANEXOS}

Anexo 01 Forças máximas (Newton) e curvas [força $(\mathrm{N}) \mathrm{X}$ tempo (s)] obtidas para o grupo 1 (bases 6x2 mm; volume 6,0 $\mathrm{mm}^{3}$; "Fator C" 3,0)

Anexo 02 Forças máximas (Newton) e curvas [força ( $N) X$ tempo (s)] obtidas para o grupo 2 (bases 6x2 mm; volume 12,0 $\mathrm{mm}^{3}$; "Fator C" 1,5)....

Anexo 03 Forças máximas (Newton) e curvas [força $(\mathrm{N}) \mathrm{X}$ tempo (s)] obtidas para 0 grupo 3 (bases $6 \times 2 \mathrm{~mm}$; volume $18,0 \mathrm{~mm}^{3}$; "Fator C" 1,0)

Anexo 04 Forças máximas (Newton) e curvas [força (N) X tempo (s)] obtidas para 0 grupo 4 (bases $6 \times 2 \mathrm{~mm}$; volume $24,0 \mathrm{~mm}^{3}$; "Fator C" 0,75 )...

Anexo 05 Forças máximas (Newton) e curvas [força $(\mathrm{N}) \mathrm{X}$ tempo (s)] obtidas para o grupo 5 (bases $6 \times 2 \mathrm{~mm}$; volume $30,0 \mathrm{~mm}^{3}$; "Fator C" 0,6 ).....

Anexo 06 Forças máximas (Newton) e curvas [força $(\mathrm{N}) \mathrm{X}$ tempo (s)] obtidas para 0 grupo 6 (bases $6 \times 2 \mathrm{~mm}$; volume $36,0 \mathrm{~mm}^{3}$; "Fator C" 0,5 ).....

Anexo 07 Forças máximas (Newton) e curvas [força $(\mathrm{N}) \mathrm{X}$ tempo (s)] obtidas para o grupo 7 (bases $3 \times 2 \mathrm{~mm}$; volume 12,0 $\mathrm{mm}^{3}$; "Fator C" 0,6; resina composta Z-250 (3M/ESPE)

Anexo 08 Forças máximas (Newton) e curvas [força $(\mathrm{N}) \mathrm{X}$ tempo (s)] obtidas para o grupo 8 (bases 2x2 mm; volume 12,0 mm ; "Fator C" 0,33; resina composta Z-250 3M/ESPE).

Anexo 09 Forças máximas (Newton) e curvas [força $(\mathrm{N}) \mathrm{X}$ tempo (s)] obtidas para o grupo 9 (bases $3 \times 2 \mathrm{~mm}$; volume 12,0 $\mathrm{mm}^{3}$; "Fator C" 0,6; resina composta Concise 3M/ESPE)

Anexo 10 Forças máximas (Newton) e curvas [força $(\mathrm{N}) \mathrm{X}$ tempo (s)] obtidas para o grupo 10 (bases 2x2 mm; volume 12,0 m $^{3}$; "Fator C" 0,33; resina composta Concise 3M/ESPE)... 
RESUMO 


\section{RESUMO}

O objetivo deste trabalho foi determinar "in vitro" a influência do volume e do fator de configuração cavitária ("Fator C") na intensidade das forças geradas durante a contração de polimerização de resinas compostas de ativação física e química. A hipótese nula testada foi que o volume e o "Fator C" não teriam influência nas forças geradas durante a contração de polimerização. Foram utilizadas bases de aço, posicionadas paralelamente na máquina de ensaios (Emic - DL 500), sendo uma conectada ao braço móvel através da célula de carga de $10 \mathrm{Kg}$ e,a outra, ao braço fixo. Primeiramente, duas bases retangulares ( $6 \mathrm{X} 2$ $\mathrm{mm}$ ) foram utilizadas e a distância entre as mesmas ajustada em 0,5; 1,0; 1,5; 2,0; 2,5 e 3,0 mm, num total de 6 grupos, variando-se o "Fator C" em 3,0; 1,5; 1,0; 0,$75 ; 0,6$ e 0,5 e o volume em $6 ; 12 ; 18 ; 24 ; 30$ e $36 \mathrm{~mm}^{3}$, respectivamente, da resina Z-250 (3M/ESPE). A resina composta, depois de inserida entre as bases, era polimerizada por $20 \mathrm{~s}$ com luz halógena (Dentsply $-500 \mathrm{~mW} / \mathrm{cm}^{2}$; $\mathrm{E}=10$ $\left.\mathrm{J} / \mathrm{cm}^{2}\right)$. As bases ficaram fixas durante o ensaio (120 s) e as tensões geradas durante a polimerização foram registradas em gráficos [curvas força $(\mathrm{N}) \times$ tempo (s)], num total de dez ensaios para cada grupo. No segundo experimento foram avaliadas as forças geradas durante a contração de polimerização da resina Z250, polimerizada por $20 \mathrm{~s}$ (Dentsply - $500 \mathrm{~mW} / \mathrm{cm}^{2}$; $\mathrm{E}=10 \mathrm{~J} / \mathrm{cm}^{2}$ ) e da resina química Concise (3M/ESPE), variando-se o "Fator C", mas com volume constante $\left(12 \mathrm{~mm}^{3}\right)$ dos espécimes de resina. Foram utilizados dois pares de bases de aço ( $2 \times 2 \mathrm{~mm}$ e $2 \times 3 \mathrm{~mm})$, com a altura ajustada entre as bases em 3,0 e 2,0 mm e "Fator C" de 0,33 e 0,6, respectivamente, num total de 10 ensaios para cada um dos 4 grupos. A resina química foi espatulada em $30 \mathrm{~s}$ e inserida na cavidade entre as bases em $90 \mathrm{~s}$, para então ser iniciado o ensaio com tempo de $600 \mathrm{~s}$. Os valores obtidos durante os tempos de $120 \mathrm{~s}$ e $600 \mathrm{~s}$ foram registrados, as tensões expressas em gráficos [curvas força $(\mathrm{N}) \times$ tempo (s)] e as médias comparadas através da análise de variância e teste de Tukey $(\mathrm{p} \leq 0,05)$. A hipótese nula apresentada deve ser rejeitada, pois o volume influenciou decisivamente nos resultados de força de contração da resina de ativação física e o "Fator C" de 
ativação química. Os resultados obtidos para a resina Z-250, polimerizada de forma convencional, demonstraram que a variação do volume empregado, independente do fator de configuração cavitária, teve influência direta na magnitude das forças geradas, diferentemente da resina Concise, que foi influenciada pelo "Fator C".

UNITERMOS: Resina Composta; Polimerização; Contração. 
1 INTRODUÇÃO 


\section{INTRODUÇÃO}

A partir da elaboração, introdução e evolução dos sistemas restauradores adesivos, nenhum material recebeu tanta atenção na Odontologia como as resinas compostas e os sistemas adesivos. A crescente demanda estética nos consultórios odontológicos por restaurações imperceptíveis, tanto na região anterior como posterior, elevou ao primeiro posto as resinas compostas fotoativadas como material de eleição em restaurações adesivas estéticas diretas, tornando o conhecimento de sua manipulação e reação de polimerização fundamental para o Cirurgião-Dentista.

As resinas compostas são materiais híbridos e apresentam em sua composição uma matriz polimérica com inclusão de partículas inorgânicas. A proporção entre as fases orgânica e inorgânica, além das características próprias de cada componente, é responsável na determinação de suas propriedades físicas. A contração de polimerização é um processo inerente às resinas compostas de ativação química ou física, em decorrência da conversão dos monômeros em polímeros. A formação dos polímeros é acompanhada pela aproximação das moléculas, levando à redução do volume do material ou a contração volumétrica. Esta aproximação decorre da conversão das ligações de Van der Waals e ligações duplas de carbono para ligações simples covalentes, durante a formação da rede polimérica, acarretando na mudança da distância intermolecular de 0,3 a 0,4 nanometros, para aproximadamente $0,15 \mathrm{~nm}$ (PEUTZFELDT ${ }^{55}$, 1997). Este acontecimento é inevitável, por ser inerente ao processo de "endurecimento" do material (BOWEN $^{9}$, 1967; RUEGGERBERG ${ }^{58}$, 1999; SAKAGUCHI $\left.{ }^{60}, 1999\right)$.

A maioria das resinas compostas atuais apresentam um sistema monomérico baseado no Bis-GMA e este monômero possui contração de polimerização em torno de $5 \%$. Devido à sua alta densidade são adicionados diluentes para que partículas inorgânicas possam ser incorporadas e resultem numa adequada viscosidade e bom manuseio clínico. Os diluentes mais comumente utilizados são o TEGDMA, UDMA e EDGMA e, quanto menor o peso molecular destes monômeros, maior a sua capacidade reativa. Após a incorporação das partículas de carga, o valor final da contração de polimerização da maioria das resinas compostas situa-se entre 2 a 3\% (PEUTZFELDT $^{55}$, 1997). Com o desenvolvimento das resinas compostas, os fabricantes procuraram diminuir a quantidade de matriz orgânica e aumentar a porcentagem de partículas 
inorgânicas. A finalidade é proporcionar ao material maior resistência à abrasão, melhorar suas propriedades físicas e diminuir a contração volumétrica.

A incorporação de maior quantidade de partículas inorgânicas na composição das resinas compostas proporciona aumento do módulo de elasticidade, fator determinante nas forças geradas durante a contração de polimerização ${ }^{11,42,43}$. Segundo a Lei de Hooke, a tensão gerada é a razão entre o módulo de elasticidade do material e sua deformação (contração), ou seja, quanto maior o módulo de elasticidade ou mais rígido for o material, maior será o estresse gerado ${ }^{31,42,43,66}$. Teoricamente, um compósito com alta concentração de carga apresenta menor contração de polimerização, porém, paradoxalmente, pode gerar maior estresse por possuir maior módulo de elasticidade e, conseqüentemente, menor capacidade de escoamento para compensar a contração ${ }^{66,68}$. Em função dos resultados observados por MONDELLI et al. ${ }^{51}$, em 2003, esta afirmação não pode ser feita de forma absoluta, pois outros fatores estão envolvidos, uma vez que resinas compostas com módulo de elasticidade alto geraram, em alguns casos, valores mais baixos das forças de contração. Isso pode ser explicado pelo fato de que a contração volumétrica parece ter papel mais importante do que o módulo de elasticidade para determinar as forças geradas. Somente quando a contração volumétrica tiver valores próximos, o módulo de elasticidade pode definir maiores ou menores valores para as forças de contração ${ }^{50,51}$.

O principal problema relacionado à contração de polimerização é a geração de estresse, responsável pela formação de fendas na margem cavitária, acompanhadas de possíveis seqüelas, tais como, fratura do substrato dental, sensibilidade térmica, irritação pulpar e cárie recorrente $29,31,38,65,71$. Em 1982 BAUSCH et al ${ }^{6}$. explicaram a significância clínica da contração de polimerização e a definiram como o resultado do reordenamento molecular em um espaço menor ao requerido durante a fase líquida (gel viscoso) do material. Foi estabelecido que a polimerização de radicais ocorre em três fases: pré-gel, ponto de geleificação e pós-gel. Durante a polimerização de um material que apresenta alta fluidez e baixo módulo de elasticidade, fase pré-gel, o mesmo é capaz de fluir ou sofrer deformações livremente nas superfícies não aderidas, compensando o estresse da contração de polimerização ${ }^{58,60,71}$. Porém, enquanto ocorre a progressão da polimerização, a viscosidade aumenta e sua capacidade de fluxo diminui. Da mesma maneira, o módulo de elasticidade também aumenta e torna a deformação plástica mais 
difícil $^{11,42,43}$. O momento que o material não pode compensar totalmente a contração de polimerização, traduzindo o movimento em forças de contração, é definido como ponto de geleificação $^{58,60}$. A contração pós-gel é caracterizada pelo desenvolvimento de forças internas no material, conseqüência do reordenamento molecular (movimentos viscoelásticos) e da impossibilidade deste em compensar a contração de polimerização através de fluxo e da deformação plástica, transformando esse movimento em forças de contração ${ }^{6,29,34,58,60,71}$. Estas forças podem ser capazes de romper a resistência adesiva da restauração às paredes cavitárias ${ }^{16}$.

A contração pré-gel não apresenta grande significância clínica como a contração que acontece a partir do ponto de geleificação, onde a mesma vai gerar forças que só

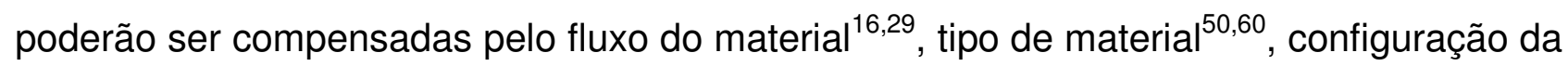
cavidade $^{34,38}$, emprego de base de $\operatorname{CIV}^{15}$, técnica de aplicação ${ }^{27}$ ou 0 tipo de polimerização empregada $3,5,6,14,29,58,60,61$.

As resinas compostas ativadas quimicamente possuem fase pré-gel de aproximadamente 3 minutos e as forças de polimerização começam a se desenvolver lentamente após o minuto inicial da reação, o que permite que a resina compense, pelo escoamento nas superfícies livres, a contração sofrida ${ }^{50}$. As resinas fotopolimerizáveis possuem polimerização mais rápida do que as químicas e, em conseqüência disso, menor capacidade de escoamento ${ }^{14,50,51}$, gerando maior estresse de contração que é decisivo para o processo adesivo.

O trabalho pioneiro na determinação das forças desenvolvidas durante 0 "endurecimento" de materiais restauradores diretos foi realizado por BOWEN , em 1967. A partir desta investigação, novos experimentos foram realizados com a finalidade de se compreender as forças geradas durante a contração de polimerização das resinas compostas. A avaliação das forças de contração de 17 resinas compostas híbridas, realizada por MONDELLI et al. ${ }^{51}$ (2003), demonstrou que a fase pré-gel é praticamente inexistente para as resinas compostas fotoativadas de maneira convencional, pois existe um crescimento imediato das forças de contração após o início da fotopolimerização. Comportamento semelhante foi observado por SAKAGUCHI; WILTBANK; MURCHISON ${ }^{61}$ (2004) e ILIE et al. ${ }^{41}$ (2005) nas curvas força $X$ tempo das resinas compostas avaliadas no início da polimerização. Desta forma, não existe compensação da contração pelo 
escoamento do material e as forças (estresse) são transmitidos para a estrutura dental desde o início da fotoativação $8,20,51,61$.

Uma vez que parte das forças de contração é liberada através do fluxo do material durante o processo de polimerização, FEILZER; DE GEE; DAVIDSON ${ }^{34}$, em 1987, estabeleceram uma relação entre o número de superfícies aderidas e o número de superfícies livres do incremento de resina composta, chamando-o de fator de configuração cavitário ou "Fator C". Os autores observaram que, quando o "Fator C" aumentava, as forças que a resina gerava durante sua contração também aumentavam. Estabeleceram que um "Fator C" baixo era determinante para que a resina liberasse, através do fluxo, as tensões produzidas durante sua polimerização. Quanto menor o número de superfícies livres ou a área total livre, menor será a capacidade da resina escoar e liberar estresse, tornando menos favorável a união da resina ao dente. Os autores observaram ainda que o volume não tinha influência sobre as forças de contração, sempre quando o "Fator C" fosse mantido constante. É importante ressaltar que esses trabalhos foram feitos com resinas quimicamente ativadas, onde o estágio prégel é muito mais extenso que nas resinas compostas fotoativadas.

As forças de contração competem com as forças adesivas e podem causar a quebra da adesão na interface dente-restauração, movimento de cúspides ou até fratura delas $^{1,8,30,31,53}$. Estas forças dependem de muitos fatores, como a contração volumétrica $^{8,40}$, capacidade de escoamento ${ }^{43,50}$, configuração da cavidade onde os incrementos de resina vão ser aplicados, polimerizados e aderidos ("Fator C") 8,34,38,49,70, 0 módulo de elasticidade da resina composta $43,70,50,51,54$, deformação do equipamento utilizado no teste $9,10,13,14,15,20,29,49,50,51,54,73$, a intensidade e tipo de fonte de luz do aparelho fotoativador $^{14,58,61,69}$, a velocidade e tipo de polimerização $0^{3,5,8,36,4550,58,70}$, a distância da fotoativação $^{11,58}$, a direção dos vetores de contração ${ }^{72,73}$, a técnica empregada para a inserção do material ${ }^{16,27,30,52,58}$ e o uso de materiais intermediários de baixo módulo de elasticidade ${ }^{15}$.

Embora as forças geradas durante a polimerização das resinas compostas apresentem um significado clínico em relação à técnica de polimerização e respectiva contração de polimerização ${ }^{62}$, constituindo um dos maiores problemas das resinas compostas, estas não podem ser medidas de forma direta ${ }^{60}$. Existem métodos indiretos 
para medir as tensões transmitidas por estas forças a um outro corpo ou aparelho. Um deles é a utilização de uma máquina de ensaios modificada associada a uma célula de carga $^{1,2,3,5,8,14,15,17,18,25,29,30,34,50,51,54,61}$, com e sem reposicionamento entre as bases. $\mathrm{Na}$ maioria dos estudos já realizados o alto volume das amostras e a forma cilíndrica das bases (vidro silanizado, dentina hibridizada ou metal) têm pouca relação com a realidade clínica da utilização das resinas compostas ${ }^{1,8,9,13,29,30,31,34,35,49,73}$, o que pode levar a interpretações de difícil aplicação na prática diária.

A preferência pela utilização das resinas compostas de ativação física em detrimento às químicas para a confecção das restaurações diretas em dentes anteriores e posteriores e a falta de estudos relacionados às forças geradas durante a contração de polimerização em função do volume e do "Fator C" levaram ao desenvolvimento deste projeto, que empregou a metodologia (base metálicas, célula de carga e máquina de ensaios), sem reposicionamento entre as bases, utilizada por CASTAÑEDA-ESPINOSA; MONDELLI $^{14}$ (2002); MONDELLI; CASTAÑEDA-ESPINOSA; FRANCO ${ }^{50}$ (2002) e MONDELLI et al. ${ }^{51}$ (2003), adaptada da metodologia de DAVIDSON; De GEE; FEILZER ${ }^{30}$ (1984) e FEILZER; DE GEE; DAVIDSON ${ }^{34}$ (1987).

Esta pesquisa avaliou, comparativamente, a influência do volume e do "Fator C" nas forças geradas durante a contração de polimerização de resinas compostas de ativação física e química. 
2 REVISÃO DE LITERATURA

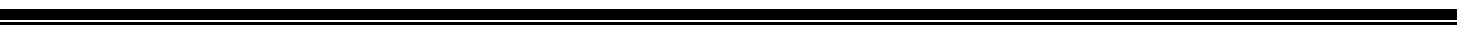




\section{REVISÃO DE LITERATURA}

Poucos anos depois de desenvolver as resinas compostas, BOWEN ${ }^{9}$, em 1967, observou que, para conseguir manter a adesão entre o material restaurador e as paredes da cavidade, era necessário que a força adesiva deste material ao substrato seja, em todo momento, pelo menos da mesma magnitude que as forças tracionais e de cisalhamento que possam transmitir estresse para esta interface. Segundo o autor, estas forças podem ser originadas, em parte, pela diferença de coeficiente de expansão térmica entre o material restaurador e o dente, pelas forças aplicadas externamente e pela contração volumétrica que acontece durante o endurecimento dos materiais resinosos. A observação de infiltração em dentes extraídos em restaurações realizadas "in vitro" poderia significar que, parte da adesão pode ser quebrada sem a necessidade de forças externas, como por exemplo, aquelas geradas durante a mastigação. $O$ autor avaliou também as forças geradas durante a contração de endurecimento de vários materiais. Dentre esses materiais, algumas resinas compostas experimentais foram avaliadas, concluindo que estas podem gerar tensões de até 2,4 MPa durante a contração de polimerização.

Conhecendo as conseqüências da contração de polimerização dos materiais restauradores resinosos, como a formação de fenda entre a parede cavitária e o material restaurador, ASMUSSEN ${ }^{4}$, em 1975, propôs investigar a possível relação entre a composição das resinas compostas e a contração de parede a parede, em cavidades preparadas em dentes humanos com diâmetro e profundidade de 2,5 mm. As marcas estudadas continham BIS-GMA diluído com um ou dois monômeros de baixa viscosidade. A contração de polimerização foi medida e determinada microscopicamente pela largura máxima alcançada pela fenda formada em dentina. Após a análise e interpretação dos resultados, o autor observou uma correlação positiva entre largura da fenda marginal e soma de diluentes, enquanto a adição de partículas inorgânicas acima de $75 \%$ por peso não teve efeito na largura das fendas marginais. Nesse sentido, foi concluído que a composição da fase orgânica é de importância primordial para o tamanho da contração de parede a parede das resinas compostas.

Sabendo que a contração de polimerização de resinas compostas leva à formação de forças de tração nas estruturas circundantes aderidas e estas podem causar fraturas 
no esmalte, HEGDAHL; GJERDET ${ }^{40}$, em 1977, determinaram a magnitude da contração linear e das tensões de contração promovidas pelas resinas Adaptic, Concise e Restodent. Para medir a contração de polimerização foi utilizado uma matriz de polietileno em forma de $\mathrm{V}$ associada a um extensômetro elétrico. Esta foi determinada dois minutos após a mistura dos materiais e registradas por um período de duas horas, por meio de uma ponte amplificadora associada a um dispositivo de registro. As tensões de contração foram medidas em uma máquina universal de testes Instron, por meio da fixação de dois cilindros ( $4 \mathrm{~mm}$ de diâmetro e $5 \mathrm{~mm}$ de comprimento) no braço móvel e estacionário da mesma. A resina era inserida entre as bases para gerar as forças de contração que eram captadas pela célula de carga. Após este período, os resultados obtidos para contração linear e tensões de contração foram, respectivamente: Adaptic: 0,42\%; 1,21MPa; Concise: 0,48\%; 1,30MPa; Restodent: 0,90\%; 1,92MPa. Os autores comentaram que existiu maior desenvolvimento de tensões de tração, quando a contração foi restrita (resina aderida às paredes), assim como seria óbvio pensar que este estresse dependeria da resiliência das estruturas nas quais o material está aderido.

Buscando possibilitar a medida da contração de polimerização de resinas quimicamente ativadas e também das fotopolimerizáveis, De GEE; DAVIDSON; SMITH ${ }^{32}$, em 1981, testaram um dilatômetro modificado no qual ao invés da utilização do mercúrio foi utilizada água. Assim, mediram a contração de polimerização de duas resinas de ativação física (Fotofil e Nuva-fil) e uma de ativação química (Concise). Os dados encontrados foram de 2,03\% para a Fotofil, 2,67\% para a Nuva-fil e 2,55\% para a Concise. Foi verificado que o desenvolvimento da contração para resina química foi mais lento. Os autores discutem que a contração inicial é de pouca importância, pois esta será compensada pelo escoamento viscoso do material. Concluíram que este aparelho modificado satisfaz os objetivos na medida de alterações dimensionais de materiais não metálicos entre a temperatura ambiente e $37^{\circ} \mathrm{C}$.

Em 1982, BAUSCH et al. ${ }^{6}$ avaliaram a contração de polimerização de algumas resinas compostas e verificaram a influência de algumas variáveis. Para a avaliação se aproximar mais à realidade clínica, determinou-se a contração volumétrica e não a linear. Os resultados revelaram que a contração volumétrica pode alcançar até 5,8\% e que esta é influenciada por todas as variáveis que alterem o índice de conversão da resina composta. Explicaram que a contração de polimerização é o resultado do reordenamento 
de moléculas em um espaço menor a aquele requerido no estado líquido, onde as moléculas tinham certa mobilidade. Assim, após a iniciação, acontece uma grande contração da massa ainda em estado plástico. Esta contração não tem tanta significância clínica como aquela que acontece a partir do início da geleificação ou transformação gradual do líquido viscoso em um material rígido, onde a contração vai gerar tensões que só poderão ser compensadas pelo fluxo do material. Quando a resina composta é aplicada em uma cavidade e aderida a suas paredes, pouco se pode dizer sobre os movimentos internos (fluxo ou escoamento do material), diferente de quando esta é polimerizada livremente, onde a resina contrai em direção à fonte de luz ou ao centro do corpo, de acordo com o sistema de ativação empregado. Quando existe adesão às paredes da cavidade, a resina composta vai ter duas possibilidades: ou ela cede sem gerar tensões às paredes cavitárias, ou vai desaderir destas. Uma situação intermediária poderia ser possível, gerando tensões internas e micro fraturas no material. Quando a resina composta apresenta suficiente flexibilidade, estas tensões podem ser compensadas, porém nas resinas compostas com alto módulo de elasticidade isto não é possível, podendo gerar rachaduras na matriz e degradação do material. Finalmente, os autores concluíram que a contração de polimerização é um dos fatores mais importantes em determinar a longevidade de restaurações de resinas compostas.

Assim, em 1983, BOWEN; NEMOTO; RAPSON ${ }^{10}$ avaliaram o estresse gerado durante a contração de polimerização da resina composta e acrílica. Para avaliar a influência da adesão às paredes da cavidade e do desenho cavitário, a pesquisa foi realizada em três grupos. Nos grupos $n^{\circ} 1$ e $n{ }^{\circ} 2$ foram utilizadas cavidades de alumínio rugoso, para promover adesão da resina composta às paredes. No grupo $\mathrm{n}^{\circ 1}$ foi deixada toda uma superfície livre, enquanto no grupo $\mathrm{n}{ }^{\circ 2}$ foi deixado livre somente um orifício, através do qual foi injetado o material. No grupo $n \stackrel{3}{3}$, o material utilizado nas paredes da cavidade foi o teflon, evitando qualquer adesão da resina composta. Foi observado que os resultados diferiam entre os três grupos, sendo que o grupo $n ` 3$ mostrou valores inferiores que os demais, enquanto maiores valores foram obtidos com o grupo $\mathrm{n}{ }^{\circ} 2$. Em função das resinas avaliadas serem de ativação química, estas acumularam uma tensão máxima após 30 minutos de sua ativação. Os autores acrescentaram que as resinas compostas desenvolveram tensões similares às resinas acrílicas durante a contração de polimerização, fato interessante em função das resinas compostas apresentarem contração volumétrica menor. Neste estudo foram registrados valores de até 7,6 MPa 
para a resina composta Isopast e 7,2 MPa para a resina acrílica Sevriton. Os autores concluíram que tensões significantes são geradas durante a contração do material quando existe adesão às paredes da cavidade. Sendo assim, para esta adesão ser clinicamente aceitável, tem que ser desenvolvida rapidamente e, principalmente, em todo momento ser superior às forças geradas durante a polimerização do material.

Diante do conhecimento do mecanismo de escoamento das tensões oriundas da contração de polimerização, especialmente quando existe uma reação gradual, em que as tensões produzidas não provocam danos nem à estrutura interna da resina nem à união adesiva, DAVIDSON; DE GEE ${ }^{29}$, em 1984, estudaram o comportamento de duas resinas, Silar e Concise que contém Bis-GMA e TEGDMA como os principais componentes, durante a polimerização. Desta forma, por meio de um dilatômetro, observaram que as resinas contraíram consideravelmente durante a reação e que a contração rígida poderia ser a grande causa dos defeitos marginais. Relataram em sua discussão que, durante a polimerização, o escoamento das tensões compensaram a contração. Verificaram, também, que a contração era máxima nos períodos iniciais da reação de polimerização, porém o material e sua cadeia polimérica ainda seriam pouco resistentes e, portanto, capazes de se deformar tomando novas posições e orientações. Após algum tempo, o material ganharia resistência, mas com a contração reduzida. Assim, concluíram que a existência de uma boa união com o esmalte pode resistir às forças de contração de polimerização, especialmente pelo fluxo das tensões e que, na ausência de união à dentina, a formação de uma fenda pode ser esperada. Mas, quando existir uma boa união com este substrato, o material poderá fluir durante a polimerização e a adaptação marginal poderá ser mantida.

No ano de 1984, DAVIDSON; DE GEE; FEILZER ${ }^{30}$ avaliaram a influência das forças da contração de polimerização de duas resinas compostas de micropartículas sobre a interface adesiva utilizando adesivo (Scotchbond). Dentre as resinas avaliadas uma foi fotoativada (Silux) e a outra quimicamente ativada (Silar). Para a avaliação utilizaram-se três parâmetros; primeiramente foi determinada a força de contração de cada resina durante a polimerização, para depois determinar a resistência de união do adesivo dentinário, ambos em diferentes períodos de tempo. Finalmente foi avaliada a existência ou não de microinfitração em restaurações de classe $V$ realizadas com os mesmos materiais. Os valores de resistência de união foram superiores em todos os 
períodos avaliados, quando comparados com as forças geradas durante a contração linear das resinas compostas, que alcançaram valores de até 2,4 MPa, depois de 30 minutos. Foi observada a existência de microinfiltração em quase $100 \%$ das paredes de dentina das restaurações. Os autores explicaram que quando a contração é restrita a uma direção (contração linear restrita) a adesão não é afetada, porém quando esta acontece em condição restrita tridimensionalmente (contração volumétrica restrita) nenhuma adesão à dentina seria capaz de suportá-la. Assim, quando existem poucas paredes cavitárias (onde o material esta aderido e vai experimentar uma contração restrita) a contração pode ser compensada pelo escoamento da resina composta. Esta liberação de tensões não acontece quando a cavidade apresenta só uma superfície livre, onde estas tensões podem alcançar até $20 \mathrm{MPa}$, dependendo da configuração da cavidade. Em função da força coesiva da resina composta ser ainda maior, não vai acontecer uma falha coesiva e sim uma falha adesiva na interface com a dentina. Finalmente os autores concluíram que não só devem ser desenvolvidos adesivos com maior resistência adesiva, como também resinas compostas com menor contração de polimerização, assim como desenhos cavitários apropriados para restaurações deste tipo.

Ainda DAVIDSON ${ }^{27}$, em 1986, enfatizou que o sucesso de restaurações adesivas de resinas compostas só poderia ser alcançado com uma aplicação disciplinada e boa técnica. Afirmou que a redução do estresse gerado pela contração de polimerização está relacionado com a forma da cavidade e acrescentou que a técnica incremental mostra-se vantajosa com as resinas compostas fotoativadas, sempre que o primeiro incremento seja aderido só a uma parede cavitária (preferivelmente de dentina), para permitir o fluxo do material nessa direção, a partir da superfície livre da cavidade.

BRAEM et al. ${ }^{11}$, em 1987, estudaram o aumento do módulo de elasticidade (Young) durante a polimerização de resinas compostas. Avaliaram quatro resinas compostas quimicamente ativadas e duas resinas compostas fotoativadas. Observaram que entre as resinas compostas quimicamente ativadas existiram diferenças significativas no módulo de elasticidade. Em todos os casos esses materiais apresentaram um incremento do módulo de elasticidade mais lento quando comparado com as resinas compostas fotoativadas, onde o aumento do módulo de elasticidade aconteceu nos primeiros segundos. Acrescentaram que o aumento lento do módulo de elasticidade poderia favorecer o fluxo interno e escoamento do material durante a polimerização, 
permitindo a formação de adequada ligação adesiva, o que poderia resolver parcialmente o problema da competição entre a adesão e a força de contração.

Em 1987, FEILZER; DE GEE; DAVIDSON ${ }^{34}$ investigaram o papel do fator de configuração cavitária ("Fator C") no desenvolvimento e relaxamento das tensões resultantes da contração de polimerização a fim de possibilitar o estabelecimento do sucesso dos adesivos dentinários. Para este estudo, dois discos de aço foram utilizados, dos quais um foi conectado à célula de carga e o outro, ao dispositivo medidor de tensões. As resinas compostas (Silar e P10) foram inseridas entre estes dois discos em forma de um cilindro nas dimensões de suas circunferências, os quais já haviam recebido um tratamento com silano. Com este aparato foi possível registrar as tensões de contração de restaurações com fator de configuração ("Fator C") conhecidos, dados pela razão das superfícies aderidas (discos planos) pelas superfícies livres (parte externa do cilindro). Nesse sentido, o "Fator C" foi expresso neste estudo pela seguinte fórmula:

\section{$C=\underline{\text { Total de superfícies dos discos }}$}

Superfície externa do cilindro

Após obtenção dos dados resultantes do experimento, observou-se que quanto maior o fator de configuração cavitária, maiores foram as tensões geradas durante a contração de polimerização, devido à redução na capacidade de escoamento. Os autores relataram que a maioria das restaurações possuem "Fator C" de aproximadamente 1 a 2 , e que valores menores ou igual a 1 referem-se a restaurações do tipo Classe IV e camadas de resina aplicadas em superfícies planas ou curvas rasas. Nestas situações, verificou-se que a adesão à dentina com os adesivos atuais sobreviveu às tensões provenientes da contração de polimerização. Para as cavidades com "Fator C" maior que 2, pode-se esperar falhas na união dentina/resina. Portanto, os autores descreveram que a maior parte das cavidades não proporciona um adequado escoamento a fim de preservar a adesão do material restaurador com a estrutura dentária obtida com os sistemas adesivos. 
Na figura a seguir (Figura 1), os autores demonstraram uma visualização da relação entre formas cavitárias encontradas clinicamente e seus respectivos valores do "Fator C".

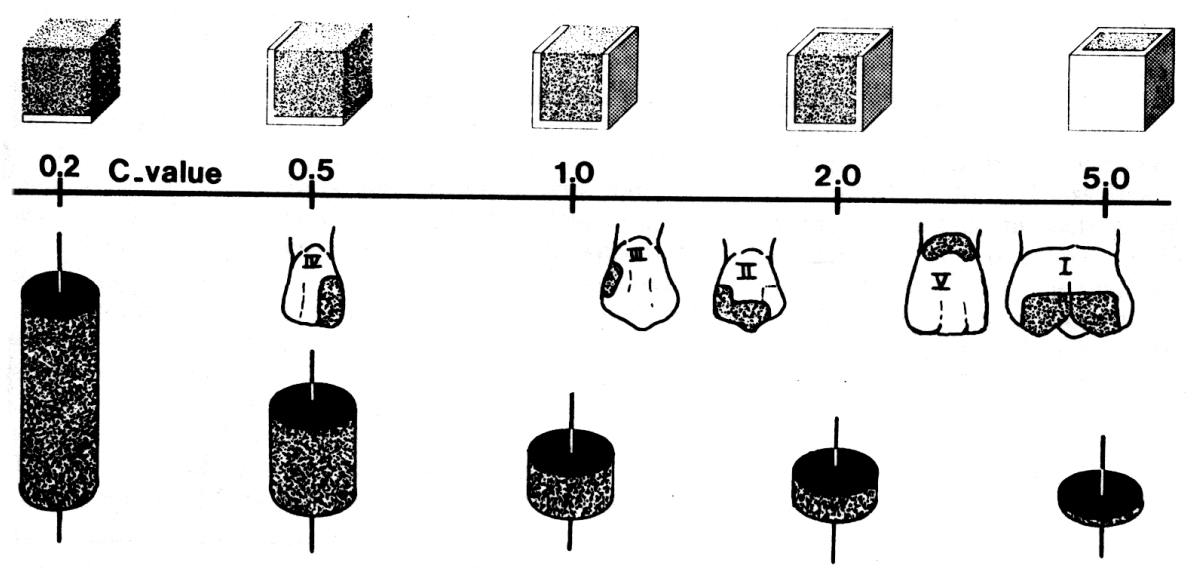

Figura 01 - Relação das cavidades com o fator de configuração cavitária. (Fonte: FEILZER; DE GEE; DAVIDSON ${ }^{34}$, 1987).

A influência do módulo de elasticidade das resinas compostas sobre as tensões geradas durante sua contração linear foi estudada, em 1988, por KEMP-SCHOLTE; DAVIDSON ${ }^{42}$ onde explicaram que as resinas expressam o produto da contração linear pelo módulo de elasticidade do material. Resinas compostas com módulo de elasticidade maior desenvolveriam maiores tensões durante a contração de polimerização. Por outro lado, o baixo módulo de elasticidade dos adesivos aliviaria em parte estas tensões. Em algumas resinas compostas com alto módulo de elasticidade esta liberação de tensões não é suficiente para diminuir as tensões até valores inferiores aos da resistência de união dos adesivos, propiciando a desunião do material às paredes da cavidade. Neste estudo, só as resinas compostas com baixo módulo de elasticidade mantiveram uma boa adaptação marginal após sua polimerização. Foi observado que a aplicação de uma resina fluida depois de terminada a restauração forneceu um perfeito selamento das margens de restaurações realizadas com resina composta de baixo módulo de elasticidade (Silux), enquanto que o mesmo procedimento não foi eficiente para resina de 
alto módulo de elasticidade (P-30). Os autores concluíram que o módulo de elasticidade da resina composta influiu significantivamente na adaptação da restauração.

Envolvidos com o estudo da adaptação de resinas compostas e atentos à possibilidade de uma relação direta entre forma cavitária e selamento marginal, HANSEN; ASMUSSEN $^{39}$, em 1989, realizaram uma análise dos resultados de estudos prévios que relacionaram diferentes formas de cavidades com a contração de polimerização. Nesse sentido, avaliaram a adaptação de restaurações de resina composta verificando a relação com algumas variáveis como volume, profundidade da cavidade, área livre e área aderida. Desta forma, os autores realizaram uma análise de regressão linear avaliando estas variáveis, das cavidades anteriormente estudadas que possuíam ângulos cavosuperficiais terminando em $90^{\circ}, 110^{\circ}, 135^{\circ}$ e $160^{\circ}$. Com os resultados desta análise pôde-se observar que, o volume por si só, possui um papel importante na adaptação marginal de resinas compostas e o aumento do raio de paredes unidas resultará em aumento da fenda marginal. Os autores verificaram que o aumento da área de uma cavidade em forma de cone para uma convencional conduziu a elevação na formação de fendas marginais $(0,4 \mu \mathrm{m}-2,8 \mu \mathrm{m})$. Desta forma, concluíram que a remoção de estrutura dentária para realização de cavidades convencionais conduz ao enfraquecimento do dente e uma pior adaptação marginal.

FEILZER; DE GEE; DAVIDSON ${ }^{35}$, em 1990, descreveram sobre o mecanismo de contração de polimerização enfatizando que as tensões produzidas são diminuídas pelo fluxo do material e, se houver uma transposição do limite elástico, pode então ocorrer uma deformação plástica. Registram também, que durante a fase inicial da reação de polimerização, a rede polimérica é ainda fraca, portanto as tensões ocorridas neste momento não promovem prejuízos nem à estrutura interna da resina, nem à união adesiva, uma vez que as moléculas ainda têm a possibilidade de se movimentar para novas posições e orientações. Este tipo de movimentação é caracterizado como escoamento ou fluxo do material, o qual é reduzido significantemente com o passar do tempo, especialmente pelo aumento da rigidez. Isto, segundo os autores, resulta em sérios problemas para a manutenção da união adesiva, justamente pelo fato das tensões aumentarem com o tempo e o material não poder compensá-lo com o escoamento. A partir disto, propuseram determinar e quantificar a redução das tensões pelo escoamento em várias configurações cavitárias ("Fator C") de quatro resinas compostas, P10, Silar, 
Brilhant e Clearfil Posterior. Desta forma, utilizou-se o mesmo aparato já descrito em trabalho $^{34}$ de suas autorias publicado em 1987, avaliando nas seguintes configurações cavitárias: 0,5;2,0;2,5 e 5,0. Diante dos dados obtidos, observou-se que em nenhuma das resinas testadas em configuração cavitária de 0,5 , as tensões de contração excederam os valores de resistência de união à dentina. Quanto à redução das tensões pelo escoamento, verificou-se que esta foi em função do fator de configuração e pelo tipo de material. Para amostras da resina P10 com "Fator C" = 0,5, verificou-se um alívio de $71 \%$ das tensões de contração, enquanto para o "Fator $C "=2$ foi de apenas 35\%. Nas amostras com "Fator C" de 2,5 e 5, a redução das tensões pelo escoamento não foi alta o bastante (24\% e insignificante, respectivamente) para prevenir fraturas, uma vez que a capacidade de escoamento foi excedida. Concluíram que a redução das tensões pelo escoamento e a capacidade de fluxo estão em função do material e da configuração cavitária, e que este escoamento contribui grandemente para redução das tensões de contração em restaurações com baixo "Fator C" e insuficientemente em situações com alto "Fator C".

KEMP-SCHOLTE; DAVIDSON ${ }^{43}$ estudaram, em 1990, o efeito de utilizar bases de materiais mais flexíveis, para conseguir aliviar parte das forças geradas durante a contração de polimerização. Para tanto, verificaram a capacidade de vedamento de restaurações realizadas com dois adesivos utilizando duas técnicas de inserção do material (incremento único ou incremental) e fizeram medições das forças geradas por cada combinação avaliada. Os resultados demonstraram que nenhum dos adesivos (SB1, SB2) foi capaz de resistir às forças geradas durante a contração de polimerização da resina composta quando aplicados sem nenhum material intermediário, independentemente da técnica de aplicação utilizada. A aplicação de uma resina fluida nas margens, depois de terminada a restauração aumentou a integridade marginal destas restaurações. A técnica mista realizada com ionômero de vidro convencionais também não foi capaz de evitar a microinfiltração, enquanto nos espécimes restaurados com ionômeros modificados com resina (Vitrebond; loline; Zionomer) ou uma resina fluida (Silux enamel bond) inserida neste caso depois da aplicação de adesivo dentinário, as restaurações mantiveram sua união com as paredes da cavidade. Nesses casos, os valores das tensões de contração de polimerização da resina composta, transmitidas através dos materiais intermediários não excederam os $5 \mathrm{MPa}$, enquanto que em restaurações sem material intermediário os valores foram significantemente maiores. 
Ainda foi observado que materiais com maior módulo de elasticidade promovem maiores tensões, e o aumento da espessura do material intermediário de baixo módulo de elasticidade promove diminuição destas tensões. Os autores concluíram que a aplicação de um material de baixo módulo de elasticidade como camada intermediária reduz efetivamente a transmissão de forças em direção às margens da restauração, propiciando um excelente selamento marginal, sempre que a adesão do material intermediário à dentina seja maior que 5MPa.

No ano de 1991, UNO; ASMUSSEN ${ }^{69}$ propuseram uma técnica de polimerização nova, observando que até então os adesivos não tinham sido capazes de evitar os efeitos destrutivos da contração de polimerização. Os autores observaram que estudos anteriores (DAVIDSON; DE GEE ${ }^{29}$, 1984) mencionaram a importância do livre escoamento do material durante a polimerização para não gerar força de contração. Postularam que uma polimerização mais lenta poderia permitir maior escoamento do material durante a polimerização. Sendo assim, o propósito desse estudo foi avaliar o efeito de uma polimerização com baixa densidade de potência sobre a adaptação marginal, adesão e resistência à compressão. $O$ estudo foi realizado em dentes humanos extraídos, onde foram confeccionadas cavidades com todas as margens em dentina. A largura máxima da fenda entre a restauração e o dente foi medida através de microscopia ótica. Foi observada melhor qualidade de margens quando uma técnica de polimerização inicial com baixa densidade de potência foi utilizada. Os valores de resistência adesiva e forças de compressão mostraram que não ocorreu perda significativa quando a polimerização inicial foi seguida de uma irradiação com alta densidade de potência. Os autores concluíram que uma polimerização inicial com baixa densidade de potência seguida de uma polimerização com alta densidade de potência poderia ser uma alternativa para melhorar a adaptação marginal em restaurações de resina composta.

SAKAGUCHI et al. ${ }^{59}$, em 1992, relataram que a resina composta possui um grande problema quando se polimeriza, o qual se define como a já tão estudada contração de polimerização, que pode ser dividida em duas fases: pré-gel e pós-gel. Descreveram que na fase inicial (pré-gel), o material é capaz de escoar e aliviar as tensões mas, com o passar do tempo, a resina torna-se mais rígida com aumento do módulo de elasticidade, tornando-se incapaz de compensar as tensões provenientes da contração de polimerização. Dentro deste aspecto, os autores avaliaram as forças de tensões de 
contração de algumas resinas compostas (Silux, Heliomolar, Herculite XR e P-50), por meio de um novo modelo desenvolvido, no qual um anel acrílico desempenhava a função de simular uma restauração de resina composta circundada por dentina. Após a aplicação da fonte de luz, a resina Heliomolar demonstrou significativamente menor contração de polimerização quando comparada aos outros materiais. Aos 14 minutos, sua diferença não foi significante, embora ainda apresentasse menores valores de contração. A resina P-50 apresentou um rápido e alto desenvolvimento de tensões de contração de polimerização (1,7 MPa). Atribuíram tais resultados à composição dos materiais, pois a resina Heliomolar não possui TEGDMA associado ao BIS-GMA e sim BIS-GMA e UEDMA, o qual possui menor módulo de elasticidade quando polimerizado. O UEDMA pode contrair-se menos ou devido ao seu menor módulo elástico, compensar a contração. A resina P-50 possui um alto módulo elástico, aumentando a tendência de gerar uma alta tensão inicial. Os autores concluíram que este modelo parece proporcionar um razoável prognóstico da contração de polimerização das resinas compostas.

Em 1993, FEILZER; DE GEE; DAVIDSON ${ }^{36}$ investigaram o desenvolvimento do estresse de polimerização de resinas fotoativadas, com e sem inclusão de porosidades, em relação ao fator de configuração cavitária e compararam os resultados com as resinas de ativação química. As resinas foram inseridas e polimerizadas entre duas placas de vidro aderidas a um dispositivo específico ligado a um tensilômetro, que verificava a distância das duas placas de acordo com as alterações provocadas pela contração ou pelas alterações térmicas. Nos casos em que o valor do "Fator C" excedeu a 2, as mensurações terminaram antes, em função de falha coesiva do material ou na interface vidro-material. Para os valores maiores do que $17 \mathrm{MPa}$, ocorreram falhas coesivas nos discos de vidro, não sendo possível determinar o valor da falha coesiva da resina P-30, quando "Fator C" era igual a 2. O estresse se desenvolveu com maior velocidade e com maiores valores finais para os materiais fotoativados quando comparados aos quimicamente ativados. As resinas fotoativadas resistiram melhor ao estresse inicial apresentando menor capacidade de escoar quando comparadas com as resinas quimicamente ativadas análogas. Finalmente, a inclusão de porosidades no interior as resinas fotoativadas diminui e torna mais lento o desenvolvimento do estresse na reação.

RUEGGEBERG; CAUGHMAN; CURTIS ${ }^{57}$, em 1994, realizaram um trabalho com o objetivo de pesquisar a interdependência da duração e da intensidade da exposição na 
polimerização, em várias profundidades, das resinas compostas. Os resultados mostraram uma relação muito grande entre a profundidade e a polimerização de resinas compostas. Em profundidades maiores do que $2 \mathrm{~mm}$ os resultados de polimerização foram pobres, estando muito susceptíveis às mudanças da intensidade de luz e do tempo de exposição. Os autores concluíram que, para uma polimerização uniforme, a exposição de tempo recomendada é de 60 segundos em uma intensidade mínima de $400 \mathrm{~mW} / \mathrm{cm}^{2}$ e a espessura de cada incremento não deve exceder $2 \mathrm{~mm}$, com $1 \mathrm{~mm}$ sendo a ideal.

A importância do entendimento dos princípios que podem interferir em uma união ideal de resina composta com a dentina e a necessidade de promover manobras clínicas a fim de melhorar a qualidade das restaurações fez com que, CARVALHO et al. ${ }^{16}$, em 1996, revisassem a respeito dos fatores que propiciam à resina composta um maior alívio das tensões provenientes da contração de polimerização. Relataram inicialmente sobre 0 fator de configuração cavitária, afirmando que o relaxamento das tensões está em função da deformação elástica do material e do escoamento para superfícies livres. Destacaram que as cavidades de Classe $\mathrm{V}$ superficiais apresentam uma adequada área livre para alívio das tensões, enquanto que as do tipo caixa possuem uma maior área de superfície aderida. Comparando resinas fotopolimerizáveis com as quimicamente ativadas, os autores descreveram que as últimas possuem uma reação mais lenta, permitindo assim um maior tempo para alívio das tensões de contração de polimerização. A respeito da sorção de água, afirmaram que, quanto maior a concentração de matriz orgânica na composição de uma resina composta, maior será a tendência para sorção de água, o que parcialmente compensa a contração de polimerização. Nesse sentido, dissertaram sobre soluções para redução da competição existente entre resistência de união à dentina e as forças de contração de polimerização, sendo que, enfatizaram inicialmente sobre a necessidade do desenvolvimento de agentes adesivos dentinários capazes de efetuar uma imediata resistência de união, superior às forças de contração de polimerização e igual à obtida com o condicionamento ácido do esmalte. Uma segunda solução seria a colocação de uma camada elástica entre a resina composta e a dentina, a fim de absorver as tensões provocadas pela contração de polimerização ou até mesmo da própria mastigação. Como terceira solução, citaram a técnica de inserção incremental, a qual reduz o volume de resina que contrai durante a polimerização, assim como diminui o "Fator C", uma vez que a porção de resina colocada possuirá grande quantidade de área livre para aliviar as tensões geradas pela contração de polimerização. Dentro deste 
aspecto, concluíram que o sucesso clínico das restaurações de resina composta está no entendimento e aplicação destes fatores, pois estes podem reduzir as forças de contração de polimerização.

PEUTZFELDT ${ }^{55}$, no ano de 1997, descreveu e discutiu sobre a evolução dos sistemas de monômeros odontológicos, ressaltando novas abordagens para a modificação e conseqüente otimização do desempenho de compósitos restauradores. $O$ monômero Bis-GMA, volumoso e de caráter bifuncional, mostrou-se superior ao metil metacrilato, devido à estrutura química e ao elevado peso molecular, o que proporciona menor volatilidade, menor contração de polimerização, enrijecimento mais rápido e produção de resinas mais fortes e rígidas. A alta viscosidade do Bis-GMA é diminuída através da mistura com monômeros dimetacrilatos de menor peso molecular, de modo a obter consistência favorável à incorporação de carga. Os monômeros mais freqüentemente utilizados como diluentes são o EGDMA e o TEGDMA. Essa diluição resulta em elevada contração de polimerização devido à diminuição dos espaços entre os monômeros. Decisivamente, a contração de polimerização é um dos fatores que determinam a longevidade de restaurações com compósitos. A extensão da contração de polimerização depende, entre outras coisas, do peso molecular e da funcionalidade do monômero. Desta forma, o volume dos grupos aromáticos da parte central da molécula de Bis-GMA causa barreiras à rotação ao redor das ligações, resultando na diminuição do grau de conversão. Assim, a resistência, a dureza e certamente outras propriedades mecânicas são influenciadas não apenas pelo grau de conversão, mas também pela natureza das unidades monoméricas que formam o polímero. A natureza polar das resinas dimetacrilato resulta em absorção de água do meio bucal, o que causa enfraquecimento da matriz resinosa, desunião entre matriz e partícula e degradação hidrolítica das partículas com subseqüente redução nas propriedades mecânicas. No intuito de minimizar a sorção de água, homólogos do Bis-GMA foram desenvolvidos como o Bis-EMA, onde a hidroxila foi eliminada. Um outro grupo de monômeros que tem sido utilizado na fabricação de compósitos restauradores odontológicos é o UEDMA. Este monômero pode ser usado sozinho ou em combinação com o Bis-GMA ou TEGDMA. As vantagens atribuídas ao UEDMA são menor viscosidade, maior flexibilidade da terminação uretano e alto peso molecular, além de elevado grau de conversão. Outros monômeros vêm sendo desenvolvidos e estudados na tentativa de obter um material que supra todas as necessidades clínicas. A autora concluiu que embora o desempenho de 
um compósito seja o resultado da inter-relação entre todos os componentes presentes no material, uma mudança no sistema de monômeros pode resultar em significativa melhora nas propriedades e no desempenho, bem como na expansão de suas indicações.

Com o objetivo de investigar, através de diferentes métodos, o efeito da espessura da camada de resina composta no estresse de contração de polimerização, ALSTER et al. ${ }^{1}$, em 1997, realizaram um trabalho no qual afirmaram que, uma vez que o valor de contração de polimerização é dependente do dispositivo em que é medido, um método para testar esse dispositivo deveria ser testado. Utilizaram a resina Clearfil F2 da Kuraray (ativação química) e um sistema com "compliance" conhecido e fixo para todas as condições experimentais $\left(0,029 \mathrm{~mm} / \mathrm{MPa}\right.$ ou $1,2 \times 10^{-3} \mathrm{~mm} / \mathrm{N}$, para o diâmetro de 5,35 $\mathrm{mm}$ ). O estresse de contração foi determinado para corpos de prova de resina de alturas de 50, 100, 200, 300, 400, 500, 600, $700 \mu \mathrm{m}, 1.4 \mathrm{~mm}$ e 2,7 mm. A concordância dos dispositivos utilizados foi calculada com a ajuda de análise de regressão não linear, usando uma equação derivada da Lei de Hooke como modelo. Os resultados mostraram que os valores de contração diminuíram com o aumento da altura dos corpos de prova cilíndricos de resina composta, fato explicado pela teoria de que quanto maior a área de superfície livre em relação à área das superfícies aderidas, maior seria a capacidade de escoamento do material e conseqüentemente menor o estresse de contração. Afirmaram que o método de medição para determinar o estresse de contração de polimerização de resinas compostas iniciadas quimicamente foi aceitável.

No mesmo ano, ALSTER et al. ${ }^{2}$ avaliaram a influência da rigidez do sistema (“compliance") na avaliação das forças geradas durante a contração de polimerização de compósitos com camadas finas. Para tanto, foram feitas alterações no comprimento dos parafusos da máquina, o que possibilitou a realização dos ensaios com diferentes "compliances", sem alterar as dimensões dos corpos-de-prova. Com isto os autores constataram que a tensão de contração desenvolvida em camadas finas de compósito diminuiu significativamente com o aumento da capacidade de deformação do sistema.

Com o intuito de contribuir para o reconhecimento e entendimento dos problemas relacionados com a contração de polimerização, DAVIDSON; FEILZER ${ }^{31}$ publicaram uma revisão sobre o tema em 1997. Foram estudadas as mudanças dimensionais que ocorrem 
durante a polimerização das resinas compostas para diferenciar a contração volumétrica, o estresse de contração e a compensação desse estresse. Comentaram que a polimerização da matriz resinosa produz a geleificação onde o material restaurador é transformado de uma fase visco-plástica a uma fase rígido-elástica. O ponto de geleificação foi definido como o momento no qual o material não pode prover mais de um fluxo viscoso que acompanhe a contração de polimerização. Desta maneira, os resultados obtidos através de dispositivos que requeiram força para seu movimento e imediata tradução a tensão só poderiam registrar valores na fase "pós-gel", onde o material é suficientemente forte para gerar e transmitir forças. Relataram que o estresse de contração de polimerização pode ser visto como o mecanismo que é responsável por problemas com as restaurações adesivas e pode causar a separação do material restaurador da cavidade ou fraturas coesivas em uma das estruturas. Afirmaram que a magnitude do estresse de contração é dependente também das propriedades do material restaurador, com os materiais mais rígidos causando maior estresse de contração, sendo que a compensação do estresse de contração pode ser conseguido ao permitir a contração livre do material em direção da interface adesiva, evitando incrementos de resina aderidos em paredes opostas, ou pela utilização de bases cavitárias para a melhor distribuição do estresse na restauração e interface adesiva. Ainda mencionaram a possibilidade de obter resultados com alta percentagem de erro quando máquinas de ensaio são utilizadas para a verificação do estresse de contração em corpos de prova de diferente volume e, sobretudo, a altura entre as bases unidas à máquina de ensaio, não sendo consideradas a deformação do dispositivo e da célula de carga. Eles sugerem a utilização de um dispositivo retroalimentador, em que a distância entre as bases onde é inserido o material seja mantida constante, chamando esta montagem de rígida. Finalmente, concluíram que não existem métodos de manipulação de restaurações descritos que garantem uma restauração à prova de falhas, de forma que o profissional tem que aceitar o problema da contração de polimerização e seu destrutivo estresse de polimerização.

Atentos aos vários fatores que afetam a contração de polimerização, BOUSCHLINCHER; VARGAS; BOYER ${ }^{8}$, em 1997, determinaram a força de contração de polimerização de tipos diferentes de resina (Silar, Silux e Z100) e de restaurações com diferentes configurações cavitárias ( "Fator $C "=1$; 3 e 5). Utilizaram hastes de vidro que, depois de condicionadas com ácido fluorídrico e silanisadas, foram tratadas com sistema 
adesivo e adaptadas a uma máquina de ensaios. O material era inserido entre dois discos de $5 \mathrm{~mm}$ de diâmetro, mas com diferentes alturas 2,5mm, 0,83mm e 0,5mm. Desta forma, conseguiu-se estabelecer, respectivamente, as seguintes configurações 1,0, 3,0 e 5,0, as quais foram obtidas a partir da equação determinada por FEILZER; DE GEE; DAVIDSON $^{34}$ (1987), que é expressada pela divisão do diâmetro da área unida por duas vezes a altura do espécime (área livre). Para verificar o efeito do tipo de resina composta, os testes foram realizados em configuração fixa ("Fator C" = 3). Após a realização dos testes, verificou-se a existência de diferença entre as resinas estudas, especialmente entre a resina de ativação química e as fotoativadas. Observou-se que a resina Silar teve um baixa elevação na força de contração $(0,1 \mathrm{~N} / \mathrm{s})$, a Silux apresentou-se com dados intermediários $(2,1 \mathrm{~N} / \mathrm{s})$ e a Z-100 com uma alta elevação da força de contração inicial $(4,14 \mathrm{~N} / \mathrm{s})$. O mesmo comportamento foi visto com o desenvolvimento da força de contração de polimerização (Z-100: 90,4 N; Silux: 65,8 N; Silar: 25 N). Quanto ao fator de configuração, verificaram resultados inversamente relatados pela teoria do "Fator C". O valor da força de contração de polimerização foi mais alto quando a configuração foi estabelecida em "Fator C" = $1(103,4 \mathrm{~N})$, quando comparado com as outras configurações, "Fator C" $=3(90,4 \mathrm{~N})$ e "Fator C" $=5(81,8 \mathrm{~N})$. Em sua discussão, relataram que resinas com alto conteúdo de carga apresentam maiores escores de microinfiltração quando comparadas com outros compósitos utilizando o mesmo sistema adesivo. Explicaram o alto valor da força de contração obtido pela resina Z-100 (Figura 2), quando comparada à resina Silux, que foi em função do módulo de elasticidade e da quantidade de partículas de carga. Em relação ao fator de configuração, relataram que 0 aparelho utilizado no trabalho de FEILZER; DE GEE; DAVIDSON ${ }^{34}$ (1987), mantinha a configuração completamente rígida, de forma que falhas coesivas precoces com "Fator C" maior que 2,0 foram verificadas. O aparelho utilizado neste estudo não se apresentava completamente rígido e um fator importante, considerado pelos autores, foi o volume de material, o qual nas altas configurações cavitárias, os espécimes apresentavam uma altura menor, ou seja, o volume de material era inferior quando comparado às configurações menores que demonstravam maior altura. Com isso, amostras associadas numericamente com baixo "Fator C" resultavam em maior contração linear e, entretanto, alto registro de forças (Figura 2). 

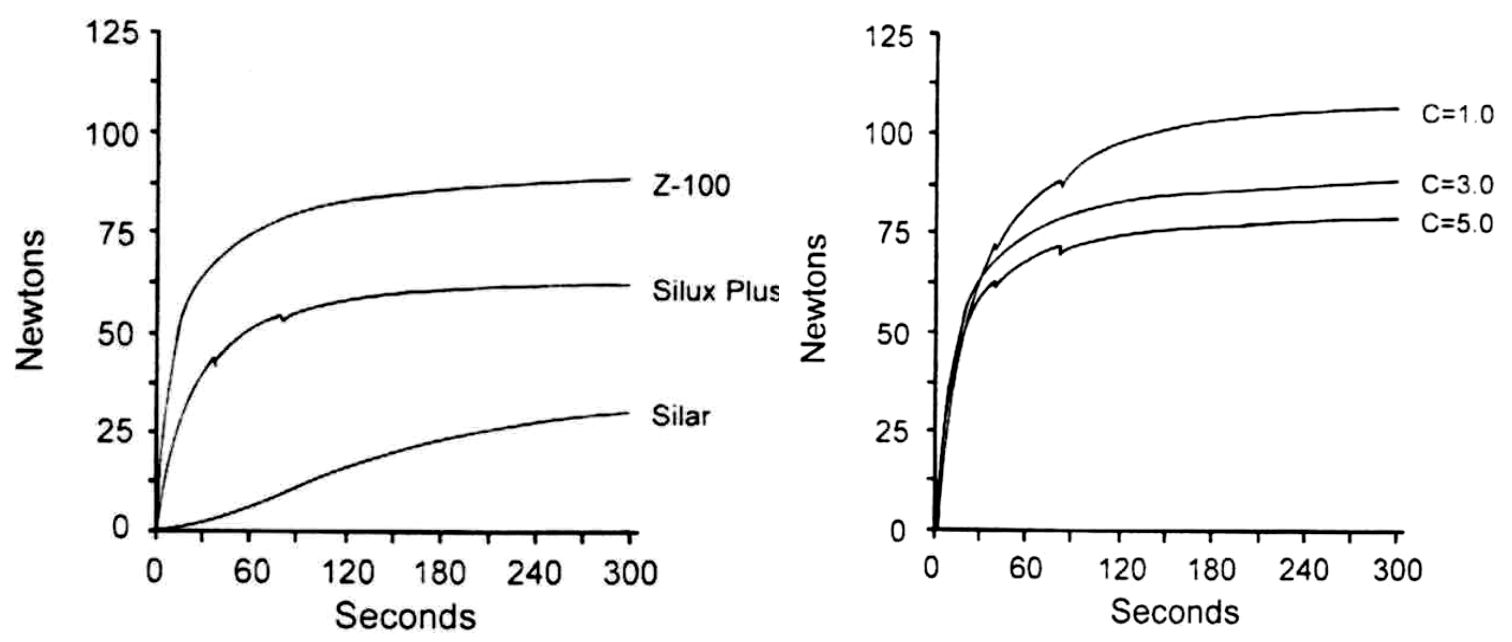

Figura 02 - Gráfico demonstrando o perfil de tensão produzida pelas três resinas (esquerda) e pelos três valores de "Fator C" (direita). (Fonte: BOUSCHLINCHER; VARGAS; BOYER ${ }^{8}$, 1997).

KORAN; KÜRSCHNER ${ }^{45}$, em 1998, realizaram um trabalho com o objetivo de verificar o efeito de iniciar a polimerização com luz de baixa densidade de potência seguido de um período de alta densidade de potência. Foram comparadas dureza superficial, adesão, contração, viscosidade e concentração de monômero residual (grau de polimerização) de corpos de prova polimerizados com irradiação variável ou contínua. Os resultados mostraram que a fotopolimerização em dois passos usando diferentes densidades de potência não modificou a contração, dureza superficial nem concentração de monômero residual quando comparada com a polimerização contínua. Os valores de adesão foram melhores para a técnica de dois passos quando comparados com a técnica contínua, amparando a teoria de que o escoamento do material é maior usando polimerização em dois passos, reduzindo o estresse de contração nas cavidades durante a polimerização preservando a integridade marginal. Os autores concluíram que a fotopolimerização seqüencial para resinas compostas provê adequado grau de polimerização e melhora a adaptação marginal por permitir maior escoamento do material durante os estágios inicias da polimerização.

DAVIDSON ${ }^{26}$, em 1998, dissertou em um simpósio sobre vários aspectos relacionados com o controle das tensões causadas pela contração de polimerização. $O$ mesmo relatou que, quanto maior for a rigidez do material, maiores serão as tensões e 
quando estas excederem a força adesiva ou coesiva dos materiais, estes vão se fraturar. Afirmou que o escoamento das tensões é limitado e ocorre principalmente durante a fase pré-gel da reação de polimerização. Quanto mais prolongada for esta fase mais a resina conseguirá se adaptar à contração. Descreveu que os compósitos de micropartículas possuem uma performance melhor do que os compósitos híbridos, quando se trata de selamento marginal, ressaltando neste aspecto, a boa função dos cimentos de ionômero de vidro modificado por resina e dos compômeros pelo fato de apresentarem um baixo módulo de elasticidade.

Participando deste mesmo simpósio em 1998, SUH ${ }^{65}$ teceu comentários sobre a contração de polimerização das resinas compostas. Desta forma, fez um apanhado sobre o fator de configuração cavitária afirmando que, quando existe uma união com três ou cinco superfícies, apenas uma permanecerá livre. Nesta situação, não haverá escoamento significativo para compensar a contração de polimerização, resultando em um estresse residual (Figura 3). Baseado na expressão que as tensões de contração são diretamente proporcionais ao coeficiente linear de contração e ao módulo de elasticidade, o autor citou em seus dados, os quais foram obtidos a partir do estudo dos substratos dentários em função do módulo de elasticidade, que existe a formação de rachaduras em esmalte das cavidades restauradas com resina composta, as quais se estendem até a junção amelodentinária e quando a união foi em dentina, não foram observadas tais trincas ou perda de união. Nesse sentido, foi concluído que as forças de união da atual geração de adesivos à dentina são resistentes o suficiente para suportarem as tensões causadas pela contração de polimerização, mas a atual geração dos compósitos dentários pode causar trincas em esmalte entre as linhas de direção dos prismas de esmalte devido ao seu alto módulo de elasticidade (Figura 4). 


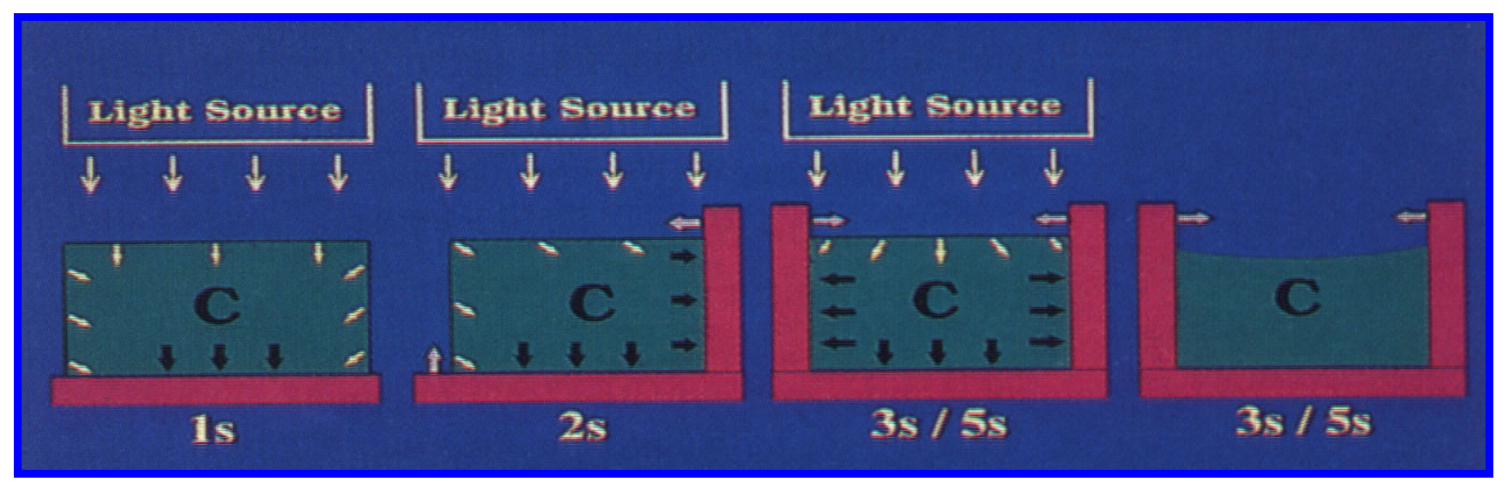

Figura 03 - Relação de alívio das tensões com o fator de configuração cavitária. (Fonte: $\left.\mathrm{SUH}^{65}, 1998\right)$.

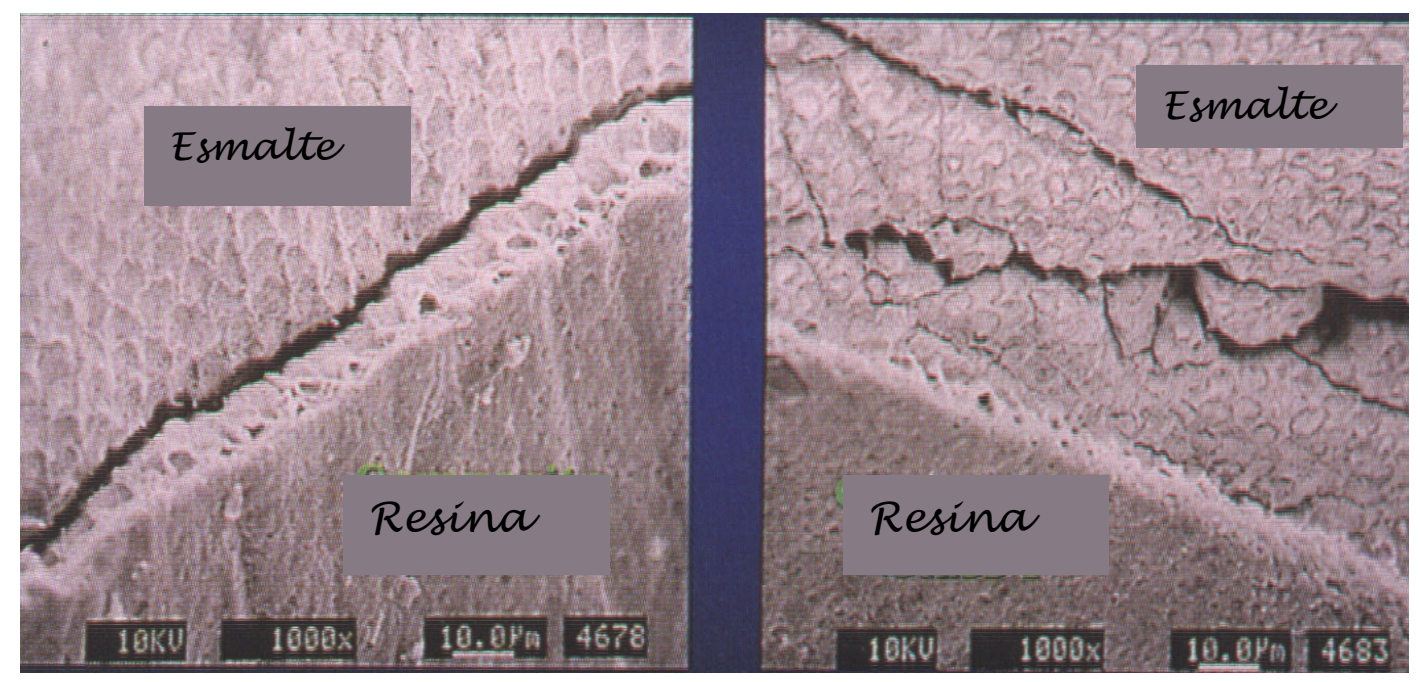

Figura 04 - Fraturas em esmalte. (Fonte: SUH ${ }^{65}$, 1998).

Em 1998, CONDON; FERRACANE ${ }^{23}$ realizaram um trabalho com o objetivo de determinar a redução do estresse de polimerização das resinas através da adição de micropartículas não adesivas. Para isso, adicionaram a uma resina de partículas pequenas e a uma resina, três tipos de micropartículas: silanisadas, não silanisadas e tratadas com um silano não funcional. $O$ estresse de contração gerado por esses 
materiais foi medido pela polimerização dos mesmos entre pratos de vidro montados em uma máquina de ensaios. A força máxima foi registrada 15 minutos após foto-iniciação. Os resultados mostraram que, na resina, a adição de micropartículas tratadas com um silano não funcional reduziu em $50 \%$ o estresse de polimerização, enquanto que a adição de micropartículas não silanisadas não reduziu o estresse. Na resina composta de partículas pequenas, a inclusão de micropartículas não silanisadas produziram uma redução de $30 \%$ quando comparadas com as micropartículas silanisadas, enquanto que as micropartículas tratadas com um silano não funcional não reduziram o estresse de contração. Afirmaram que a contração de polimerização de resinas compostas dentais podem transmitir altos níveis de estresse às superfícies dentais às quais estão aderidas e que essa contração pode levar a falha na formação de uma ligação adesiva com a superfície dental. Micropartículas que não são aderidas à matriz resinosa podem proporcionar sítios para alívio dos estresses internos, reduzindo o estresse de contração das resinas compostas.

No ano de 1998, VERLUIS; TANTBIROJN; DOUGLAS ${ }^{72}$ realizaram um estudo no qual relataram que muitas das técnicas restauradoras com resinas compostas fotoativadas foram desenvolvidas em concordância com a teoria da contração em direção à fonte de luz das resinas. Entretanto, os autores afirmaram que não há suporte consistente na literatura para essa teoria. Com esse propósito utilizaram a metodologia de simulação de teste através de análise de elemento finito para observar a direção de contração de polimerização das resinas compostas químicas e fotoativadas. $A$ análise mostrou que a direção de contração de polimerização não foi afetada significativamente pela orientação da fonte de luz, mas foi determinada principalmente pela adesão da restauração ao dente e pelas superfícies livres. Conseqüentemente, a diferença entre a contração das resinas auto e fotopolimerizáveis foi mínima. Os autores concluíram que as resinas compostas não contraem em direção à luz e a direção de contração é determinada pelo desenho da cavidade e qualidade adesiva, sendo que a posição da fonte de luz não parece ser um fator influente para a melhoria da qualidade marginal.

Sobre a influência do módulo de elasticidade SUH; CINCIONE; SANDRIK ${ }^{64}$, em 1998, avaliaram a relação entre o módulo de elasticidade do substrato, em cavidades experimentais, com o tipo de falha da restauração. Foi utilizada uma resina composta híbrida inserida em cavidades preparadas em dente (esmalte e dentina), resina composta, 
porcelana e vidro. Foram preparadas cavidades de classe I com dimensões de $3 \times 3 \times 3$ $\mathrm{mm}$, com "Fator C" alto. Os resultados mostraram que os sistemas adesivos foram suficientes para resistir às forças de contração de polimerização da resina composta, porém, o alto módulo de elasticidade do substrato provocou falhas coesivas a uma curta distância da interface adesiva. O alto módulo de elasticidade do vidro (67 GPa), porcelana (69 GPa) e esmalte (85 Gpa) determinaram falhas coesivas a poucos micrômetros da interface, porém o conjunto substrato/dentina adesivo permaneceu intacto. Os substratos com baixo módulo de elasticidade, como a dentina (18 GPa) e a resina composta (16 $\mathrm{GPa}$ ), resistiram às tensões transmitidas. O autor concluiu que um substrato cavitário com baixo módulo de elasticidade é desejável em função da capacidade de deformação deste, entretanto, os substratos com alto módulo de elasticidade promovem falhas coesivas sob tensões de contração.

Os métodos de polimerização das resinas compostas foram descritos por RUEGGEBERG ${ }^{58}$, 1999. Relatou que o componente fotoabsorvente mais comum utilizado nos materiais restauradores é a canforoquinona (CQ), que absorve energia dentro do espectro de luz visível azul entre 450 e 500 nm, com pico aproximadamente em 465 nm. Quanto excitada com essa energia a canforoquinona colide com a amina formando um radical livre que forma ligações covalentes com as moléculas de dupla ligação carbônicas dos monômeros, formando uma reação em cadeia, polimerizando o material. A diminuição da intensidade de luz, à medida que a profundidade do material aumenta, constitui um problema que deve ser compensado com um aumento da duração da exposição da resina à luz ou com aumento da intensidade de luz para maior excitação das moléculas. Relatou ainda que os metacrilatos utilizados na composição dos materiais a base de resina sofrem contração de polimerização; para cada molécula $C=C$ reagindo e formando uma ligação simples (C-C) existem 23 cc de contração. Com a adição de maior quantidade de carga às resinas, os fabricantes reduziram a contração volumétrica para 1,5 a $3 \%$ que, entretanto, ainda podem resultar em estresse às paredes cavitárias levando a fendas marginais e fraturas do esmalte com a conseqüente sensibilidade pósoperatória. Afirmou que durante a fase inicial de polimerização, onde os polímeros encontram-se ainda flexíveis e em estado fluido, o estresse da contração pode ser aliviado pelo escoamento da resina e não há transmissão do estresse para a interface dente/resina. Quando o polímero apresentar a estrutura mais rígida (maior módulo de elasticidade) o estresse atinge a estrutura dental. $\mathrm{O}$ ponto no qual o polímero adquire um 
maior módulo de elasticidade e pode transferir o estresse para a interface dente/resina é chamado de ponto gel. O estresse desenvolvido durante a polimerização pode ser minimizado considerando a proporção entre as superfícies aderidas e não aderidas quando a proporção aumenta, como nos casos das cavidades classe I e V, o polímero tem pouca superfície para escoar e, conseqüentemente, o estresse aumenta. No caso de cavidades classe II e IV o estresse é reduzido, pois não existe muita diferença entre as superfícies aderidas e as superfícies livres. Essa proporção tem sido chamada de fator de configuração ou "Fator C". Afirmou ainda que diminuindo a intensidade de luz nos instantes iniciais da polimerização, esta ocorre lentamente, gerando menor valor de estresse pelo maior tempo que o material tem para escoar - essa técnica é conhecida como soft-start. Quando o material atinge o estado gel, é submetido a altas intensidades de luz, garantindo grau de conversão equivalente ao obtido com a técnica convencional. Afirmou ainda que, com a polimerização ocorrendo mais lentamente, as propriedades físicas dos polímeros são melhoradas, pois cadeias mais longas e com maior peso molecular são obtidas.

SAKAGUCHI ${ }^{60}$, em 1999, afirmou que a contração de polimerização dos compostos dentais é o maior responsável pela sensibilidade da técnica quando esses materiais são utilizados clinicamente. Relatou que as dificuldades com os contatos proximais, integridade marginal, espaços internos, sensibilidade pós-operatória e estabelecimento da oclusão, estão todos relacionados com a contração de polimerização. A contração é inerente aos sistemas atualmente disponíveis e persistirá até o surgimento de polímeros com baixa ou nenhuma contração. Portanto, o entendimento da origem e magnitude do estresse de contração é útil para proporcionar procedimentos clínicos racionais durante a inserção das resinas. Explicou que durante a polimerização há uma irreversível transformação de um líquido viscoso para um gel visco-elástico, no chamado de ponto de geleificação. Nos sistemas fotoativados a geleificação ocorre poucos segundos após a exposição à luz. Relatou que a contração que ocorre antes da geleificação é chamada de pré-gel e aquela que ocorre após a geleificação é chamada de pós-gel, sendo esta última de maior importância clínica, pois forças são transferidas desde a resina, através dos adesivos, para o esmalte e a dentina. Descreveu métodos utilizados para a medição do estresse de polimerização das resinas, afirmando que não é possível medir o estresse diretamente, e que a força da contração necessita ser transferida para um segundo corpo. Finalmente afirmou que alguns métodos medem a 
contração pós-gel, mas não está claro se esses métodos captam toda a deformação pósgel, e que os clínicos deveriam ser cautelosos em usar os valores de estresse como indicador de sucesso clínico de alguma marca de resina em particular sem o conhecimento das condições do teste efetuado.

Em 1999, SUH ${ }^{66}$ discorreu sobre os fatores envolvidos no entendimento e controle do efeito das tensões de contração de polimerização em restaurações com resina composta. Afirmou que a contração é uma propriedade química inerente e associada à polimerização das resinas compostas. Quanto às fases da contração, explicou que até o ponto gel a resina desenvolve uma certa rigidez, porém ainda é capaz de aliviar as tensões pelo escoamento molecular. A partir deste ponto ocorrerá a contração pós-gel, resultando no acúmulo de tensões clinicamente significantes. Demonstrou que as resinas quimicamente ativadas apresentam um estágio pré-gel mais evidente do que as fotopolimerizáveis, sendo que a cinética de polimerização, neste caso, deve ser considerada juntamente com a contração e o módulo de elasticidade. Relatou que o fato de uma resina apresentar baixa contração de polimerização, não significa necessariamente que produzirá baixas tensões, pois a tentativa de se acrescentar mais carga inorgânica pode aumentar o módulo de elasticidade do material, anulando-se o efeito da redução da contração. Quanto às técnicas de polimerização, apresentou alguns resultados demonstrando uma superioridade da pulse delay, em termos da geração de menores tensões de contração. Dentro das novas perspectivas, chamou a atenção sobre a importância em se conhecer a energia mínima necessária para se alcançar uma polimerização adequada. Assim, deve ser necessária a descrição deste valor na embalagem do produto, como por exemplo: $10 \mathrm{~J} / \mathrm{cm}^{2}$, a qual corresponderia à $10.000 \mathrm{~mJ} / \mathrm{cm}^{2}$ e, com $500 \mathrm{~mW} / \mathrm{cm}^{2}$ X $20 \mathrm{~s}$ ou $250 \mathrm{~mW} / \mathrm{cm}^{2}$ X $40 \mathrm{~s}$, promoveria-se uma polimerização adequada. Finalizando, também, foi relatado sobre a necessidade de se descrever o tipo de fotoiniciador nas embalagens dos produtos, pois os novos aparelhos emitem luz em uma faixa mais estreita em termos de comprimento de onda.

VERLUIS; TANTBIROJN ${ }^{71}$ afirmaram, também em 1999, que a contração de polimerização dos materiais restauradores resinosos causam preocupações clínicas porque o estresse residual é transmitido para o dente restaurado. Esses estresses podem, entre outras coisas, causar fraturas do esmalte, microinfiltração marginal e sensibilidade pós-operatória. Relataram que a quantidade do estresse de contração não 
depende somente de quanto o compósito contrai, mas também do módulo de elasticidade do compósito, da forma da cavidade e da adesão estabelecida entre o dente e a restauração. Afirmaram ainda, que a relação entre esses vários fatores podem ser descritos por leis físicas, e que para analisar o estresse de contração, modelos teóricos devem ser usados para relacionar as várias propriedades da contração e as condições clínicas através das leis físicas e, assim, os modelos podem nos ajudar a repensar e otimizar os caminhos para o sucesso clínico. Relataram, em seu trabalho, três definições que descrevem a contração: a quantificação (contrações volumétrica e linear), a fase (prégel, pós-gel e a contração total) e a distribuição (contração uniforme e não uniforme). Finalmente, descreveram que, para entender o problema de contração das restaurações dentais, é importante perceber que duas mudanças físicas maiores ocorrem durante a polimerização da resina: a contração e a solidificação e que a interação entre ambos os fenômenos causam o estresse de contração, o que individualmente eles não causariam.

Ainda em 1999, LABELLA et al. ${ }^{46}$ estudaram a contração de polimerização e elasticidade tanto de resinas fluidas como de adesivos com carga inorgânica. Os resultados mostraram que as resinas fluidas apresentam menor módulo de elasticidade que as resinas híbridas e similar às resinas de micropartículas e os adesivo com carga. Em relação à contração de polimerização, as resinas fluidas apresentaram maior contração volumétrica que as resinas compostas híbridas e de micropartículas, e menor que os adesivos com carga. Os autores acrescentaram que o menor módulo de elasticidade e a maior contração volumétrica apresentada pelas resinas fluidas em relação às resinas híbridas e de micropartículas é uma evidencia indireta que a fluidez desses materiais é conseguida através do incremento da proporção de monômero na formulação da pasta resinosa. Observando os resultados obtidos com Aelite Flow, Glaze, Durafill Flow e o adesivo Solid Bond, onde a relação inversa entre a contração de polimerização e o módulo de elasticidade não foi muito evidente, comentaram que possivelmente nessas resinas tenha-se utilizado monômeros de menor contração e mais flexíveis, levando os resultados a uma análise mais complexa que a simples relação matriz-carga. Finalmente concluíram que entre os materiais avaliados, as resinas fluidas e as resinas compostas híbridas se encontram em extremos opostos em relação aos valores de contração de polimerização e módulo de elasticidade. Enquanto as resinas fluidas foram os materiais com maior contração de polimerização e maior flexibilidade, as resinas compostas híbridas apresentaram um comportamento oposto. A magnitude e 
cinética da contração de polimerização junto com o módulo de elasticidade, podem ser de utilidade na predição de falhas adesivas.

UNTERBRINK; LIEBENBERG ${ }^{70}$ afirmaram, no ano de 1999 , em uma revisão da literatura sobre resinas fluidas, que a odontologia adesiva poderia ser entendida como 0 simples relacionamento entre adesão e estresse, e que os fatores relacionados com 0 estresse de contração seriam, em ordem de importância: geometria da cavidade (fator de configuração e tamanho da cavidade), técnica de aplicação (camadas de resina e posição de luz) e material restaurador (módulo de elasticidade e mudanças dimensionais). Relataram que os adesivos com carga oferecem vantagens, pois a espessura da camada seria suficiente para eliminar o problema da inibição pelo oxigênio e causariam pouco estresse de contração em função de um fator de configuração favorável. Recomendaram o uso de resina composta fluida radiopaca associada a qualquer sistema adesivo para criar uma parede cavitária verdadeiramente elástica, considerando ser essa a chave para a obtenção de resultados clínicos aceitáveis.

Ainda em 1999, KINOMOTO et al. ${ }^{44}$ compararam a distribuição e magnitude do estresse de contração entre uma resina quimicamente ativada e uma fotoativada. 0 estudo foi realizado utilizando análise de fotoelasticidade. Observou-se que a distribuição do estresse principal e do estresse gerado na parede da cavidade foi semelhante para as resinas compostas quimicamente ativadas e fotoativadas. No entanto, quando a magnitude do estresse foi avaliada, a resina fotoativada gerou valores significativamente maiores do que a resina quimicamente ativada. Os autores concluíram que a diferença na magnitude do estresse não estaria em função de sua distribuição, e que a velocidade de polimerização aparece como principal fator na magnitude de estresse interno durante a contração de polimerização.

DAVIDSON ${ }^{28}$, em 2000, relatou que, para iniciar a reação de polimerização de resinas compostas fotoativadas, a ativação da canforoquinona é essencial e pode ser obtida pela irradiação de luz azul com $470 \mathrm{~nm}$ de comprimento de onda. Afirmou que, para uma ótima conversão da resina, a energia pode ser suprida de diversas maneiras e é dependente das características da fonte de luz e do tempo de irradiação, sendo que para a prática odontológica uma combinação de baixo tempo de irradiação, grau de conversão alto e uniforme e baixo estresse de contração são o desejado. Afirmou que, 
uma conversão rápida é acompanhada de tensão que pode afetar negativamente a integridade marginal da restauração adesiva, existindo o paradoxo que tudo o que fazemos para melhorar o grau de conversão contribuirá negativamente para a preservação da continuidade marginal. Enfatizou que nas áreas profundas da restauração a energia é atenuada e, portanto, a completa conversão pode estar em risco. Relatou que o prolongamento do tempo de irradiação é mais efetivo para conversão adequada do que o aumento de densidade de potência, mas que a utilização de uma fonte de luz confiável com saída de densidade de potência conhecida é recomendada. Finalizou afirmando que a qualidade marginal da restauração é garantida pela adequada seleção do material e a manipulação da energia de irradiação.

Em 2000, CONDON; FERRACANE ${ }^{24}$ mediram a magnitude das tensões oriundas da contração de polimerização de vários tipos de resinas. Espécimes foram confeccionados a partir de 11 diferentes resinas compostas (micropartículas, híbridas e de ativação química) e resinas experimentais, e as tensões de contração determinadas em uma máquina de ensaios. O efeito de um monômero derivado de um metacrilato álcool estireno-alil (MSAA), na redução dessas forças também foi determinado. Dentre os materiais estudados, a resina Durafill apresentou a menor porcentagem de partículas de carga (38 \% por volume). Verificaram, diante dos dados obtidos, uma significativa relação entre volume de partículas e aumento nas tensões de contração de polimerização, sendo que a Durafill apresentou menor valor de tensões de contração e a resina Herculite 0 maior (57 \% por volume). Na discussão, atribuíram estes resultados à rigidez dos diferentes materiais, pois, quanto maior o conteúdo inorgânico de uma resina composta, maior será seu módulo de elasticidade e, conseqüentemente, maiores as tensões provenientes da contração de polimerização. Prova disto, foi a exclusão da resina Z100 e P-50 (alta porcentagem de carga) deste estudo, devido aos níveis de tensões serem tão altos a ponto de haver quebra dos corpos-de-prova durante a fase de fotopolimerização. A introdução do MSAA reduziu em $30 \%$ as forças de contração das resinas experimentais, mostrando que monômeros com menor contração de polimerização induzem menores forças de contração, melhorando o prognóstico da interface adesiva. Entretanto, os autores ponderaram os seus resultados no sentido de considerar que resinas com baixo conteúdo inorgânico possuem baixa resistência à fratura e ao 
desgaste, devendo, desta forma, serem indicadas em áreas com baixas tensões oclusais (Classe V).

Em 2000, DAUVILLIER; AARNTS; FEILZER ${ }^{33}$, realizaram uma revisão das propriedades dos materiais e das técnicas restauradoras no sentido de dar caminhos para a redução dos efeitos da contração de polimerização das resinas compostas. Relataram que vários são os fatores que influenciam a contração de polimerização, como o tamanho da molécula monomérica contida na resina composta. Quanto maior o tamanho desta antes da polimerização, menor será a contração. Outro fator citado foi a concentração de carga inorgânica dentro da resina composta, incluindo partes pré-polimerizadas, onde a alta porcentagem de carga conduz a uma baixa contração. E por último, foi descrito que o tipo ou a natureza da matriz tem papel importante na contração. Afirmaram que a maior parte da contração ocorre nos estágios iniciais da reação de polimerização, 15 minutos para as resinas quimicamente ativadas e 60 segundos para as fotoativadas (Figura 5). Assim, problemas associados com a perda da adesão freqüentemente ocorrem durante o estágio inicial de polimerização, ocasionalmente antes do paciente sair da cadeira do profissional. Propuseram algumas possibilidades para que o desenvolvimento das tensões de contração seja minimizado. Uma opção seria o desenvolvimento de materiais que não contraem $(<0,4 \%)$ ou reduzir a velocidade de polimerização das resinas fotoativadas, sem diminuir o grau de conversão. Para isto, pode-se modificar quimicamente a resina de várias formas: adicionando agentes retardadores, reduzindo a quantia de fotoiniciadores ou desenvolvendo novos fotoiniciadores que proporcionasse uma reação lenta de polimerização, porém com alta conversão de monômeros.

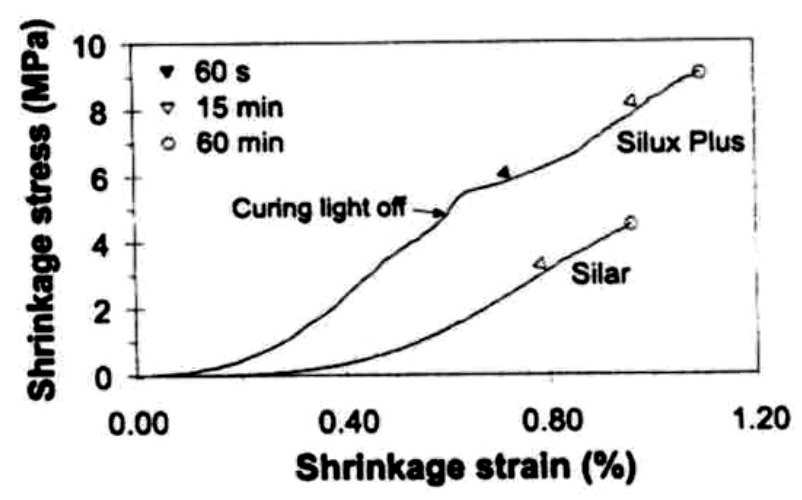

Figura 05- Perfil das tensões de contração produzidos por uma resina quimicamente ativada (Silar) e uma fotoativada (Silux). (Fonte: DAUVILLIER; AARNTS; FEILZER ${ }^{33}$, 2000). 
Buscando avaliar as técnicas de polimerização, BOUSCHLICHER; RUEGGEBERG; BOYER ${ }^{7}$, em 2000, determinaram a força de contração gerada por uma resina composta fotoativada por quatro métodos: $\mathrm{G} 1-40 \mathrm{~s} \times 800 \mathrm{~mW} / \mathrm{cm}^{2}, \mathrm{G} 2-10 \mathrm{~s} \times$ $100 \mathrm{~mW} / \mathrm{cm}^{2}+30 \mathrm{~s} \times 800 \mathrm{~mW} / \mathrm{cm}^{2}$; G3- $60 \mathrm{~s} \times 800 \mathrm{~mW} / \mathrm{cm}^{2}$ e G4- $10 \mathrm{~s} \times 100 \mathrm{~mW} / \mathrm{cm}^{2}+$ $50 \mathrm{~s} \times 800 \mathrm{~mW} / \mathrm{cm}^{2}$. As medidas foram efetuadas em uma máquina universal de testes. Os dados obtidos foram: G1- 177 N; G2- 172 N; G3- 213 N e G4- 197 N. Não foram observadas diferenças estatísticas entre G1 e G2, assim como entre G3 e G4. Porém, G2 proporcionou menor força de contração do que G3. Admitiram que a razão desta similaridade entre os grupos pode ser devido a fatores ligado à metodologia, pois como o espécime apresentava um diâmetro de $5 \mathrm{~mm}$, foi necessário realizar a polimerização em dois lados do mesmo. Este detalhe pode ter reduzido o efeito da baixa intensidade inicial em prolongar a fase pré-gel da resina, o que seria distinto do que ocorre na clínica. Foi verificado, nos grupos de polimerização gradual, que nos $10 \mathrm{~s}$ iniciais não houve geração de forças, estando relacionado à baixa quantidade de energia aplicada, indicando a presença da fase pré-gel da resina composta. Diante destes resultados, aconselharam que um tempo intermediário ou uma intensidade progressiva pode resultar em baixa produção de forças de contração, permitindo um escoamento das tensões pelo fluxo, ou mesmo reduzir a quantidade de fotoiniciadores e de agentes redutores.

CHOI; CONDOM; FERRACANE ${ }^{22}$, em 2000, comentaram que as resinas compostas apresentam ainda algumas propriedades não desejadas que podem afetar sua durabilidade como material restaurador. Uma delas, segundo os autores, é a contração que inevitavelmente acontece quando o material polimeriza e troca a distância de Van der Whaals entre suas moléculas por uma distância de ligação covalente. Essa contração pode transmitir estresse quando o material é confinado dentro de uma cavidade adesiva. Uma forma prática que estaria sendo utilizada para diminuir as conseqüências desta contração é o uso de camadas de maior espessura de adesivo como camada intermediária entre a resina composta e o dente. Uma camada de espessura considerável de material de baixo módulo de elasticidade poderia absorver parte do estresse de contração gerado pela resina composta durante sua polimerização. Assim, o propósito deste estudo foi avaliar e medir quantitativamente o estresse de contração de uma resina composta variando a espessura do adesivo, e relacionar esse efeito com a microinfiltração em cavidades de classe $V$ preparadas em dentes bovinos. A montagem do teste foi semelhante àquela descrita por FEILZER; DE GEE; DAVIDSON ${ }^{34}$. A força de 
contração foi registrada durante 15 minutos e o valor máximo nesse período foi considerado. Foram avaliados 30 corpos de prova, nos quais a espessura do adesivo Scotchbond MP (3M/ESPE) variou de 20 a $300 \mu \mathrm{m}$, em cavidades com "Fator C" de 2 e 3. Para o teste de microinfiltração foram utilizados 24 dentes bovinos extraídos onde foram preparadas cavidades de classe V semelhantes entre elas, separadas em dois grupos, com "Fator C" de 2 e 3 . Os resultados mostraram que existiu diminuição de $17 \%$ no estresse de contração quando o corpo de prova passava a utilizar duas camadas de adesivo no lugar de uma única camada. Quando passou a utilizar três camadas apresentou diminuição adicional de $13 \%$, em cavidades de "Fator C" 2. Em cavidades de "Fator C" 3, a utilização de duas camadas promoveu a diminuição de aproximadamente $24 \%$ no estresse de contração, enquanto que uma terceira camada não promoveu beneficio algum. A diminuição de estresse de contração produzida pelo adesivo tem sido relacionada com seu baixo módulo de elasticidade intrínseco e na área de interdifusão com a dentina. Esse estudo demonstrou que o estresse transmitido durante a polimerização da resina composta foi significantemente reduzido pela aplicação de espessuras maiores do adesivo e a aplicação de uma camada adicional aumenta a espessura desta de duas a quatro vezes. Adicionalmente, o estresse foi positivamente relacionado com a microinfitração precoce da restauração. Desta forma, segundo os autores, aumentar a espessura do adesivo pela utilização de camadas adicionais poderia levar a melhor adaptação marginal e, conseqüentemente, aumentar a vida útil da restauração.

$\mathrm{CHAIN}^{19}$, em 2001, citou em seu trabalho que a contração de polimerização nunca foi superada de forma relevante sendo um problema da odontologia restauradora. Relatou que a rigidez ou módulo de elasticidade de um material é tão importante quanto sua deformação, e que não há relação entre a contração volumétrica e a tensão de contração, mas sim uma relação significante entre esta última e o módulo de elasticidade. Assim, afirmou que quanto mais carga tiver o compósito, menor é a sua contração volumétrica, mas maior também a sua rigidez, causando maior tensão de contração. Concluiu que nem grande quantidade de carga e nem alto módulo de elasticidade são propriedades favoráveis das resinas compostas sendo a contração volumétrica um número inútil para predizer o comportamento clínico de uma resina composta. Para contornar esse problema o clínico deve utilizar técnicas de fotopolimerização que prolonguem o ponto gel das resinas, como a técnica estratificada e do pulso tardio. 
CHEN et al. $^{20}$, em seu trabalho de 2001, tiveram o objetivo de determinar o estresse de contração de polimerização das resinas compactáveis ALERT, Surefil, Solitaire e Solitaire 2 e do ormocer Definite, em comparação com a resina híbrida Tetric Ceram. A força de contração gerada pelos materiais testados foi medida durante a polimerização de restaurações de resina composta em uma bandeja plástica entre dois acessórios de alumínio montados em uma máquina de teste Stress-Strain-Analyzer, com o tamanho dos espécimes $4 \times 4 \times 2 \mathrm{~mm}$ e "Fator C" de 0,33. A força de contração foi registrada durante 300 segundos sob uma exposição padronizada de $800 \mathrm{~mW} / \mathrm{cm}^{2}$ durante 40 segundos. O máximo estresse de contração (MPa), a força (N/s) e a força relativa de cada material foram estatisticamente analisados por ANOVA e teste de Tukey ( $p \leq 0.05)$. Os resultados mostraram que o máximo estresse de contração dos materiais compactáveis foram 4,60 $\pm 0,32 \mathrm{MPa}$ (ALERT), 4,16 $\pm 0,18 \mathrm{MPa}$ (Definite), 3,36 \pm 0,08 MPa (Solitaire 2); 3,33 \pm 0,23 MPa (Solitaire) e 3,13 \pm 0,18 MPa (Surefil), que foram significativamente maiores que os valores obtidos pela resina Tetric Ceram $(2,52 \pm 0,14 \mathrm{MPa})$. Tetric Ceram exibiu significativamente a mais baixa força de contração e a curva força-tempo obtida foi em forma de S. A resina Solitaire apresentou a mais longa fase pré-gel antes do registro das forças de contração. Os autores afirmaram que altos valores de estresse de contração de polimerização e o rápido desenvolvimento dessas forças podem levar a falhas de adesão às estruturas dentárias. Esse estudo sugeriu que as resinas compactáveis têm menor capacidade de reduzir o estresse de contração durante os estágios iniciais de reação, não sendo superior do que a resina híbrida Tetric Ceram em manter a adesividade às paredes cavitárias.

RENGO et. al. $^{56}$, ainda em 2001, realizaram um trabalho com o objetivo de determinar o estresse gerado durante a polimerização de várias resinas compostas utilizando diferentes fontes de luz, assim como a efetividade de polimerização e o grau de conversão obtidos. Comparando a contração volumétrica das resinas usando baixa intensidade de luz $\left(150 \mathrm{~mW} / \mathrm{cm}^{2}\right)$ e alta intensidade $\left(750 \mathrm{~mW} / \mathrm{cm}^{2}\right)$ os autores não encontraram diferenças significantes, embora com baixa intensidade a contração a tenha sido mais lenta. Com as mesmas intensidades de luz os autores avaliaram a fratura produzida pelas resinas Prodigy (Kerr), Charisma (Kulzer) e Z-100 (3M/ESPE) na superfície de vidros especialmente tratados e os resultados mostraram que a quantidade de contração volumétrica não determinou a quantidade de estresse, mas sim o módulo de elasticidade das resinas, apresentando melhores resultados a resina Charisma que não 
produziu fraturas em nenhuma das intensidades, seguida da resina Prodigy que produziu fraturas em alta intensidade e, finalmente, a resina Z-100 que produziu fraturas em ambas as intensidades. Em seguida, utilizando diferentes fontes de luz, halógena $\left(500 \mathrm{~mW} / \mathrm{cm}^{2}\right.$ durante 60 segundos), plasma $\left(1000 \mathrm{~mW} / \mathrm{cm}^{2}\right.$ por 3 segundos e mais de $1000 \mathrm{~mW} / \mathrm{cm}^{2}$ por mais 3 segundos) e halógena em dois passos $\left(100-300 \mathrm{~mW} / \mathrm{cm}^{2}\right.$ por 3 segundos e, depois de 3 minutos, $500 \mathrm{~mW} / \mathrm{cm}^{2}$ por 30 segundos), os autores mediram o estresse de diversas resinas e obtiveram como resultado menores valores de contração para a luz plasma, seguida da luz halógena em dois passos e da luz halógena convencional. Os autores concluíram que uma polimerização mais lenta é melhor para atenuar o estresse gerado na interface dente/resina e que os materiais fotopolimerizados com a luz plasma mostraram menor contração e estresse do que aqueles fotopolimerizados com a luz halógena em dois passos, os quais, por sua vez, apresentaram menores valores de contração do que os polimerizados com luz halógena convencional.

TESSORE; TRINCHERO ${ }^{68}$, em 2001, realizaram um trabalho sobre a sensibilidade pós-operatória em conseqüência das restaurações de resina composta em dentes posteriores. Relataram que a sensibilidade pós-operatória é o resultado de um selamento imperfeito ao nível de dentina, de esmalte ou de ambos, e que as razões para esse selamento imperfeito estão relacionadas com a impregnação imperfeita do sistema adesivo sobre o substrato dentinário ou pelas forças de contração de polimerização que podem causar microfraturas na estrutura de esmalte ou o descolamento da resina composta da estrutura dental. Explicaram que, durante a polimerização, as resinas compostas estão sujeitas a uma redução volumétrica de 2 a $6 \%$, e que essa redução exerce uma força de 8 a 23 MPa nas paredes da cavidade, dependendo do tipo de resina e da forma da cavidade, podendo causar o aparecimento de fendas, pela separação do adesivo das estruturas dentinárias, ou microfraturas da estrutura do esmalte. Afirmaram ainda que, teoricamente, um compósito com alta concentração de carga tem uma menor contração de polimerização, mas, paradoxalmente, ele gera um maior estresse por ser menos elástico e possuir menor capacidade de escoar para compensar a contração. Assim, recomendam a utilização, na prática clínica, de uma base com um material altamente elástico após a camada adesiva para reduzir o estresse transmitido às estruturas dentárias, além de uma técnica de polimerização que prolongue a fase pré-gel, como a técnica do pulso tardio iniciando a polimerização com baixa intensidade (200 $\mathrm{mW} / \mathrm{cm}^{2}$ ) e por um tempo curto (3 segundos), aguardando 3 minutos para o 
compósito alcançar o ponto gel e finalizando com uma polimerização de 10 ou 20 segundos a $600 \mathrm{~mW} / \mathrm{cm}^{2}$. Recomendam, ainda, a utilização de selantes de superfície para eliminar as porosidades da resina, as fendas na interface dente/restauração e as microfraturas de esmalte, reduzindo assim a sensibilidade pós-operatória.

MIGUEL; DE LA MACORRA ${ }^{49}$ (2001) propuseram uma fórmula matemática associando o estresse de contração de polimerização em relação às superfícies livres e aderidas da cavidade, o volume do material e a deformação de materiais resinosos. Os autores criticam a metodologia de FEILZER; DE GEE; DAVIDSON ${ }^{34}$ expondo algumas limitações na montagem do ensaio. Explicam que o sistema de reposicionamento usado nesse estudo só reconhece a mudança de distância entre as bases e a repõe, gerando movimento para, em teoria, manter a distância constante. Segundo os autores, esse não pode ser considerado um sistema rígido, desde que as bases estão continuamente aproximando-se em decorrência das tensões produzidas pelo material durante a polimerização e afastando-se em função do sistema de reposicionamento. Para eles, esse contínuo movimento de bases poderia induzir a leituras errôneas, desde que poderia ser possível que o material seja parcialmente estressado. Outra limitação, segundo os autores, é mais de origem conceptual. Não existe um sistema totalmente rígido na natureza; os dentes e a restauração inevitavelmente possuem uma certa capacidade de deformação, que permite que as tensões sejam parcialmente relaxadas. Também critica 0 fato de que o "Fator C" não considere volume da restauração, nem as características específicas do material. Avaliaram corpos de prova cilíndricos de 9 materiais quimicamente ativados. Os diâmetros dos discos foram 5,81; 8,5; 11,26; 12,42; 17,02 e 23,14 mm com alturas de 0,02 e 5,9 mm. Foram deixados polimerizar por um período de 25 minutos. Os resultados mostraram que não existiu uma relação linear direta entre o "Fator C" e o estresse de contração, e o maior "Fator C" determinou as menores tensões. Mesmo com resultados contrastantes, observaram que o modelo de FEILZER; DE GEE; DAVIDSON $^{34}$ é até agora a melhor solução para medir o máximo estresse de contração, mas que não representa o que acontece na cavidade, onde parte do estresse é mascarada pelo movimento da estrutura dentária, relaxando tensões dos incrementos de resina composta, sugerindo finalmente a utilização de sistemas não rígidos, que considerem a deformação do sistema para avaliar o estresse de polimerização. Os valores que acharam (0,05 até 0,6 MPa) foram menores que valores publicados em trabalhos prévios. Novamente, enfatizaram que isso estaria em função da deformação do 
modelo não rígido. Ainda os autores sugerem que a influência da superfície aderida não é necessariamente a mesma que a da superfície livre, e postulam que esta última poderia ser maior, tornando o volume um fator importante. Sugerem que a utilização de corpos de prova cilíndricos montados entre duas bases para a interpretação da situação clínica (cavidades) poderia ser um erro, sugerindo que corpos de prova com forma de cavidades reais deveriam ser empregados.

Considerando que a resina contrai durante sua polimerização e que os adesivos atuais podem, em certas situações, resistir às tensões transmitidas pela resina composta SUH; WANG ${ }^{67}$, no ano de 2001, avaliaram a direção desta contração para diferentes situações de adesão ao substrato. Foram utilizadas uma resina fotoativada e uma quimicamente ativada. Para simular a preparação de classe I, cada resina composta foi inserida em um anel de vidro com diâmetro interno de $3,2 \mathrm{~mm}$, diâmetro externo de 8,5 mm e altura de 3,0 mm. Três condições adesivas foram testadas: grupo 1 testou a ausência de adesão a qualquer parede; o grupo 2 testou a adesão exclusivamente nas paredes de vidro; o grupo 3 testou a adesão às paredes e a um piso da cavidade feito de resina pré-polimerizada. A resina composta fotoativada foi inserida em cavidades com 3 diferentes fatores de configuração cavitária e duas técnicas de inserção (incremento único e incremental). Para cada uma das seis condições experimentais foram realizados 3 corpos de prova. Os resultados mostraram que, tanto nos corpos de prova com adesão às paredes, como naqueles grupos onde não existiu adesão às paredes, o material apresentou uma concavidade (deflexão cêntrica em direção ao centro da massa) depois da polimerização. A magnitude dessa deflexão aumentou significantemente quando a quantidade de paredes adesivas aumentou. Os autores acrescentaram que nos grupos 1, 2 e 3 a resina se afastou da fonte de luz. A maior deflexão aconteceu no centro do extremo superior do corpo de prova, mesmo que esse ponto tenha ficado mais perto da fonte de luz e, conseqüentemente, tenha sido o primeiro a receber a luz, confirmando as observações de VERLUIS; TANTBIROJN; DOUGLAS ${ }^{72}$ (1998). Observaram que no extremo inferior do anel a concavidade foi maior. A explicação dos autores foi que a resina fotoativada que fica nesse extremo recebe menor intensidade de luz e a sua polimerização seria mais lenta, permitindo que a fase pré-gel seja mais extensa, e o ponto de geleificação demore mais em ser alcançado. Essas condições permitiriam maior possibilidade de compensar o estresse de contração através do fluxo na superfície livre, 
em comparação com a resina no extremo superior onde essa fase pré-gel é alcançada rapidamente. A resina quimicamente ativada mostrou o mesmo padrão de contração que a resina fotoativada. Esses resultados sugerem que a direção de contração tanto para as resinas fotoativadas como quimicamente ativadas estaria mais em função das paredes da cavidade e superfície livre que do tipo de resina composta. Em relação à técnica incremental, observaram que não existiu diferença estatisticamente significativa entre essas técnicas, sugerindo que o processo de fluxo do primeiro incremento deve ter sido suspendido em uma fase inicial da polimerização, pelo segundo incremento, não observando vantagem alguma na técnica incremental no aspecto avaliado.

YOSHIKAWA; BURROW; TAGAMI ${ }^{76}$, em 2001, avaliaram o selamento e a adaptação marginal de restaurações de resina em dois tipos de cavidades com "Fator C" distintos (2,3 e 3). Três sistemas adesivos, Clearfil Photo Bond, Clearfil Liner Bond 2 e Super-Bond D Liner, e uma resina híbrida, Photo Clearfil Bright, foram utilizados. Avaliouse então, o grau de microinfiltração e a formação de fendas marginais em função de duas técnicas de fotoativação (convencional: $60 \mathrm{~s}$ x $600 \mathrm{~mW} / \mathrm{cm}^{2}$ e gradual: $10 \mathrm{~s} \times 270 \mathrm{~mW} / \mathrm{cm}^{2}$ $+5 \mathrm{~s}$ de intervalo $+50 \mathrm{~s} \times 600 \mathrm{~mW} / \mathrm{cm}^{2}$ ). Foi verificado um aumento na formação de fendas marginais quando o "Fator C" aumentou de 2,3 para 3, exceto com o sistema adesivo Super Bond D Liner, o qual foi superior aos demais e proporcionou selamento total quando fotoativado de forma gradual ("Fator C" de 2,3). Os autores creditaram esses resultados ao seu comportamento elástico e por ser ativado quimicamente, uma vez que possui larga fase "borrachóide", permitindo a absorção das tensões provindas da contração de polimerização. De forma geral, houve uma significativa melhora no selamento marginal quando foi realizada a técnica gradual de polimerização quando comparada à convencional.

SANTOS; SILVA E SOUZA JR.; MONDELLI ${ }^{63}$ realizaram uma revisão de literatura, em 2002, na qual citam que a contração de polimerização é um dos fatores que mais contribui para o insucesso das resinas compostas e que ela é o resultado da movimentação e aproximação dos monômeros entre si durante a formação da cadeia polimérica. Afirmaram que quanto maior for o grau de conversão do monômero, maior seria a contração de polimerização, e que, nas resinas atuais, o grau de conversão fica em torno de 60 a 70 \% e a contração de polimerização foi reduzida para 1,5 a $3 \%$. 
Relataram que a contração de polimerização é inerente às resinas compostas e irá persistir até que resinas sem contração ou portadoras de monômeros que sofram expansão durante a reação de polimerização estejam disponíveis. Concluíram que inúmeros fatores são responsáveis pelo estresse gerado na contração de polimerização, tais como módulo de elasticidade, composição da resina composta, fator de configuração da cavidade e intensidade de luz emitida pelo aparelho fotopolimerizador. Indicaram, como formas de minimizar esta contração, o uso de intensidades mais baixas de luz, com o intuito de prolongar a fase pré-gel, e o uso da técnica incremental, para reduzir o "Fator C".

A influência da qualidade adesiva da interface sobre a direção da contração de polimerização foi avaliada por $\mathrm{CHO}$ et al. ${ }^{21}$, em 2002. Segundo os autores, a forte adesão existente nos adesivos atuais poderia afetar a direção da contração de polimerização e mudar o conceito clássico da suposta contração das resinas fotoativadas em direção da fonte de luz e das quimicamente ativadas em direção ao centro da massa do material. Foi demonstrado que a presença de adesão influiu significantemente nos resultados e que para obter uma forte adesão com capacidade de enfrentar a força de contração de polimerização o adesivo deve ser polimerizado antes da inserção da resina composta. Outra observação importante nesse trabalho foi que a resina fluida apresentou piores resultados, produzindo maior deformação pela contração de polimerização. Os autores comentaram que esses resultados sugerem que a excessiva contração de polimerização desenvolvida pela resina fluida foi o suficientemente grande para ultrapassar a força de adesão e que a flexibilidade do material não foi suficiente para compensar essa contração, determinando a geração de estresse. Sugeriram, com base nos seus resultados, que a direção dos vetores de contração de polimerização foi para um centro localizado muito perto da superfície adesiva, porém a localização exata era dependente da qualidade desta.

Uma nova metodologia para avaliar as forças de contração durante a polimerização de resinas compostas de ativação química e física foi proposta por MONDELLI; CASTAÑEDA-ESPINOSA; FRANCO ${ }^{50}$, em 2002. Relataram em seu trabalho que as forças geradas durante a polimerização das resinas estão relacionadas à sua composição e modo de ativação. Analisaram as forças de contração geradas na polimerização de uma resina quimicamente ativada (Concise, 3M/ESPE) e três fotoativadas: micropartícula 
(A-110, 3M/ESPE), micro-híbrida (Z-250, 3M/ESPE) e condensável (P-60, 3M/ESPE). Utilizaram como metodologia duas bases de aço em forma retangular (6 $\times 2 \mathrm{~mm})$, posicionadas paralelamente, sendo uma conectada ao braço móvel da máquina de ensaios (Emic - DL 500), através de uma célula de carga de $10 \mathrm{Kg}$, e a outra ao braço fixo. As resinas compostas foram introduzidas entre as bases metálicas, com $1 \mathrm{~mm}$ de altura, volume de $12 \mathrm{~mm}^{3}$ e fator C 1,5. As bases ficaram fixas durante o ensaio (600 s) e as tensões geradas durante a polimerização foram registradas através de uma curva força (N) X tempo (s), num total de dez ensaios para cada resina (Figura 6). As resinas fotoativadas foram polimerizadas durante 60 segundos com luz halógena (Dentsply $500 \mathrm{~mW} / \mathrm{cm}^{2}$ ). Os valores obtidos após 60 segundos foram registrados e as médias comparadas através da análise de variância e teste de Tukey. Os resultados mostraram que a resina Concise $(4,216 \mathrm{~N})$ apresentou os menores valores de força de contração, com diferenças estatisticamente significantes em relação às fotoativadas. A resina A-110 $(8,365 \mathrm{~N})$ apresentou valores significantemente maiores do que a Z-250 (7,500 N). Não houve diferenças significativas entre A-110 e P-60 (8,111 N) e entre Z-250 e P-60. Os autores concluíram que todas as resinas compostas avaliadas desenvolveram forças de contração durante sua polimerização, com diferenças entre o modo de ativação e as categorias das resinas avaliadas. 


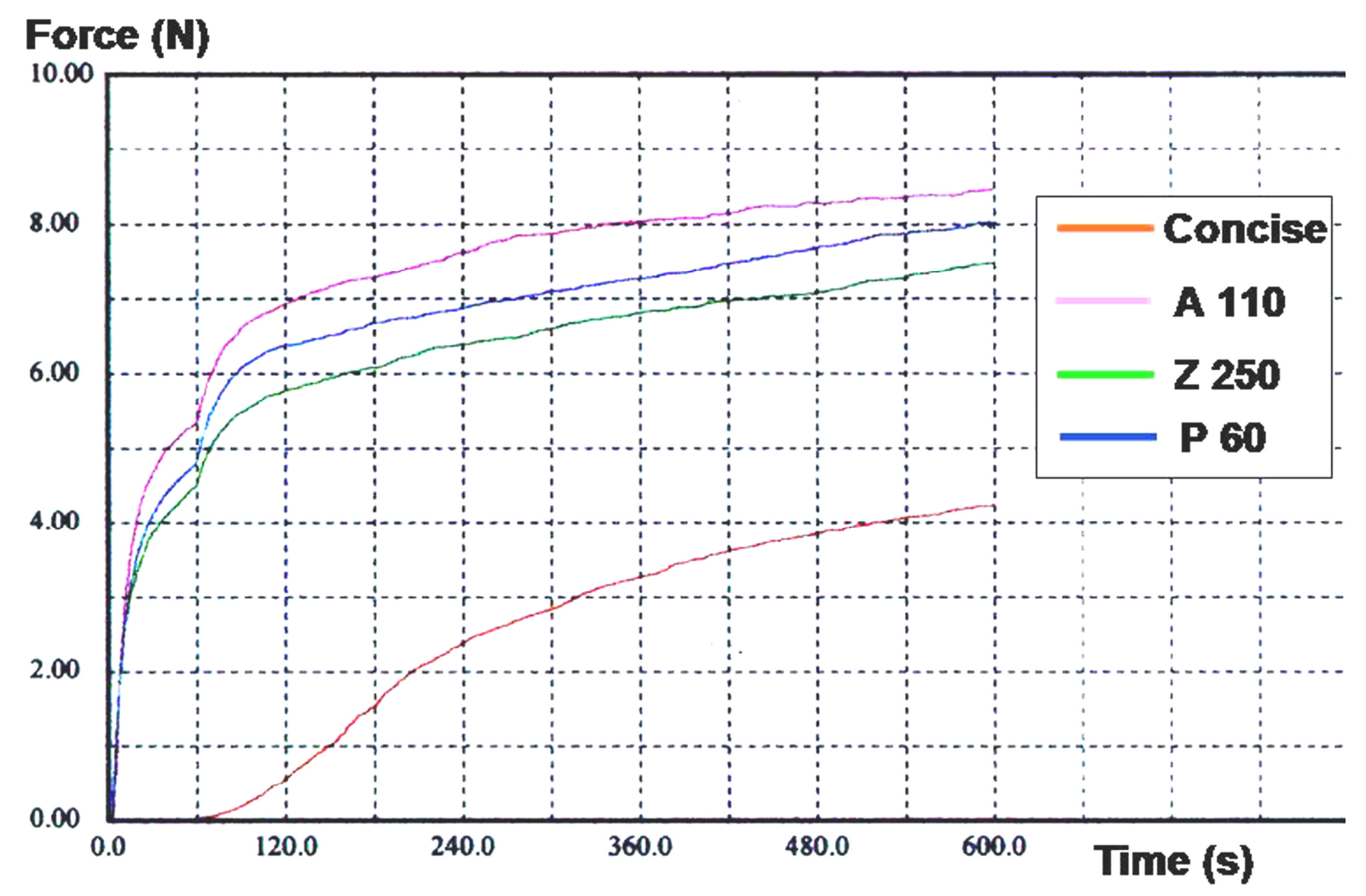

Figura 06 - Gráfico da força de contração das resinas compostas avaliadas. (Fonte: MONDELLI; CASTAÑEDA-ESPINOSA; FRANCO ${ }^{50}, 2002$ ).

Ainda em 2002, CASTAÑEDA-ESPINOSA; MONDELLI ${ }^{14}$ utilizaram a mesma metodologia proposta por MONDELLI; CASTAÑEDA-ESPINOSA; FRANCO ${ }^{50}$ (2002) para avaliar as forças de contração na polimerização de resinas compostas ativadas com luz halógena e LED. Foram utilizadas duas bases de aço em forma retangular (6 x $2 \mathrm{~mm}$ ), posicionadas paralelamente, sendo uma conectada ao braço móvel da máquina de ensaios (Emic - DL 500), através de uma célula de carga de $10 \mathrm{Kg}$, e outra ao braço fixo. As resinas compostas foram introduzidas entre as bases metálicas, com $1 \mathrm{~mm}$ de altura, volume de $12 \mathrm{~mm}^{3}$ e "Fator C" 1,5. As bases ficaram fixas durante o ensaio e as forças geradas durante a polimerização foram registradas através de uma curva força $(\mathrm{N}) \mathrm{X}$ tempo (s), num total de dez ensaios para cada grupo. As resinas compostas de micropartículas (A-110, 3M/ESPE), micro-híbrida (Z-250, 3M/ESPE) e condensável (P-60, 3M/ESPE) foram polimerizadas por 60 segundos com luz halógena (Dentsply $500 \mathrm{~mW} / \mathrm{cm}^{2}$ ) ou LED (Dabi Atlante - $150 \mathrm{~mW} / \mathrm{cm}^{2}$ ). Os resultados do trabalho demonstrou que os valores da força de contração obtidos no período de 120 segundos foram significantemente maiores que ao 60 segundos para todas as resinas, independente da fonte de luz. A resina A-110 apresentou valores significantemente 
maiores que Z-250 e P-60 em todos os casos, e não houve diferenças entre Z-250 e P60. Os valores obtidos com luz halógena foram significantemente maiores em comparação com LED nos períodos avaliados, com exceção da resina A-110 aos 60 segundos. Os autores concluíram que resinas ativadas com LED apresentaram menores valores de força de contração em comparação com luz halógena.

YAP; SOH; SIOW ${ }^{74}$ realizaram um trabalho, em 2002a com o objetivo de investigar a efetividade de polimerização das resinas compostas com ativação por pulsos e com a polimerização soft-start. Utilizaram a resina composta Z-100 e a unidade de luz VIP (Bisco) que permitiu o controle independente da intensidade de luz. Seis modos de fotoativação foram utilizados: controle $(\mathrm{C}): 400 \mathrm{~mW} / \mathrm{cm}^{2}$ (40 segundos); pulso tardio I (PDI): $100 \mathrm{~mW} / \mathrm{cm}^{2}$ (3 segundos), espera (3 minutos), $500 \mathrm{~mW} / \mathrm{cm}^{2}$ (30 segundos); pulso tardio II (PDII): $200 \mathrm{~mW} / \mathrm{cm}^{2}$ (20 segundos), espera (3 minutos), $500 \mathrm{~mW} / \mathrm{cm}^{2}$ (30 segundos); soft-start (SS): $200 \mathrm{~mW} / \mathrm{cm}^{2}$ (10 segundos), $600 \mathrm{~mW} / \mathrm{cm}^{2}$ (30 segundos); pulso I (PCl): $400 \mathrm{~mW} / \mathrm{cm}^{2}$ (10 segundos), espera (10 segundos), $400 \mathrm{~mW} / \mathrm{cm}^{2}$ (10 segundos), espera (10 segundos) e $400 \mathrm{~mW} / \mathrm{cm}^{2}$ (20 segundos); pulso II (PCII): dois pulsos de $400 \mathrm{~mW} / \mathrm{cm}^{2}$ (20 segundos) com 20 segundos de intervalo entre eles. A efetividade de polimerização dos diferentes métodos foi determinada pela medição da dureza da superfície do topo e da base da amostra de resina na espessura de $2 \mathrm{~mm}$ utilizando um aparelho digital de microdureza. A efetividade da polimerização na base foi também estabelecida pelo espectrofotômetro Fourier Transform Infrared (FTIR). Não foram observadas diferenças no topo, exceto para PDI e PDII. Na base, os valores obtidos pelo grupo controle foram significativamente melhores que os obtidos por PDII, SS e PCII. Os autores concluíram que a utilização de certas técnicas de ativação por pulsos e técnicas soft-start podem reduzir a efetividade da polimerização nas bases das restaurações de resina composta.

YAP; SOH; SIOW $^{75}$ realizaram outro trabalho, também em $2002 b$ com o objetivo de investigar a influência da ativação por pulsos e da polimerização soft-start na contração pós-gel das resinas compostas ativadas por luz visível. Utilizaram a resina composta Z100 e a unidade de luz VIP (Bisco) que permitiu o controle independente da intensidade de luz. Seis modos de fotoativação foram utilizados: Controle (C): $400 \mathrm{~mW} / \mathrm{cm}^{2}$ (40 segundos); pulso tardio I (PDI): $100 \mathrm{~mW} / \mathrm{cm}^{2}$ (3 segundos), espera (3 minutos), 500 
$\mathrm{mW} / \mathrm{cm}^{2}$ (30 segundos); pulso tardio II (PDII): $200 \mathrm{~mW} / \mathrm{cm}^{2}$ (20 segundos), espera (3 minutos), $500 \mathrm{~mW} / \mathrm{cm}^{2}$ (30 segundos); soft-start (SS): $200 \mathrm{~mW} / \mathrm{cm}^{2}$ (10 segundos), $600 \mathrm{~mW} / \mathrm{cm}^{2}$ (30 segundos); pulso I (PCl): dois pulsos com $400 \mathrm{~mW} / \mathrm{cm}^{2}$ (10 segundos) e um pulso com $400 \mathrm{~mW} / \mathrm{cm}^{2}$ (20 segundos) com dez segundos de intervalo entre eles; pulso II (PCII): dois pulsos de $400 \mathrm{~mW} / \mathrm{cm}^{2}$ (20 segundos) com 20 segundos de intervalo entre eles. Foi mensurada a contração de polimerização linear durante a polimerização e até 60 minutos depois, utilizando cinco espécimes para cada modo de polimerização. Os resultados mostraram que a contração pós-gel do grupo PDI foi significativamente menor que os grupos PDII, SS e PCI imediatamente após a fotopolimerização. Um minuto após a fotopolimerização o grupo PDI mostrou significativamente menor contração quando comparado com os grupos PDII e SS. Diferenças estatisticamente significativas entre os grupos PDI e SS foram observadas somente aos 10, 30 e 60 minutos. Em todos os intervalos de tempo os autores não observaram diferenças significativas na contração pós-gel entre o grupo controle e os grupos de ativação por pulso e soft-start.

Dentre as várias maneiras de se reduzir a contração de polimerização das resinas compostas, BRAGA; FERRACANE ${ }^{12}$, em 2002, propuseram aumentar a concentração do inibidor (butilato de hidroxitolueno) a fim de reduzir a velocidade da reação de polimerização. Neste propósito avaliaram o grau de conversão e a geração de tensões provenientes da contração de polimerização de uma resina experimental com diferentes concentrações de substância inibidora, 0,05, 0,2, 0,5 e 1,0 \% em peso. Quanto aos valores obtidos da tensão de contração, foi verificado uma redução de $29 \%$ de tensões quando o inibidor foi aumentado de 0,5 a 1,0 \%, no entanto, entre 0,05, 0,2 e 0,5 não foram observadas diferenças significantes. O grau de conversão não foi comprometido quando a concentração de $1 \%$ foi utilizada. Segundo os autores, cada molécula inibidora pode inativar temporariamente duas ou mais cadeias poliméricas, levando a uma reação lenta inicial até que o inibidor seja completamente consumido. Assim, este fato se torna importante, pois aumenta a fase pré-gel da resina composta, proporcionando maior alívio das tensões iniciais de contração de polimerização. Finalizaram afirmando que estes dados são importantes para os fabricantes, pois podem representar um caminho efetivo para redução das forças de contração sem comprometer às propriedades físicas finais. 
Utilizando uma máquina de ensaios universal, LIM, et al. ${ }^{47}$, em 2002, verificaram se a técnica pulso tardio realmente reduz as forças de contração de polimerização. As técnicas de fotoativação testadas foram: T1: $60 \mathrm{~s}$ x $330 \mathrm{~mW} / \mathrm{cm}^{2}$; T2: $5 \mathrm{~s} \times 60 \mathrm{~mW} / \mathrm{cm}^{2}+2$ minutos de intervalo $+60 \mathrm{~s} \times 330 \mathrm{~mW} / \mathrm{cm}^{2}$. Três diferentes resinas foram testadas: Herculite, Z-100 e Heliomolar. Diante dos dados, foi observado que a T2 realmente reduziu as tensões de contração em 26,5 \%, 19 \% e 29,7 \%, respectivamente, para os três materiais. O grau de conversão foi também avaliado, o qual não foi afetado com a técnica de pulso. Os autores creditaram estes resultados ao aumento da fase pré-gel da resina, o que possibilita um rearranjo molecular antes do material se tornar rígido. Isto sugere que a reação ocorre lentamente durante o intervalo de espera e, devido ao baixo módulo de elasticidade neste momento, pouca força de contração é gerada. Este fato não foi observado em um teste piloto, citado pelos autores, quando a fotoativação foi feita em duas intensidades, porém sem intervalo entre as mesmas. Os menores valores registrados de força de contração foram obtidos com a resina Heliomolar nas duas técnicas de fotoativação. Assim, indicaram que para se reduzir as tensões de contração de uma resina deve-se realizar uma combinação entre baixa intensidade de luz e um maior tempo de intervalo antes da utilização de uma alta intensidade.

Em 2003, FRANCO; LOPES ${ }^{37}$ publicaram uma revisão da literatura sobre todos os aspectos relacionados com os conceitos na polimerização dos sistemas restauradores resinosos. Descreveram a reação de polimerização tanto para resinas quimicamente ativadas como fotoativadas, tipos de fontes de luz existentes na atualidade com suas correspondentes densidades de potência e comprimentos de onda, importância das forças de contração na formação de fendas marginais e a possibilidade de diminuí-las através de uma irradiação controlada, volume adequado de resina, conhecimento do efeito do "Fator C", uso de bases intermediárias e conhecimento do conceito de densidade de energia.

O efeito do "Fator C" na microinfiltração de restaurações cervicais confeccionadas com quatro sistemas restauradores adesivos estéticos foi avaliado por FRANCO et al. ${ }^{38}$, no ano de 2003. Cavidades convencionais $(2,9 \mathrm{~mm}$ de diâmetro e 1,5 $\mathrm{mm}$ de profundidade) com "Fator C" de 2,7 e cavidades em forma de pires com "Fator C" de 2,0 foram confeccionadas em 60 pré-molares humanos hígidos, com as margens 
determinadas em esmalte e dentina/cemento. Os sistemas restauradores empregados foram: Z-100 / Single Bond; Freedon / Stae; Vitremer / Primer e Duraffil / Duraffil Bond; as restaurações foram confeccionadas em incremento único e de acordo com as orientações dos fabricantes. Os dentes foram submetidos a termociclagem e imersão em corante, seccionados e avaliados quanto o grau de infiltração. Somente o sistema restaurador Duraffil / Duraffil Bond apresentou resultado em acordo com a teoria do "Fator C", ou seja, as cavidades em forma de pires e menor "Fator C" apresentaram menor infiltração em relação às cavidades convencionais. Os outros sistemas avaliados não apresentaram diferenças significantes na microinfiltração entre os dois tipos de cavidades.

A avaliação da contração de polimerização e das tensões promovidas em função de diferentes sistemas de polimerização e de materiais, utilizando extensores elétricos (stain gauge) e análise por fotoelasticidade, foi realizada por LOPES ${ }^{48}$, no ano de 2003. Foram empregados os sistemas de fotopolimerização por LEDs $\left(60 \mathrm{~s}-130 \mathrm{~mW} / \mathrm{cm}^{2}\right.$ ), com o sistema halógeno na forma convencional $\left(60 \mathrm{~s}-600 \mathrm{~mW} / \mathrm{cm}^{2}\right)$ e pulso de fotopolimerização (3s - $200 \mathrm{~mW} / \mathrm{cm}^{2} / 3$ minutos / $59 \mathrm{~s}-600 \mathrm{~mW} / \mathrm{cm}^{2}$ ). Da mesma forma, categorias distintas de resinas foram comparadas, como: resina híbrida (Z100 - 3M); resina de micropartículas (A110 - 3M); resina "condensável" (SureFil - Dentsply); e resina composta de ativação química (Bisfil II - Bisco). Para medir a contração de polimerização foram confeccionados cinco espécimes para cada condição experimental, obtidos pela inserção da resina em um anel de silicona com um diâmetro interno de $5 \mathrm{~mm}$ e altura de $2 \mathrm{~mm}$. Um extensômetro elétrico (strain gauge), localizado abaixo da resina, registrou a deformação do material em função da contração de polimerização. Nessa mesma proposição, as tensões decorrentes da contração de polimerização foram medidas pelo método de fotoelasticidade. Os dados foram submetidos ao teste de análise de variância a dois critérios e teste de Tukey $(p \leq 0,05)$. O sistema químico de ativação (Bisfil 2B) produziu os menores valores de contração de polimerização e de tensões, seguido da resina SureFil que produziu os menores valores dentre as fotoativadas. A técnica pulso interrompido reduziu os valores de contração de polimerização e das tensões, enquanto a fonte de luz à base de LEDs produziu menores valores de contração de polimerização do que a fonte halógena, quando aplicados convencionalmente, mas com tensões semelhantes. 
MONDELLI et al. ${ }^{51}$, em 2003, estudaram a força de contração de polimerização de 17 resinas compostas híbridas utilizando a metodologia descrita por MONDELLI; CASTAÑEDA-ESPINOSA; FRANCO ${ }^{50}$. Observaram que a força de contração é dependente de cada formulação, sobretudo da relação entre matriz orgânica e partículas inorgânicas, assim como da composição da matriz e das partículas. A curva força (N) $\mathrm{X}$ tempo (s) mostrou que as forças de contração foram geradas rapidamente nas resinas avaliadas (todas fotoativadas). Foi observado que no momento em que a fonte de luz se desligava, a velocidade de formação de forças de contração aumentava por alguns segundos antes de voltar a retomar uma velocidade menor. As resinas Renew (10,030 N) e Z-100 (8,508 N) apresentaram os maiores valores de força de contração enquanto que Admira (5,871 N), Z-250 (5,965 N), Synergy (5,960 N) e Renamel (5,616 N) apresentaram os menores valores. Chamou a atenção dos autores o baixo valor obtido por Admira, em relação à percentagem de carga, sendo explicado esses resultados pela formulação da matriz da resina, à base de ormocer.

As forças de contração de polimerização da resina Z-250 (3M/ESPE), utilizando diferentes métodos de irradiação com a mesma densidade de energia, foram avaliadas por CAVALCANTI; CASTAÑEDA-ESPINOSA; MONDELLI ${ }^{17}$, em 2003. Utilizaram a mesma metodologia descrita nos trabalhos anteriores MONDELLI; CASTAÑEDAESPINOSA; FRANCO ${ }^{50}$ e CASTAÑEDA-ESPINOSA; MONDELLI ${ }^{14}$. Os diferentes métodos de ativação avaliados incluíram: $1-500 \mathrm{~mW} / \mathrm{cm}^{2}$ durante 30 segundos por duas vezes, deixando um período de 30 segundos entre cada irradiação; $2-500 \mathrm{~mW} / \mathrm{cm}^{2}$ durante 60 segundos; e $3-500 \mathrm{~mW} / \mathrm{cm}^{2}$ durante 20 segundos por três vezes, deixando um período de 20 segundos entre cada irradiação. Em todos os casos a densidade de potência foi de $30 \mathrm{~J} / \mathrm{cm}^{2}$. Os resultados mostraram que não existiu diferença estatisticamente significante entre os grupos 1 e 3, porém o grupo 2 apresentou valores de força de contração significantemente maiores que os outros grupos. Os autores concluíram que uma irradiação prolongada geraria maior força de contração de polimerização, quando comparada com repetidas irradiações de menor duração, mesmo que a densidade de energia seja a mesma, devendo-se evitar tempos de irradiação que excedam 30 segundos contínuos. 
CAVINA et al. ${ }^{18}$, em 2003, estudaram a influência da densidade de energia sobre as forças de contração de uma resina composta. As forças foram registradas em uma máquina de ensaios especificamente montada para esse propósito (descrita em 2002 por MONDELLI; CASTAÑEDA-ESPINOSA; FRANCO ${ }^{50}$ ). Todos os grupos foram polimerizados com uma fonte de luz LED de densidade de potência de $500 \mathrm{~mW} / \mathrm{cm}^{2}$, porém os tempos de irradiação foram; 1 - 10 segundos; 2- 20 segundos; 3- 30 segundos; e 4- 40 segundos. Os resultados mostraram diferenças significantes entre os grupos avaliados $(p \leq 0,05)$. O teste de Tukey acusou que somente o grupo irradiado por 10 segundos foi significantemente diferente que os outros grupos avaliados onde os valores foram maiores. Entre os outros grupos não existiu diferença estatisticamente significante. Concluiu-se que tempos menores que 20 segundos devem ser evitados pela possibilidade de não polimerizar o material adequadamente. Por outro lado, este estudo poderia sugerir que a utilização da fonte de luz LED com e energia de $10 \mathrm{~J} / \mathrm{cm}^{2}$ determinaria uma polimerização aceitável.

Ainda em 2003, ASENJO-MARTINEZ et al. $^{3}$, avaliaram a força de contração de polimerização utilizando a técnica de rampa. Foi utilizada a mesma metodologia descrita em MONDELLI; CASTAÑEDA-ESPINOSA; FRANCO ${ }^{50}$. Os grupos avaliados foram: 1: $700 \mathrm{~mW} / \mathrm{cm}^{2}$ durante 40 segundos (energia de $28 \mathrm{~J} / \mathrm{cm}^{2}$ ); 2 : rampa 150-200 $\mathrm{mW} / \mathrm{cm}^{2}$ durante 15 segundos até $700 \mathrm{~mW} / \mathrm{cm}^{2}$ durante 25 segundos (energia de $20 \mathrm{~J} / \mathrm{cm}^{2}$ ); 3: $450 \mathrm{~mW} / \mathrm{cm}^{2}$ durante 20 segundo (energia de $9 \mathrm{~J} / \mathrm{cm}^{2}$ ); e 4: $700 \mathrm{~mW} / \mathrm{cm}^{2}$ durante 20 segundos (energia de $14 \mathrm{~J} / \mathrm{cm}^{2}$ ). Os valores das médias obtidos foram $6,07 \mathrm{~N} ; 5,71 \mathrm{~N}$; $5,64 \mathrm{~N}$ e 5,80 $\mathrm{N}$ para os grupos 1, 2, 3 e 4 respectivamente. O grupo 1 apresentou valores significantemente maiores que os outros grupos avaliados e os grupos 2,3 e 4 não apresentaram diferenças significantes entre eles. Observou-se que a técnica em rampa com densidade de energia de $20 \mathrm{~J} / \mathrm{cm}^{2}$ apresentou força de contração de polimerização significantemente menor que o grupo 1, onde a densidade de energia foi de $28 \mathrm{~J} / \mathrm{cm}^{2}$, porém semelhante a os grupos 3 e 4 onde as densidades de potência foram inferiores (9 e $14 \mathrm{~J} / \mathrm{cm}^{2}$, respectivamente). Pode-se concluir que a técnica em rampa aparentemente favoreceu parcialmente a liberação das forças de contração quando comparada com os outros grupos avaliados, onde a densidade de energia foi menor ou maior.

No mesmo ano e aplicando a mesma metodologia, AZEVEDO et al. ${ }^{5}$, avaliaram a força de contração de polimerização utilizando a técnica de pulso tardio com a fonte de 
luz VIP. Os grupos avaliados incluíram: $1-300 \mathrm{~mW} / \mathrm{cm}^{2}$ durante 20 segundos (energia de $6 \mathrm{~J} / \mathrm{cm}^{2}$ ); 2- $600 \mathrm{~mW} / \mathrm{cm}^{2}$ durante 10 segundos (energia de $6 \mathrm{~J} / \mathrm{cm}^{2}$ ) 3- $600 \mathrm{~mW} / \mathrm{cm}^{2}$ durante 20 segundos (energia de $12 \mathrm{~J} / \mathrm{cm}^{2}$ ); e $4-100 \mathrm{~mW} / \mathrm{cm}^{2}$ durante 5 segundos, 40 segundos de espera e $600 \mathrm{~mW} / \mathrm{cm}^{2}$ durante 20 segundos (energia de $12,5 \mathrm{~J} / \mathrm{cm}^{2}$ ). Os resultados mostraram valores médios para G1 $=5,52 \mathrm{~N}, \mathrm{G} 2=5,86 \mathrm{~N}, \mathrm{G} 3=6,14 \mathrm{~N}$ e $\mathrm{G} 4=5,56 \mathrm{~N}$. A análise estatística constatou que G3 apresentou maiores valores com diferenças significantes entre os outros grupos avaliados. O grupo polimerizado com menor densidade de potência (G1) e com a técnica de pulso tardio (G4) apresentaram valores significantemente menores que os grupos 2 e 3 , independentemente da densidade de energia. Pode-se notar ao comparar os grupos 1 e 2 , onde a energia foi a mesma, que a alta densidade de potência induz a maiores valores de força de contração (Figura 7). Ao comparar os grupos 2 e 3 observou-se que, mantendo a mesma densidade de potência, o maior tempo de irradiação, promoveu maiores valores de contração de polimerização. Ao comparar o grupo 3 com o grupo 4 observa-se que, mesmo com energias semelhantes, a utilização de uma irradiação inicial curta de baixa densidade de potência e descanso antes da irradiação com alta densidade de potência, favoreceu o grupo 3 fotopolimerizado com a técnica do pulso tardio. 


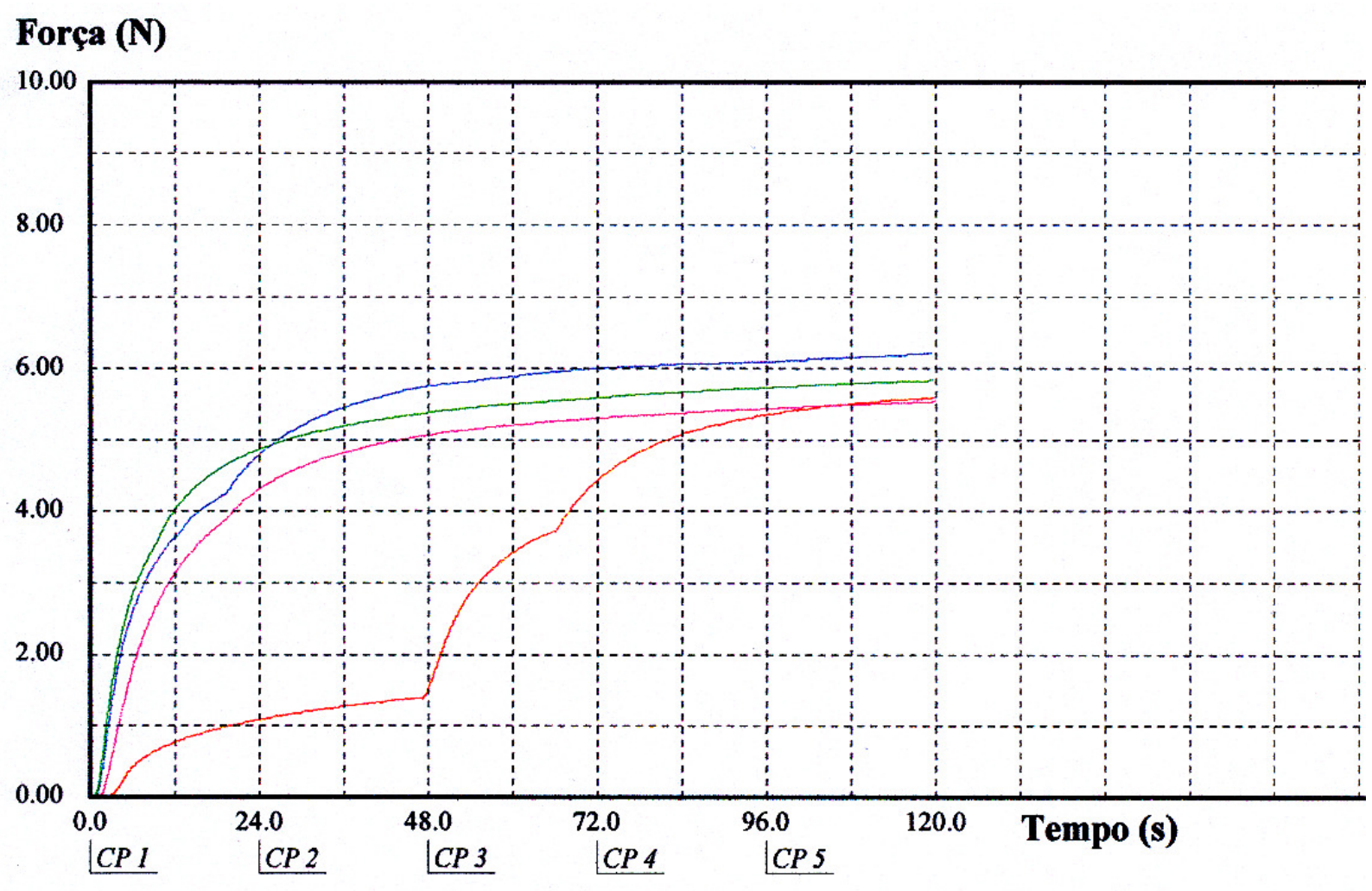

Observação: Verm. 100x5s+40livre+600x20s $\square$ Rosa 300x20 0 Verde 600x10 $\square$ Azul 600x20

Figura 07 - Curvas da força de contração da resina Z-250, em função do modo de ativação. (Fonte: AZEVEDO et al. ${ }^{5}, 2003$ ).

A transmissão das forças de contração de polimerização de uma resina composta por meio da utilização de materiais de bases com menor módulo de elasticidade foi realizada por CASTAÑEDA-ESPINOSA et al. ${ }^{15}$, no ano de 2003. Utilizando a mesma metodologia já descrita, as forças de contração de polimerização da resina composta Z250, com e sem a utilização de materiais intermediários com diferentes espessuras (0,5 e $1,0 \mathrm{~mm}$ ), foram avaliadas. Quando a resina composta de baixa viscosidade foi utilizada como base (Filtek Flow), independente da espessura, promoveu aumento das forças de contração do incremento da resina Z-250. A utilização do Vitrebond como material de base, independente da espessura, proporcionou diminuição significante das forças geradas durante a contração de polimerização da resina Z-250 (Figura 8). Os autores concluem que o CIV modificado por resina foi capaz de absorver parte das forças de contração de polimerização da resina fotoativada, diferentemente da resina Filtek Flow. 


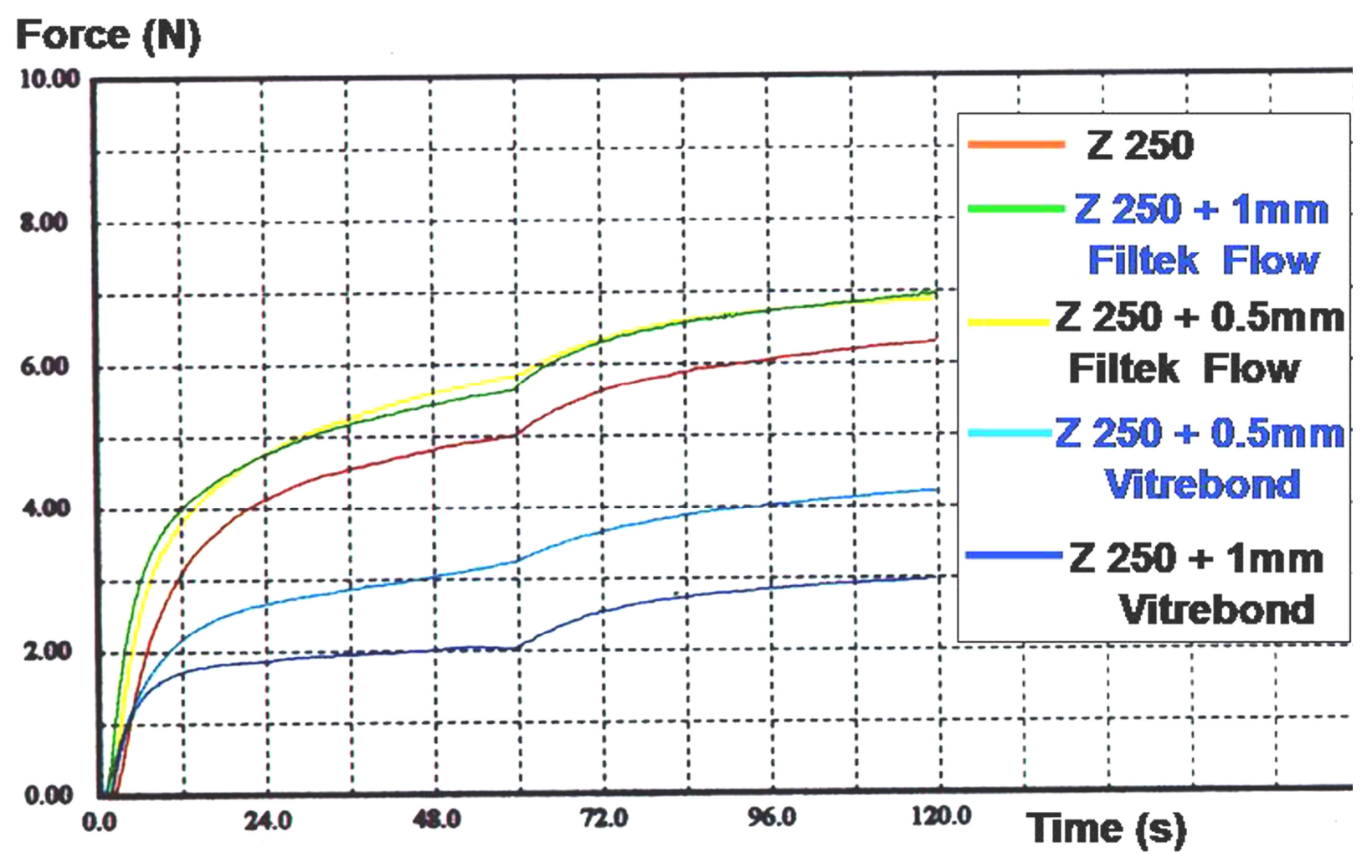

Figura 08 - Gráfico das curvas da força de contração da resina Z-250, em função da utilização de materiais de base. (Fonte: CASTAÑEDA-ESPINOSA et al. ${ }^{15}$, 2003).

A intensidade das forças geradas durante a contração de polimerização da resina composta Filtek Z-250 (3M/ESPE), variando-se a fonte de luz e a densidade de potência foi determinada por CORTÉS et al. ${ }^{25}$, em 2003 . Cinco diferentes fontes de luz foram empregadas: Grupo I - Optilux/Demetron: Grupo II - Elipar® FreeLight/3M - ESPE; Grupo III - Ultralume ${ }^{\mathrm{TM}}$ LED2/Ultradent; Grupo IV - Ultraled/Dabi Atlante e Grupo V Ultrablue DMC. Foram utilizadas duas bases de aço em forma retangular (6 $\times 2 \mathrm{~mm})$, posicionadas paralelamente, sendo uma conectada ao braço móvel da máquina de ensaios (Emic - DL 500), através da célula de carga de $10 \mathrm{Kg}$, e a outra ao braço fixo. A resina foi introduzida entre as bases metálicas, com $1 \mathrm{~mm}$ de altura, volume de $12 \mathrm{~mm}^{3} \mathrm{e}$ "Fator C" de 1,5. As bases ficaram fixas durante o ensaio (40s) e as tensões geradas durante a polimerização foram registradas numa curva de força versus tempo; os valores finais foram expressos em $\mathrm{N}$, num total de dez ensaios para cada aparelho. $\mathrm{A}$ análise de variância e teste Newman-Keuls, com nível de significância de 95\%, foi realizada. As médias dos grupos foram: Grupo I - 6,65 N (D); Grupo II - 5,57 N (B); Grupo III - 5,44 N 
(B); Grupo IV - 4,83 N (A) e Grupo V - 6,11 N (C). A força de contração da resina composta avaliada foi influenciada de forma significativa pela fonte de luz (halógena e LED) e os aparelhos empregados.

Um novo modelo (dispositivo) de teste, denominado de Bioman, foi utilizado por WATTS; MAROUF; AL-HINDI ${ }^{73}$ no ano de 2003, com a finalidade de determinar a cinética do estresse da contração de polimerização de resinas compostas fotoativadas. $O$ dispositivo é composto de um suporte (base), onde uma célula de carga suspensa é conectada a uma das extremidades por meio de um cilindro, dispensando a utilização de máquina universal para testes. O sistema é dotado de uma sonda transdutora que apenas monitora o deslocamento, sem a função de "feed back" ou reposicionamento das bases para adesão, o que determina um sistema de "compliance" alto (Figura 9). O monitoramento do deslocamento da extremidade móvel permite o cálculo do "compliance" do equipamento, que foi determinado em $6 \mathrm{~m} / \mathrm{MPa}$ ou 7,6 $\times 10^{-5} \mathrm{~mm} / \mathrm{N}$. Os autores determinaram as forças de contração das resinas Clearfil, Point 4, P-60 e Z-250, utilizando bases para adesão com diâmetro de $10 \mathrm{~mm}$ e variando a altura dos corpos-deprova em 0,8 e 1,2 mm, o que determinou "Fator C" de 6,25 e 4,16, respectivamente. Os resultados observados demonstraram que a resina Point 4 apresentou os maiores valores de força de contração dentre as quatro resinas avaliadas. Os grupos das resinas com maior espessura e menor "Fator C" apresentaram resultados superiores aos grupos com menor altura e maior "Fator C", cerca de 11 a 15\%, comportamento característico dos sistemas de alto "compliance". 


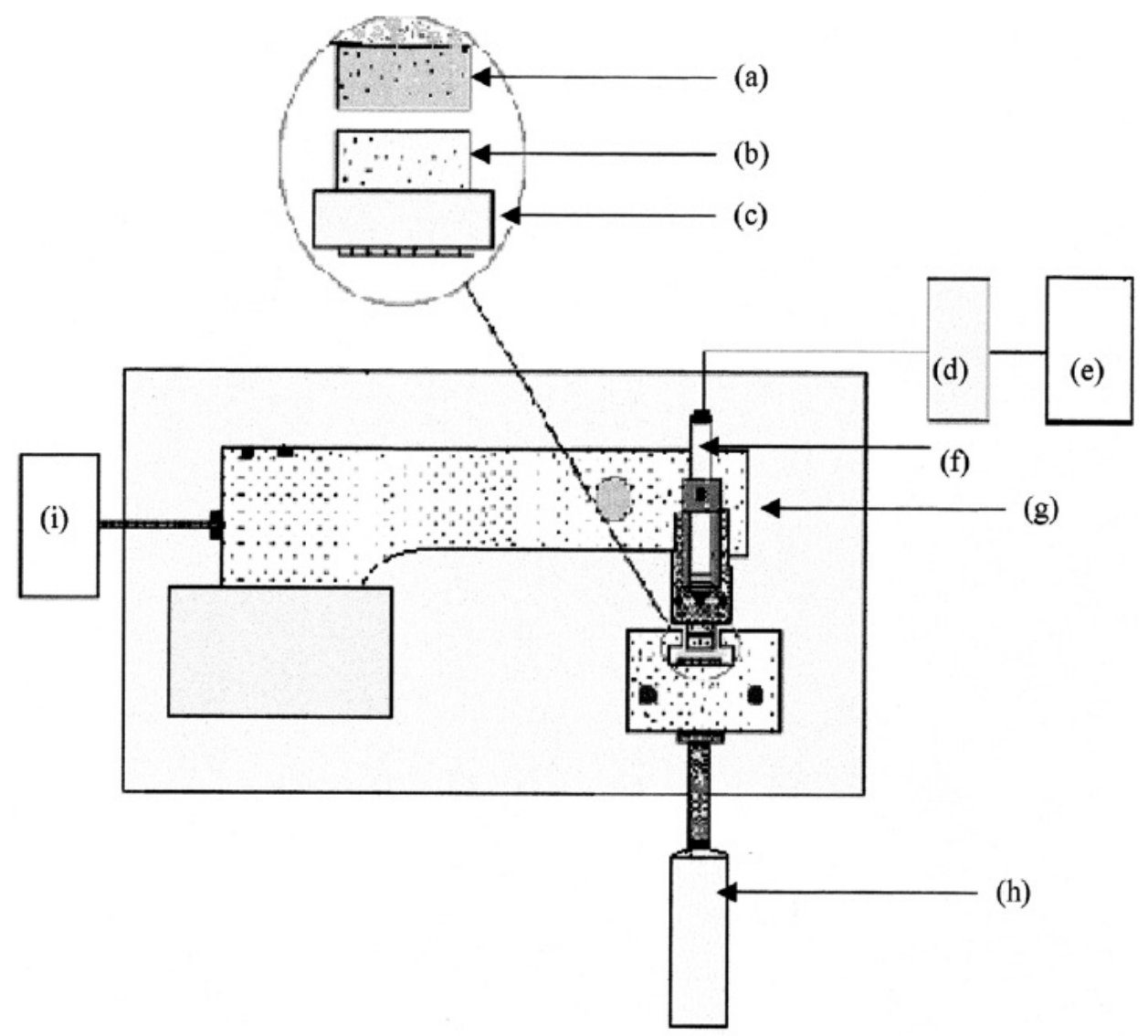

Figura 09 - Esquema do dispositivo Bioman empregado na pesquisa. (Fonte: WATTS; MAROUF; AL-HINDI ${ }^{73}$, 2003).

Em 2004, SANTOS et al. ${ }^{62}$ avaliaram o efeito do método de fotoativação sobre a contração volumétrica de resinas compostas. Com essa finalidade foi determinada a contração de polimerização de três resinas compostas: Z-100, P-60 e Suprafil. Os métodos de fotoativação avaliados incluíram: 1) irradiação contínua a intensidade convencional; 2) irradiação contínua a alta intensidade; 3) irradiação progressiva e 4) irradiação com o método de pulso retardado. Foram realizados 5 discos para cada condição de teste. Os corpos de prova foram pesados com uma balança analítica hidrostática eletrônica tanto em ar quanto em água para determinar os valores de gravidade específica. A contração volumétrica foi calculada matematicamente. Os resultados mostraram diferenças estatisticamente significantes entre os materiais avaliados, porém não existiu diferença estatisticamente significante entre os métodos empregados, exceto para Z-100 onde o método 2 resultou em maior contração volumétrica que os métodos 1 e 4 . Os autores concluíram que o método de fotoativação não teve um efeito significante sobre a contração volumétrica das resinas compostas. 
Ainda em 2004, SAKAGUCHI; WILTBANK; MURCHISON ${ }^{61}$ mencionaram que a força gerada durante a polimerização das resinas compostas representa as forças que potencialmente poderiam afetar a integridade do adesivo, do dente e a união entre eles. Assim, estudaram a relação entre a densidade de energia e a força de contração. A metodologia utilizada foi o registro das forças de contração de polimerização através de uma máquina de ensaios universal onde foram confeccionados corpos de prova cilíndricos de resina com $5 \mathrm{~mm}$ de diâmetro e 1,1 $\mathrm{mm}$ de altura, onde a resina composta era introduzida entre duas bases de vidro e polimerizada através da base de vidro inferior. A fotoativação foi realizada durante 60 segundos e a força de contração registrada durante 600 segundos. Foram avaliados 7 grupos onde os primeiros 6 grupos foram fotopolimerizados incrementando-se a densidade de potência de 100 até $600 \mathrm{~mW} / \mathrm{m}^{2}$, e o sétimo grupo foi irradiado utilizando a técnica de pulso retardado. Os resultados mostraram que a força de contração de polimerização aumentou rapidamente seguindo a fotoativação, mostrando uma descontinuidade no trajeto da curva logo após a luz ter sido desligada (Figura 10). A força de contração mostrou-se estabilizada aproximadamente aos 500 segundos e a força resultante do método de pulso retardado foi significantemente diferente que nos outros grupos avaliados. A velocidade com que as força de contração foram geradas esteve linearmente correlacionada com a densidade de potência quando esta foi irradiada em um só episodio. Esta correlação não foi muito evidente quando os valores máximos foram relacionados com o tempo ou o tipo de irradiação, mostrando que a magnitude da força de contração foi praticamente idêntico nos grupos irradiados com intensidade entre 200 e $400 \mathrm{~mW} / \mathrm{cm}^{2}$. O método de pulso retardado mostrou uma velocidade menor na formação de forças de contração de polimerização. 


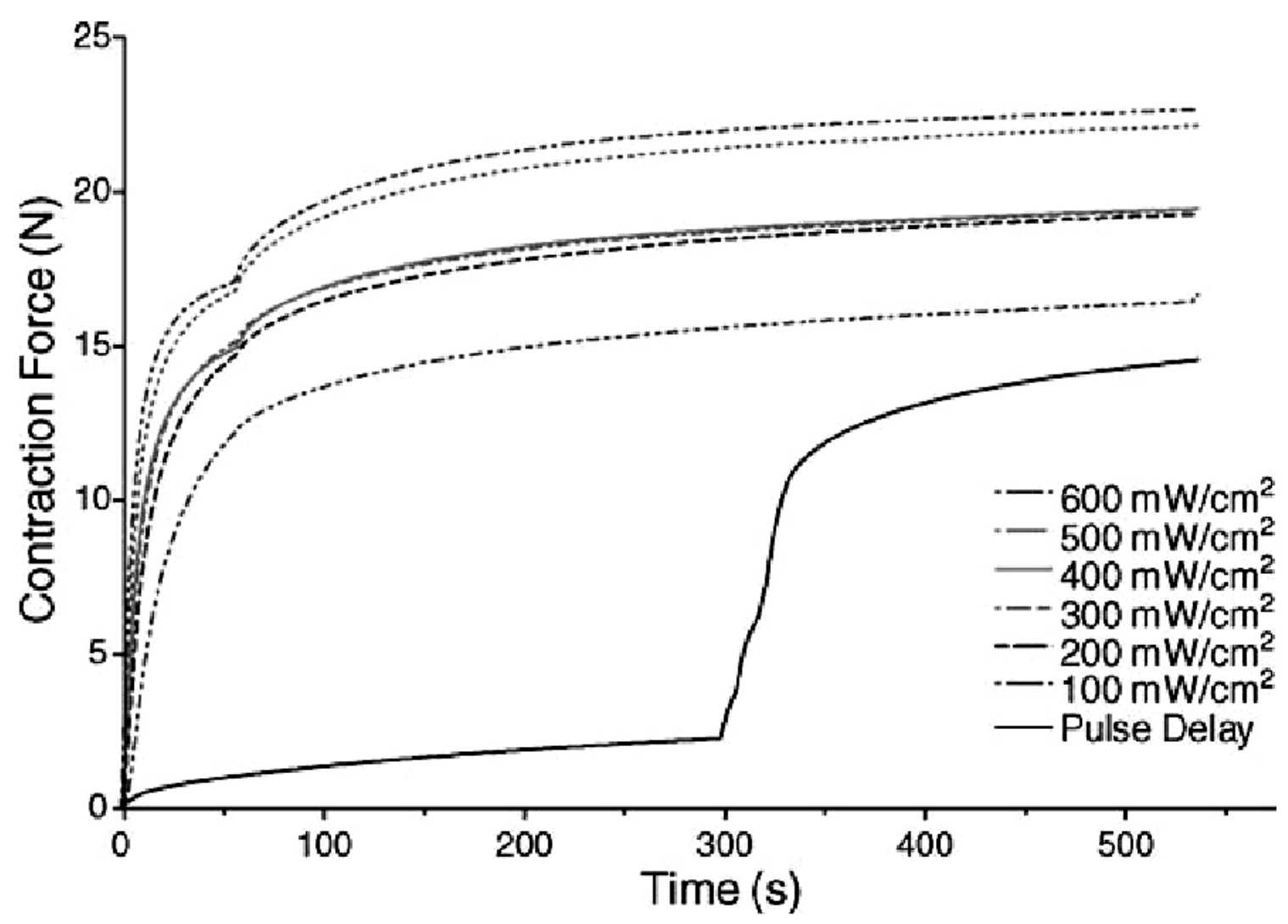

Figura 10 - Gráfico das curvas da força de contração $(\mathrm{N})$ de uma resina composta em função do tempo (s), variando a densidade de potência e o modo de ativação. (Fonte: SAKAGUCHI; WILTBANK; MURCHISON ${ }^{61}$, 2004).

A análise da intensidade das forças geradas durante a contração de polimerização de seis resinas microparticuladas de ativação física e duas híbridas foi realizada

por $\mathrm{PAN}^{54}$, em 2004. Foram utilizadas duas bases de aço em forma retangular ( $\left.6 \times 2 \mathrm{~mm}\right)$, posicionadas paralelamente, sendo a base superior conectada ao braço móvel da máquina de ensaios (Emic - DL500), através da célula de carga de $10 \mathrm{Kg}$, e a base inferior, conectada ao braço fixo. As resinas foram introduzidas entre as bases metálicas, com $1 \mathrm{~mm}$ de altura, totalizando um volume de resina de $12 \mathrm{~mm}^{3}$, em semelhança à metodologia utilizada nos trabalhos de MONDELLI; CASTAÑEDA-ESPINOSA; FRANCO ${ }^{50}$ (2002) e CASTAÑEDA-ESPINOSA; MONDELLI ${ }^{14}$ (2002). As bases permaneceram fixas durante o ensaio (120s) e as tensões geradas durante a polimerização foram registradas, num total de dez corpos de prova para cada resina analisada. Cada amostra de resina foi polimerizada durante 60 segundos com luz halógena (Dentsply $-500 \mathrm{~mW} / \mathrm{cm}^{2}$ ). As resinas microparticuladas foram: Durafill (Heraeus/Kulzer), A-110 (3M/ESPE), Sculpt-it 
(Jeneric/Pentron), Heliomolar (Ivoclar/Vivadent), Amelogen Microfill (Ultradent) e Renamel Microfill (Cosmedent); como grupo controle (resinas híbridas) Z-250 (3M/ESPE) e Charisma (Heraeus/Kulzer). Os valores obtidos durante 2 minutos de ensaio foram registrados em curvas [força $(\mathrm{N}) \mathrm{X}$ tempo (s)] e as médias comparadas através da análise de variância e teste de Tukey. Estatisticamente, os menores valores foram obtidos para Sculpt-it $(4,625 \mathrm{~N})$, enquanto que os maiores valores foram apresentados pelas resinas Renamel - Cosmedent $(11,58 \mathrm{~N})$, com diferenças significantes em relação às outras resinas do estudo. A autora observou ainda que as resinas compostas avaliadas apresentaram diferentes intensidades nas forças geradas durante a contração de polimerização.

A relação entre o estresse de contração e o grau de conversão de diferentes compósitos foi determinada, no ano de 2004, por CALHEIROS et al. ${ }^{13}$. Para as leituras da força de contração foi utilizada uma máquina de ensaios universal Instron dotada de um extensômetro para manutenção constante da altura entre as bases. Foram utilizadas duas bases de vidro cilíndricas com 5,0 mm de diâmetro, altura dos espécimes de 2,0 mm e "Fator C" de 1,25. Os incrementos das resinas avaliadas (A-110; Z-250; Heliomolar e Tetric Ceram) eram inseridos entre as bases de vidros silanizadas e hibridizadas, para então serem fotopolimerizados simultaneamente com dois aparelhos de luz halógena (Optililux 500, Demetron Kerr), com densidade de potência de $450 \mathrm{~mW} / \mathrm{cm}^{2}$ cada equipamento. As resinas foram irradiadas por 5; 15; 30; 60 e 120 segundos, com energia de 4,$5 ; 13,5 ; 27,0 ; 54,0$ e $108,0 \mathrm{~J} / \mathrm{cm}^{2}$, respectivamente, e o tempo do ensaio foi de 10 minutos. O grau de conversão foi determinado com o emprego de um espectrofotômetro foto-acústico infravermelho. Os resultados observados sugerem que a influência da composição da matriz orgânica da resina determina o desenvolvimento do estresse de contração dos compósitos. Os autores comentam que o diâmetro de $5,0 \mathrm{~mm}$ dos espécimes pode ter causado uma polimerização deficiente na porção central das resinas e novos estudos são necessários para estabelecer os níveis ideais da densidade de energia utilizada para melhor determinar a relação entre grau de conversão, propriedades físicas e o estresse de contração, contribuindo para a maior longevidade das restaurações. Para os autores, o clínico deve ter em mente que o aumento da energia na fotopolimerização das resinas compostas não necessariamente aumenta o grau de conversão, podendo causar aumento significante do estresse de contração. 


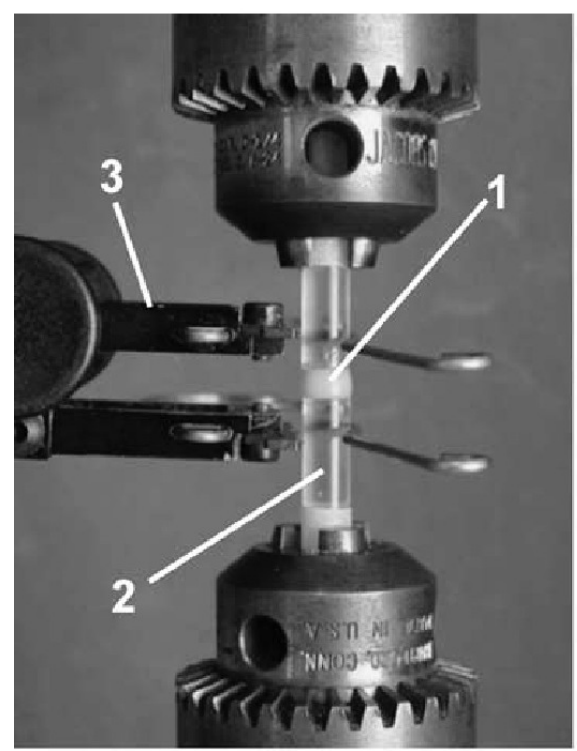

A

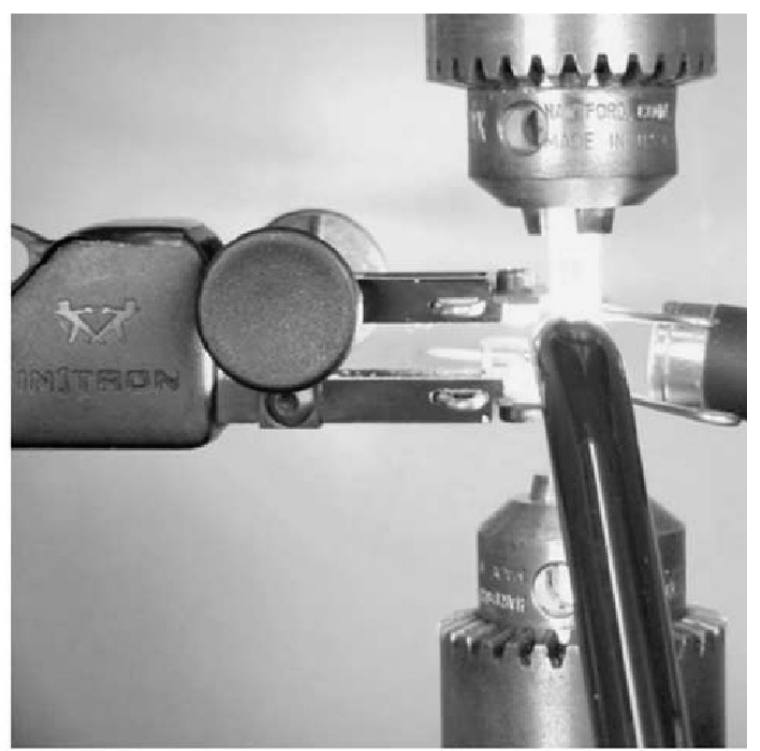

B

Figura 11 - Dispositivo empregado nos ensaios. A- resina composta (1), cilindros de vidros (2) e extensômetro (3); B- ativação com duas fontes de luz auxiliadas com um guia de posicionamento. (Fonte: CALHEIROS et al. $\left.{ }^{13}, 2004\right)$.

A influência na resistência adesiva de uma resina composta associada a três sistemas adesivos, em função da variação do "Fator C" e da utilização de base cavitária com resina flow, foi avaliada por NIKOLAENKO et al. ${ }^{52}$, no ano de 2004. A resistência adesiva foi determinada por meio do emprego de ensaios de microtração em discos preparados de dentina e em cavidades de classe I oclusal (4 x $4 \times 4 \mathrm{~mm}^{3}$ ). Os discos de dentina e as cavidades foram restaurados com a aplicação dos sistemas adesivos Optibond FL (Kerr), Single Bond (3M/ESPE) e One Up Bond F (Tkoyama Tokyo) e a resina composta, com e sem o emprego da resina Filtek Flow (3M/ESPE) como base. Os espécimes dos grupos aderidos aos discos de dentina ("Fator C" 0,2) exibiram maior resistência adesiva do que os espécimes obtidos das cavidades restauradas ("Fator C" 4,0), com diferenças significativas. Nos grupos das cavidades, os adesivos Optbond FL e Single Bond não apresentaram diferenças estatísticas, mas com resultados superiores ao One Up Bond F. A aplicação da resina em incrementos horizontais resultou em maior resistência adesiva do que incrementos verticais e oblíquos. A utilização da resina flow não aumentou a resistência adesiva do Optbond FL. Para os outros adesivos avaliados, a resina flow aumentou a resistência adesiva apenas para os incrementos verticais e oblíquos. Os autores concluem que o "Fator C" é um fator influente na determinação da 
adesão à dentina e cavidades com alto "Fator C" apresentam maior risco de ocorrer falha adesiva na interface dente-restauração.

O desenvolvimento de novos monômeros resinosos pode oferecer redução considerada no estresse de contração de polimerização gerado na interface adesiva dente-restauração quando comparado com monômeros existentes no mercado. PALIN et al. ${ }^{53}$, em 2005, avaliaram in vitro o grau de conversão, infiltração marginal e deflexão das cúspides de pré-molares com cavidades MOD restaurados com duas resinas convencionais (Z-100 e Z-250 3M/ESPE) e duas experimentais compostas de dois novos monômeros a base de oxirano e silorano. A deflexão das cúspides foi determinada com utilização de "Strain Gauge", onde as resinas Z-100 (20 \pm 4,7 $\mu \mathrm{m})$ e Z-250 (16,5 \pm 3,3 $\mu \mathrm{m})$ apresentaram altos valores de deflexão em comparação as resinas experimentais a base de oxirano $(2,5 \pm 0,9 \mu \mathrm{m})$ e silorano $(6,0 \pm 1,8 \mu \mathrm{m})$. As cavidades restauradas com a resina experimental a base de oxirano apresentaram maior infiltração marginal em comparação às resinas convencionais, enquanto a outra a base de silorano apresentou grau de infiltração semelhante à resina Z-100 e menor infiltração do que a resina Z-250. O grau de conversão das resinas experimentais, determinado nos períodos iniciais avaliados $(0,1 ; 0,5$ e 1,0 hora), foi menor e com diferenças estatísticas em relação às resinas Z-100 e Z-250. Os autores comentam que o estresse remanescente na interface dente-restauração é responsável pelos efeitos deletérios da contração de polimerização, sendo derivado de uma combinação de fatores: propriedades do material, geometria da cavidade e a qualidade adesiva entre o substrato dental e o material restaurador. Os monômeros experimentais, que apresentam polimerização do tipo catiônica diferentemente do mecanismo de polimerização com radicais livres dos monômeros convencionais, proporcionaram a diminuição do estresse da contração de polimerização na interface dente-restauração em comparação as resinas comerciais. O monômero a base de oxirano apresentou falhas adesivas e inadequado selamento marginal, o que compromete sua utilização clínica, enquanto o monômero a base de silorano apresentou resultados satisfatórios no sentido de diminuir o estresse de contração de polimerização com bom selamento marginal.

A influência na força de contração de uma resina composta ativada com diferentes energias, fontes de luz (LED, halógena e arco de plasma) e modos de ativação 
foi determinada por ILIE et al. ${ }^{41}$, em 2005. Foram empregados 14 regimes diferentes para a fotoativação da resina InTen-s (Ivoclar/Vivadent), em máquina de ensaio com reposicionamento entre as bases e "Fator C" de 0,3. As curvas dos gráficos [força (N) X tempo (s)] obtidas nos ensaios de contração apresentam a forma de "s", característica do aumento na força de contração em função do final da fotoativação e, conseqüentemente, da diminuição repentina da temperatura da resina composta, gerando maior contração neste momento. As forças geradas durante a contração de polimerização da resina composta foram influenciadas significantemente pela energia empregada, independente da fonte de luz, ou seja, quanto maior a energia para a polimerização, maior as forças de contração. Os resultados mais baixos de contração foram observados para os regimes com menor energia utilizando os aparelhos de LED com menor densidade de potência. As maiores forças foram determinadas pelos aparelhos de arco de plasma, luz halógena e LED de alta densidade de potência. O modo de polimerização do tipo pulso tardio proporcionou maior liberação das tensões de contração da resina. 
3 PROPOSIÇÃO 


\section{PROPOSIÇÃO}

Este trabalho tem como objetivo determinar a influência do volume e do fator de configuração cavitária na intensidade das forças geradas durante a contração de polimerização de uma resina composta de ativação física (Z-250 3M/ESPE) e a influência na variação do "Fator C" nas forças geradas durante a contração de polimerização da resina Z-250 e da resina de ativação química Concise (3M/ESPE), com volume constante.

Serão testadas as hipóteses nulas de que o volume e o "Fator C" não terão influência na intensidade das forças geradas durante a contração de polimerização das resinas compostas avaliadas. 


\section{MATERIAIS E MÉTODO}

Para realização deste experimento foi empregada a metodologia desenvolvida e idealizada por MONDELLI; CASTAÑEDA-ESPINOSA; FRANCO ${ }^{50}$ (2002), CASTAÑEDAESPINOSA; MONDELLI ${ }^{14}$ (2002) e MONDELLI et al. ${ }^{51}$ (2003). O emprego desta metodologia proporciona a avaliação das forças geradas durante a contração de polimerização de materiais restauradores de forma simples, objetiva e de fácil reprodução. A metodologia foi baseada nos experimentos de DAVIDSON; DE GEE; FEILZER $^{30}$ (1984) e FEILZER; DE GEE; DAVIDSON ${ }^{34}$ (1987), com algumas diferenças básicas como a geometria e o material de confecção das bases, volume dos corpos-deprova, possibilidade de ativação com apenas uma fonte de luz em um único procedimento, tipo de sistema (com e sem reposicionamento das baseso) e as possíveis variações que podem ser aplicadas nos ensaios de acordo com o tamanho e geometria das bases metálicas.

Estas características de ajuste do equipamento associadas à precisão na determinação do deslocamento e captação das forças geradas (máquina de ensaio, célula de carga, bases metálicas e método empregado) permitem o emprego desta metodologia em diferentes centros de pesquisa na realização de diversos trabalhos utilizando esta mesma linha (MONDELLI et al. ${ }^{51}$, 2003).

Esta metodologia, de acordo com as dimensões e a altura entre as bases metálicas empregadas, proporciona o controle de algumas variáveis (volume do incremento e fator de configuração cavitária do material a ser avaliado), possibilitando a comparação das forças geradas durante a contração de polimerização de diferentes resinas compostas (MONDELLI et al. ${ }^{51}$, 2003; PAN $^{54}$, 2004), a influência de diferentes fontes de luz (CASTAÑEDA-ESPINOSA; MONDELLI ${ }^{14}, 2002$; CORTÉS, et al. ${ }^{25}, 2003$ ), a influência do modo e da energia de ativação (ASENJO-MARTINEZ et al. ${ }^{3}, 2003$; AZEVEDO et al. $\left.{ }^{5}, 2003\right)$, a influência da utilização de materiais de base na transmissão das forças geradas (CASTAÑEDA-ESPINOSA et al. ${ }^{15}$, 2003), energia de ativação semelhante à empregada na clínica diária (MONDELLI; CASTAÑEDA-ESPINOSA; FRANCO ${ }^{50}$, 2002) e também proporciona a variação no volume no "Fator C" e a variação do "Fator C" com volume constante, objetivos deste estudo. 


\subsection{Descrição do Método}

Semelhante aos trabalhos realizados por MONDELLI; CASTAÑEDA-ESPINOSA; FRANCO $^{50}$ (2002), CASTAÑEDA-ESPINOSA; MONDELLI ${ }^{14}$ (2002) e MONDELLI, et al. ${ }^{51}$ (2003), foi utilizada a máquina de ensaios universal Emic DL 500 (Emic Equipamentos e Sistemas de Ensaio Ltda, Paraná, Brasil) (Figura 12) e duas bases de aço retangulares $(6,0 \times 2,0 \mathrm{~mm})$. Durante os ensaios, a distância entre as bases era ajustada em 1,0 mm, determinando volume constante $\left(12,0 \mathrm{~mm}^{3}\right)$ dos incrementos (corpo-de-prova) das resinas compostas avaliadas e fator de configuração cavitária ("Fator C") de 1,5, também constante.

Estas bases metálicas, após jateamento com óxido de alumínio para permitir a adesão da resina ao metal sem a necessidade de aplicação de sistema adesivo, eram ajustadas e fixadas paralelamente na máquina de ensaios por meio de dispositivos específicos (Figuras 12 e 13). A base metálica superior era acoplada ao braço móvel da máquina de ensaios através da célula de carga de $10 \mathrm{~kg}$ (Figuras 12B e 13A) e a base metálica inferior acoplada à base fixa da máquina de ensaios através do dispositivo BENCOR Multi-teste (Figura 12C).

Após a montagem e ajuste das bases metálicas na máquina de ensaio, o braço móvel superior era movimentado até contatar a base inferior. Neste momento, o relógio digital indicador da posição de deslocamento (décimos de milímetros) e da carga (Newton) era zerada no programa de computador Tesc (Emic Equipamentos e Sistemas de Ensaio Ltda, Paraná, Brasil) utilizado para realização dos ensaios. Uma vez ajustadas às bases metálicas e zerada a carga e posição do braço superior, era ajustada a distância pretendida entre as bases metálicas (altura do corpo-de-prova) através da movimentação do braço superior com precisão em décimos de milímetro. 


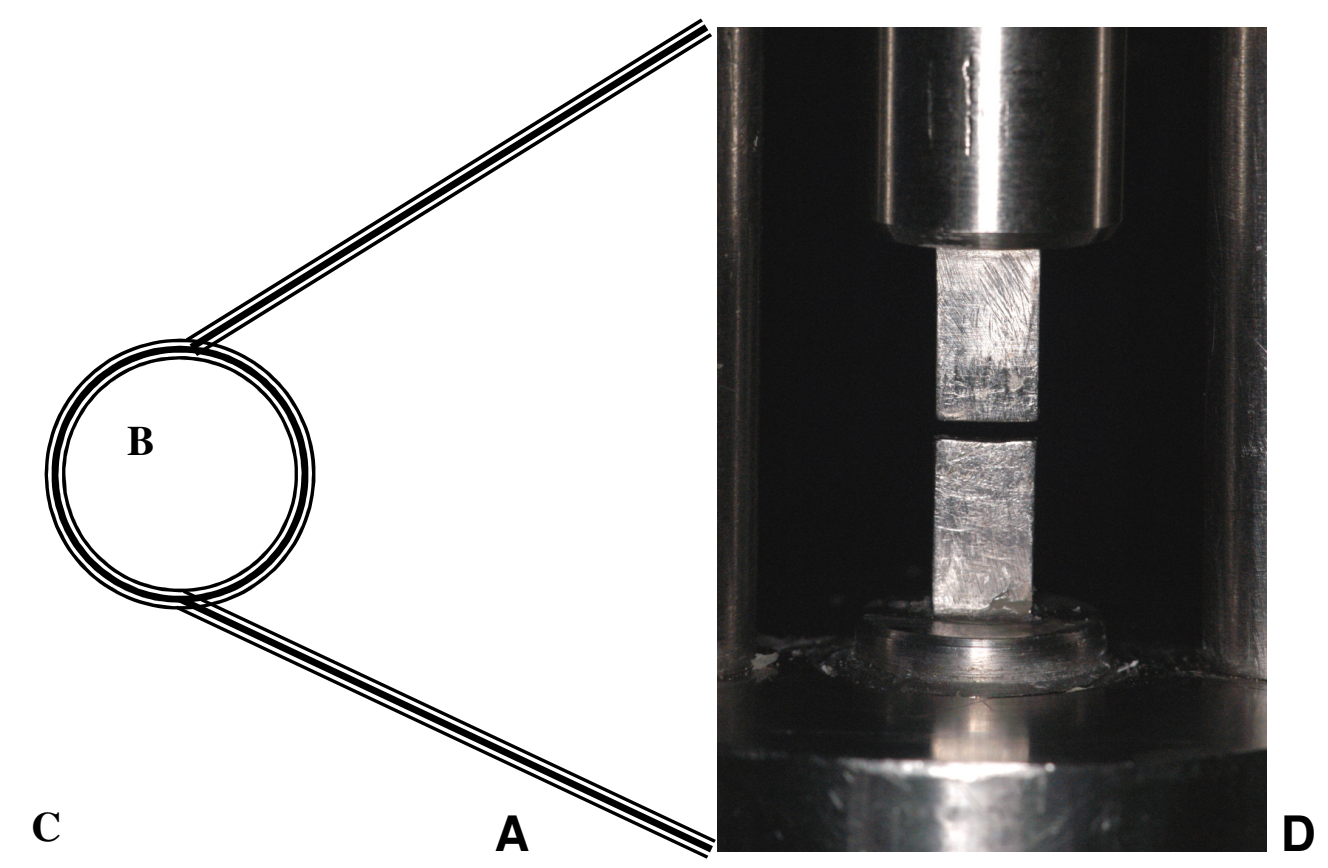

Figura 12 - A- bases fixadas de forma paralela na máquina de ensaios universal Emic DL 500; B- base metálica superior acoplada ao braço móvel da máquina de ensaios através da célula de carga de $10 \mathrm{~kg}$; C- base inferior acoplada à base fixa da máquina através do dispositivo BENCOR Multi-teste; D- vista aproximada das bases metálicas.

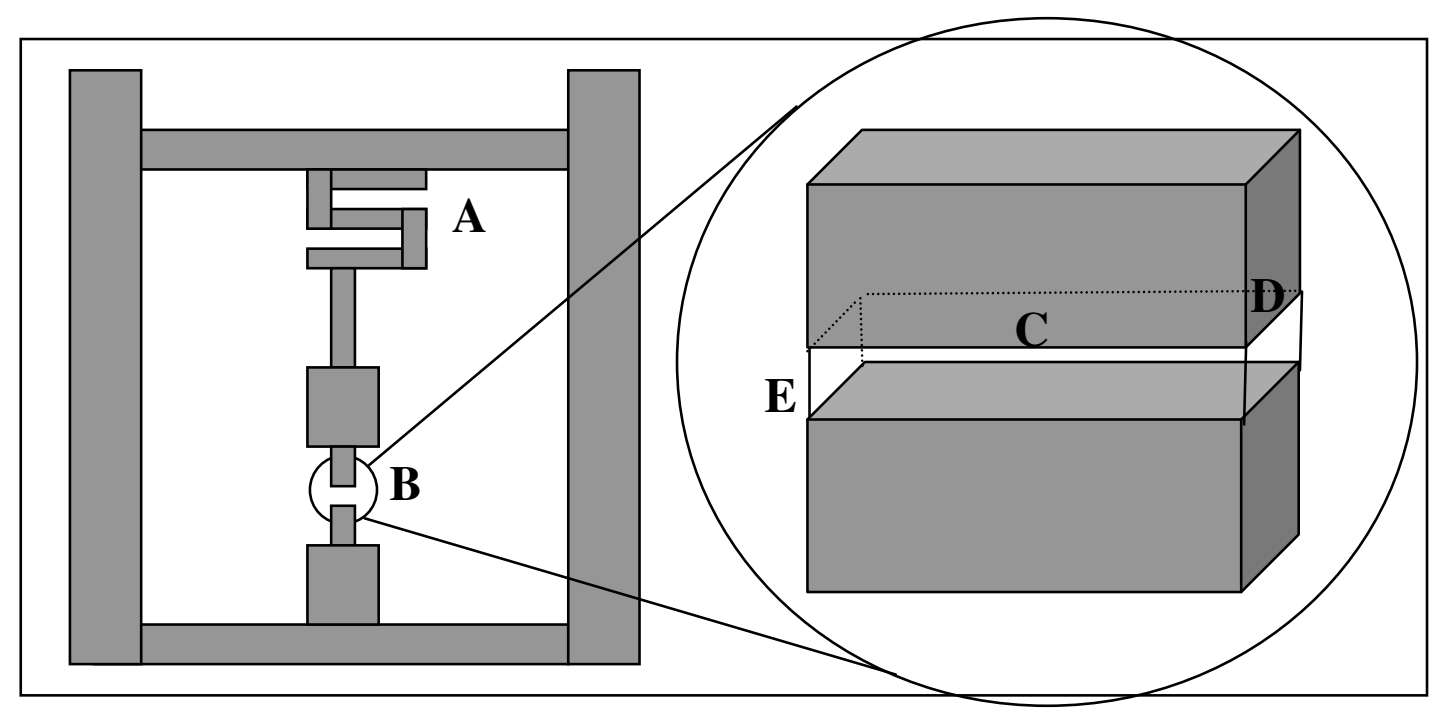

Figura 13 - Esquema dos equipamentos utilizados no teste. A- célula de carga de $10 \mathrm{~kg}$; B- bases metálicas fixadas à máquina, C- comprimento da base metálica (6,0 mm); D- largura da base metálica $(2,0 \mathrm{~mm})$; E- espaço ajustável entre as bases para inserção da resina composta $(1,0 \mathrm{~mm})$. 
Para realização dos testes em recinto com temperatura ambiente controlada em 23,0 ${ }^{\circ} \mathrm{C} \pm 2$, um método específico para o programa Tesc foi desenvolvido com a finalidade de manter imóvel o braço superior da máquina durante a realização dos ensaios. As forças geradas durante a contração de polimerização do material avaliado eram captadas pelo programa através da deformação da célula de carga de $10 \mathrm{~kg}$. Esta deformação, que resulta em força de tração, permite o registro contínuo da geração de forças durante a contração de polimerização em tempo pré-determinado para cada ensaio realizado. Estas forças eram registradas através de curvas relacionadas à força gerada, expressa em Newton ( $\mathrm{N})$, com o tempo transcorrido, expresso em segundos (s), [curvas força $(\mathrm{N}) \mathrm{X}$ tempo $(\mathrm{S})]$.

Para a realização dos ensaios, após adaptação e determinação da distância (altura) entre as bases metálicas, a resina composta era inserida e adaptada entre as mesmas com ajuda de espátulas metálicas (Suprafill 1 e 2 - Duflex), preenchendo toda a cavidade em incremento único (Figuras 14A e B). Após inserção da resina composta de ativação física, apenas um aparelho de luz era empregado na polimerização (Figura 14C) por tempo e energia de ativação pré-determinados, onde o início do teste coincidia com o início da fotopolimerização do grupo da resina avaliada. A irradiação era realizada com a ponteira da fonte de luz o mais próxima possível da face de $6,0 \mathrm{~mm}$ da amostra, permitindo a passagem de luz através da espessura de 2,0 mm (Figura 14C) do incremento de resina composta. O tempo de duração do ensaio foi determinado em 2 minutos para as resinas de ativação física e para as resinas de ativação química, pelas características de manipulação e reação de polimerização, 10 minutos. 


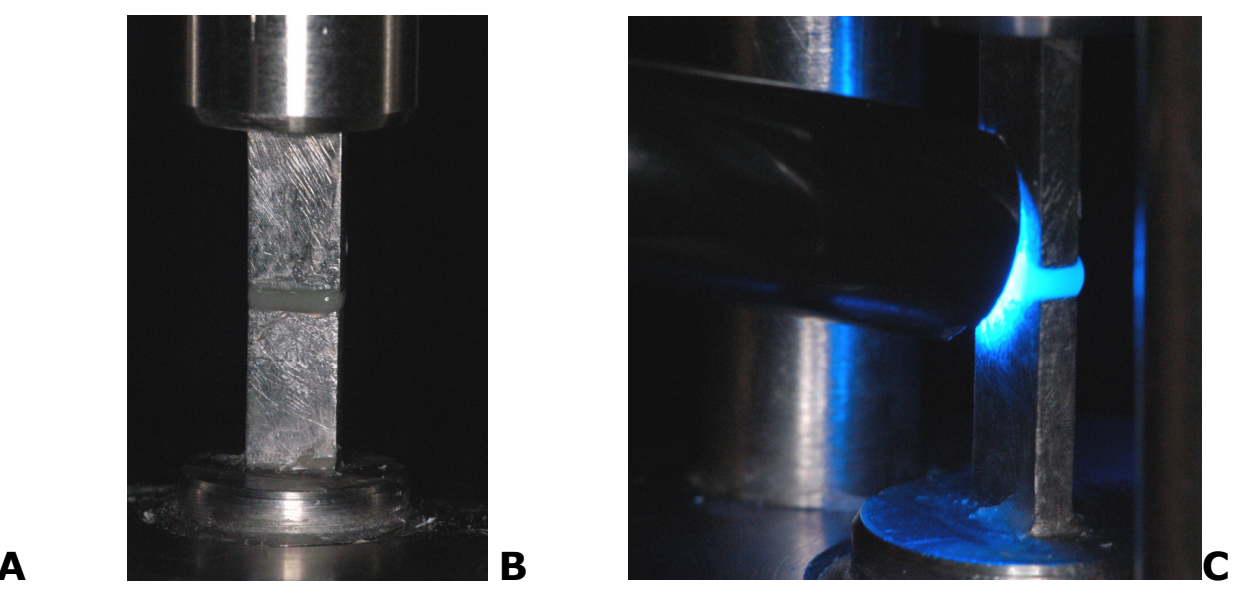

Figura 14 - A- inserção e adaptação do incremento de resina composta entre as bases metálicas (1,0 mm de altura), com auxílio de espátula; B- corpo-de-prova preparado para o início do ensaio; C- fotopolimerização do incremento de resina composta com apenas uma fonte de luz.

Como exemplo, as medidas utilizadas por estes autores (Figuras 12 e 13) serão empregadas nos cálculos para obtenção do volume dos incrementos de resina composta e do fator de configuração cavitária ("Fator C").

\subsubsection{Determinação do volume dos incrementos de resina composta}

Para determinar o volume do incremento de resina composta inserido entre as bases metálicas (Figura 15), deve-se multiplicar o comprimento da base ou do incremento $(6,0 \mathrm{~mm})$ (Figuras $13 \mathrm{C}$ e $15 \mathrm{~A})$, pela espessura $(2,0 \mathrm{~mm})$ (Figuras 13D e 15B) e pela altura $(1,0 \mathrm{~mm})$ (Figuras 13E e 15C), ou seja:

$$
\begin{aligned}
& \text { Volume }=6,0 \times 2,0 \times 1,0 \\
& V=12,0 \mathrm{~mm}^{3}
\end{aligned}
$$

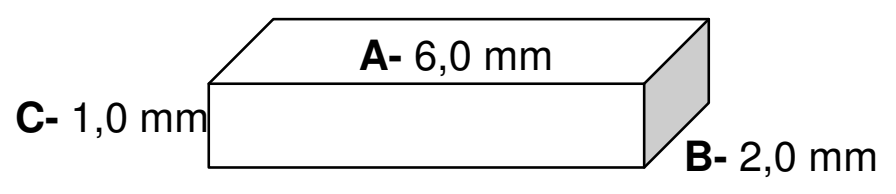

Figura 15 - Forma geométrica e dimensões do incremento (corpo-de-prova) de resina composta inserido entre as bases metálicas. A- comprimento de $6,0 \mathrm{~mm}$; B- espessura de 2,0 mm; C- altura de 1,0 $\mathrm{mm}$. 


\subsubsection{Determinação do fator de configuração cavitária ("Fator C")}

O "Fator C" é determinado pela relação entre as superfícies aderidas (contração rígida) e as superfícies livres (contração livre) do material restaurador. A superfície aderida deve ser determinada pela somatória das áreas das bases metálicas que ficaram em contato com a resina composta (2 CD) (Figura 13) e a superfície livre pela somatória das áreas laterais do incremento da resina composta livre do contato com as bases metálicas (2 CE + $2 \mathrm{DE})$ (Figura 13).

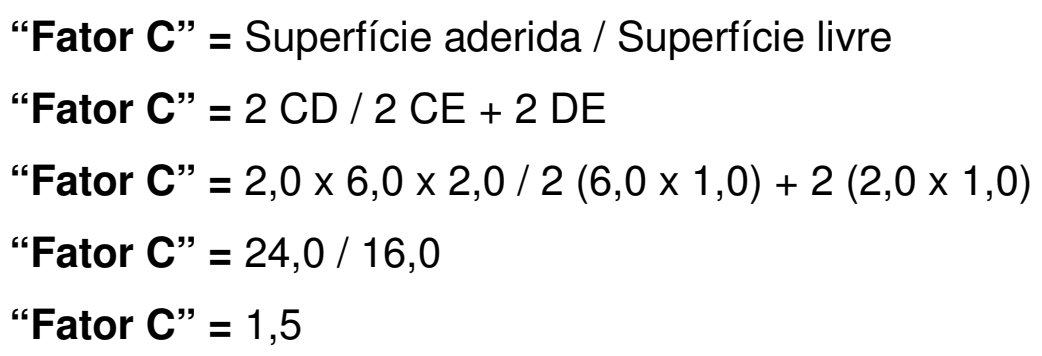

A partir do entendimento dos cálculos para obtenção do volume e do fator de configuração cavitária, serão descritos, a seguir, os experimentos realizados utilizando esta metodologia.

\subsection{Influência do volume e do fator de configuração cavitária na intensidade das forças geradas durante a contração de polimerização de uma resina composta fotoativada}

Semelhante à metodologia descrita no item 4.1 e utilizada por MONDELLI; CASTAÑEDA-ESPINOSA; FRANCO ${ }^{50}$ (2002), CASTAÑEDA-ESPINOSA; MONDELLI ${ }^{14}$ (2002) e MONDELLI et al. ${ }^{51}$ (2003), neste ensaio foram utilizadas duas bases de aço, em forma retangular, com as dimensões de $6,0 \mathrm{~mm}$ de comprimento e 2,0 $\mathrm{mm}$ de largura (Figuras 13 e 14).

As forças geradas durante a contração de polimerização da resina composta Z-250 (3M/ESPE), de ativação física (Tabela 1), cor A2 e número de série 4 AC, foram avaliadas em função da variação do volume e do fator de configuração cavitária do incremento de resina composta inserido entre as bases. Esta resina foi escolhida para ser empregada 
neste estudo devido à sua grande utilização clínica, por ter sido avaliada em estudos preliminares e ter apresentado bons resultados nas forças geradas durante sua contração de polimerização ${ }^{14,15,50,51}$.

Tabela 01 - Composição básica da resina composta avaliada no experimento.

\begin{tabular}{c|c|c|c|c|c|c|}
\hline Material & $\begin{array}{c}\text { Matriz } \\
\text { Orgânica }\end{array}$ & $\begin{array}{c}\text { Carga } \\
\text { Inorgânica }\end{array}$ & $\begin{array}{c}\text { Tipo de } \\
\text { Ativação }\end{array}$ & $\begin{array}{c}\text { Tipo de } \\
\text { partícula }\end{array}$ & $\begin{array}{c}\text { \% Carga } \\
\text { (Volume) }^{*}\end{array}$ & $\begin{array}{c}\text { \% Carga } \\
\text { (Peso) }^{*}\end{array}$ \\
\hline Z-250 & Bis-GMA & $\begin{array}{c}\text { Zircônio / } \\
\text { Sílica }\end{array}$ & Física & $\begin{array}{c}\text { Microhíbrida } \\
(0,6 \mu \mathrm{m})\end{array}$ & 60 & 78 \\
3M/ESPE & TEGDMA & * & & \\
\hline
\end{tabular}

* Informações do fabricante

Seis grupos foram avaliados neste experimento, em que a distância (altura) entre as bases metálicas foi ajustada em 0,$5 ; 1,0 ; 1,5 ; 2,0 ; 2,5$ e 3,0 mm, onde o aumento do volume determinou a diminuição do fator de configuração cavitária. Desta forma, o volume dos incrementos (corpo-de-prova) da resina composta Z-250 (3M/ESPE) para cada grupo foi de 6,$0 ; 12,0 ; 18,0 ; 24,0 ; 30,0$ e 36,0 mm$^{3}$ e o fator de configuração cavitária ("Fator C") de 3,$0 ; 1,5 ; 1,0 ; 0,75 ; 0,6$; e 0,5 , respectivamente (Tabela 2). A resina composta, depois de inserida entre as bases, foi polimerizada por $20 \mathrm{~s}$ com unidade de luz halógena (Spectrum, Dentsply), com densidade de potência (irradiância) de $500 \mathrm{~mW} / \mathrm{cm}^{2}$ e energia de ativação de $10 \mathrm{~J} / \mathrm{cm}^{2}$.

Dez ensaios foram realizados para cada grupo, com tempo de duração de $120 \mathrm{~s}$. Durante os ensaios as bases ficaram fixas e as tensões geradas durante a contração de polimerização foram registradas pela célula de carga e os gráficos [curvas força $(N) x$ tempo (s)] obtidos. As médias foram comparadas através da análise de variância a um critério e teste de Tukey $(p \leq 0,05)$. 
Tabela 02 - Grupos avaliados em função da variação do volume e do fator de configuração cavitária da resina composta Z-250 (3M/ESPE).

\begin{tabular}{|c|c|c|c|c|c|}
\hline Grupos & $\begin{array}{c}\text { Altura entre } \\
\text { as bases }(\mathbf{m m})\end{array}$ & $\begin{array}{c}\text { Volume da } \\
\text { resina }\left(\mathbf{m m}^{\mathbf{3}}\right)\end{array}$ & "Fator C" & $\begin{array}{c}\text { Tempo de } \\
\text { polimerização }\end{array}$ & $\begin{array}{c}\text { Energia de } \\
\text { Ativação }\end{array}$ \\
\hline 1 & 0,5 & 6,0 & 3,0 & $20 \mathrm{~s}$ & $10 \mathrm{~J} / \mathrm{cm}^{2}$ \\
\hline 2 & 1,0 & 12,0 & 1,5 & $20 \mathrm{~s}$ & $10 \mathrm{~J} / \mathrm{cm}^{2}$ \\
\hline 3 & 1,5 & 18,0 & 1,0 & $20 \mathrm{~s}$ & $10 \mathrm{~J} / \mathrm{cm}^{2}$ \\
\hline 4 & 2,0 & 24,0 & 0,75 & $20 \mathrm{~s}$ & $10 \mathrm{~J} / \mathrm{cm}^{2}$ \\
\hline 5 & 2,5 & 30,0 & 0,6 & $20 \mathrm{~s}$ & $10 \mathrm{~J} / \mathrm{cm}^{2}$ \\
\hline 6 & 3,0 & 36,0 & 0,5 & $20 \mathrm{~s}$ & $10 \mathrm{~J} / \mathrm{cm}^{2}$ \\
\hline
\end{tabular}

4.3 Influência da variação do fator de configuração cavitária na intensidade das forças geradas durante a contração de polimerização de resinas compostas de ativação física e química

Neste experimento, foi determinada a influência do "Fator C" nas forças geradas durante a contração de polimerização de resinas compostas com dois tipos de ativação. Foram avaliadas as resinas de ativação física Z-250 (3M/ESPE), cor 2 e número de série 4 AC, e química Concise (3M/ESPE) (Tabela 3), cor universal e número de série DT1.

Tabela 03 - Composição básica das resinas compostas avaliadas no experimento.

\begin{tabular}{|c|c|c|c|c|c|c|}
\hline Material & $\begin{array}{c}\text { Matriz } \\
\text { Orgânica }\end{array}$ & $\begin{array}{c}\text { Carga } \\
\text { Inorgânica }\end{array}$ & $\begin{array}{c}\text { Tipo de } \\
\text { Ativação }\end{array}$ & $\begin{array}{l}\text { Tipo de } \\
\text { partícula }\end{array}$ & $\begin{array}{c}\text { \% Carga } \\
\text { (Volume)* }^{*}\end{array}$ & $\begin{array}{c}\text { \% Carga } \\
\text { (Peso) }^{*}\end{array}$ \\
\hline $\begin{array}{c}\text { Z-250 } \\
\text { 3M/ESPE }\end{array}$ & $\begin{array}{l}\text { Bis-GMA } \\
\text { TEGDMA }\end{array}$ & $\begin{array}{l}\text { Zircônio / } \\
\text { Sílica }\end{array}$ & Física & $\begin{array}{c}\text { Microhíbrida } \\
(0,6 \mu \mathrm{m})\end{array}$ & 60 & 78 \\
\hline $\begin{array}{c}\text { Concise } \\
3 \mathrm{M} / \mathrm{ESPE}\end{array}$ & $\begin{array}{l}\text { Bis-GMA } \\
\text { TEGDMA }\end{array}$ & Sílica & Química & $\begin{array}{c}\text { Macropartíc } \\
\text { ula } \\
(1-40 \mu \mathrm{m})\end{array}$ & 67 & 78 \\
\hline
\end{tabular}

* Informações do fabricante 
Para determinação da influência do "Fator C", o volume dos incrementos das resinas compostas foi constante $\left(12 \mathrm{~mm}^{3}\right.$ ) (Figura 17). Foram confeccionadas duas bases de aço em forma retangular com dimensões de 3,0 x 2,0 mm (Figura $16 \mathrm{~A}$ ) e duas bases quadradas com 2,0 x 2,0 mm (Figura $16 \mathrm{E}$ ). Estas dimensões foram empregadas uma vez que o ajuste da altura entre as bases retangulares em 2,0 mm (Figura 16 D) e o ajuste da altura em 3,0 mm das bases quadradas (Figura $16 \mathrm{H}$ ), proporcionou a variação do "Fator C" em 0,6 e 0,33, respectivamente (Figuras 16 e 17), com o mesmo volume para os incrementos das resinas compostas avaliadas.

Neste experimento quatro grupos foram avaliados em função da resina composta e do fator de configuração cavitária (Tabela 4). A resina composta de ativação física Z-250 (3M/ESPE) foi inserida entre as bases e polimerizada por $20 \mathrm{~s}$ com unidade de luz halógena (Spectrum, Dentsply), com densidade de potência (irradiância) de 500 $\mathrm{mW} / \mathrm{cm}^{2}$ e energia de ativação de $10 \mathrm{~J} / \mathrm{cm}^{2}$. O tempo total dos dez ensaios para cada grupo da resina Z-250 foi de 120 segundos. Para os dez ensaios de cada grupo da resina de ativação química Concise (3M/ESPE) as pastas base e catalisadora foram proporcionadas em partes iguais, espatuladas por $30 \mathrm{~s}$ e inseridas entre as bases num tempo de $90 \mathrm{~s}$. Após $120 \mathrm{~s}$, foi iniciado o ensaio com tempo total de duração de $600 \mathrm{~s}$, necessário para a reação de polimerização da resina química.

A

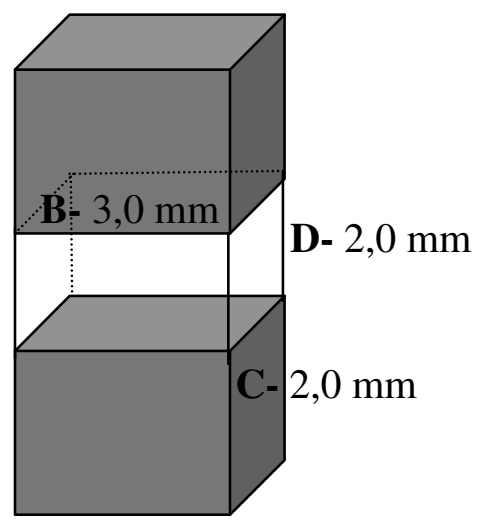

$\mathbf{E}$

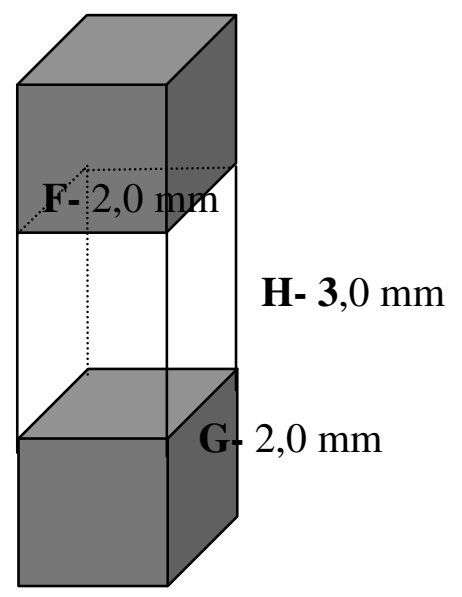

Figura 16 - Esquema das bases metálicas que foram empregadas. A- Bases metálicas retangulares de $3,0 \times 2,0 \mathrm{~mm}$; B- comprimento da base metálica $(3,0 \mathrm{~mm})$; C- largura da base metálica $(2,0 \mathrm{~mm})$; D- altura entre as bases $(2,0 \mathrm{~mm})$ e "Fator C" de 0,6; E- Bases metálicas quadradas de 2,0 x 2,0 mm; F- comprimento da base metálica $(2,0 \mathrm{~mm})$; G- largura da base metálica $(2,0 \mathrm{~mm}) ; \mathbf{H}$ - altura entre as bases $(3,0 \mathrm{~mm})$ e "Fator C" de 0,33. 
A

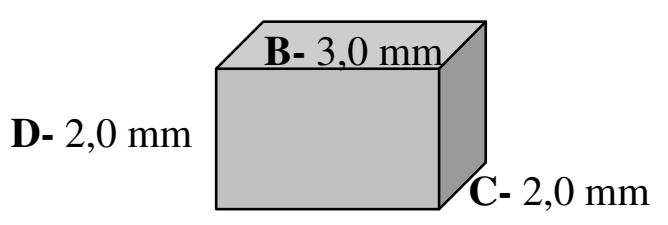

$\mathbf{E}$

H- 3,0 mm

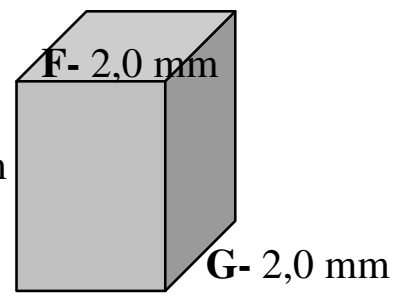

Figura 17 - Forma geométrica e dimensões dos incrementos (corpos-de-prova) de resina composta inseridos entre as bases metálicas ( $\left.V=12,0 \mathrm{~mm}^{3}\right)$. A- incremento de resina obtido a partir da base metálica de $3,0 \times 2,0 \mathrm{~mm}$; B- comprimento de $3,0 \mathrm{~mm}$; C- espessura de 2,0 mm; D- altura de 2,0 $\mathrm{mm}$ e "Fator C" de 0,6; E- incremento de resina obtido a partir da base metálica de 2,0 x 2,0 mm; F- comprimento de 2,0 mm; G- espessura de $2,0 \mathrm{~mm} ; \mathbf{H}-$ altura de 3,0 mm e "Fator C" de 0,33.

Tabela 04 - Distribuição dos grupos das resinas compostas em função do modo de ativação e do fator de configuração cavitária.

\begin{tabular}{|c|c|c|c|c|c|}
\hline Grupos & $\begin{array}{c}\text { Resina } \\
\text { Composta }\end{array}$ & $\begin{array}{c}\text { Base } \\
\text { Metálica }\end{array}$ & Fator C & $\begin{array}{c}\text { Tempo de } \\
\text { polimerização }\end{array}$ & $\begin{array}{c}\text { Energia de } \\
\text { Ativação }\end{array}$ \\
\hline 7 & Z-250 & $3,0 \times 2,0 \mathrm{~mm}$ & 0,6 & $20 \mathrm{~s}$ & $10 \mathrm{~J} / \mathrm{cm}^{2}$ \\
\hline 8 & Z-250 & $2,0 \times 2,0 \mathrm{~mm}$ & 0,33 & $20 \mathrm{~s}$ & $10 \mathrm{~J} / \mathrm{cm}^{2}$ \\
\hline 9 & Concise & $3,0 \times 2,0 \mathrm{~mm}$ & 0,6 & - & - \\
\hline 10 & Concise & $2,0 \times 2,0 \mathrm{~mm}$ & 0,33 & - & - \\
\hline
\end{tabular}

Durante os ensaios as bases ficaram fixas e as tensões geradas durante a contração de polimerização foram registradas numericamente e os gráficos [curvas força (N) $x$ tempo (s)] obtidos. As médias foram comparadas através da análise de variância a dois critérios e teste de Tukey $(p \leq 0,05)$. 


\section{RESULTADOS}

Os resultados obtidos serão apresentados em função dos experimentos realizados utilizando a metodologia proposta.

\subsection{Influência do volume e do fator de configuração cavitária na intensidade das forças geradas durante a contração de polimerização de uma resina composta fotoativada}

As forças geradas durante a contração de polimerização da resina composta Z-250 (3M/ESPE), de ativação física, foram avaliadas em função da variação do volume e do fator de configuração cavitária do incremento de resina composta inserido entre as bases metálicas (Tabela 5). As médias obtidas foram submetidas à análise de variância a um critério (Tabela 6), onde foi constatada a ocorrência de diferenças significantes entre os grupos estudados $(p \leq 0,05)$. O teste de Tukey para comparações múltiplas entre os grupos (Tabela 7) acusou diferenças significantes $(p \leq 0,05)$ entre os seis grupos avaliados.

Tabela 05 - Médias, Desvio-Padrão, Coeficiente de Variação e Análise Estatística das forças geradas durante a contração de polimerização da resina composta Z-250, em função da variação do volume e do fator de configuração cavitária.

\begin{tabular}{|c|c|c|c|c|c|c|}
\hline Grupos & $\begin{array}{c}\text { Volume } \\
\mathrm{mm}^{3}\end{array}$ & "Fator C" & $\begin{array}{c}\text { MÉDIA } \\
\text { FORÇA } \\
\text { MÁXIMA (N) }\end{array}$ & $\begin{array}{c}\text { DESVIO- } \\
\text { PADRÃO }\end{array}$ & $\begin{array}{c}\text { COEFICIENTE } \\
\text { VARIAÇÃO(\%) }\end{array}$ & $\begin{array}{c}\text { ANÁLISE } \\
\text { ESTATÍSTI } \\
\text { CA }\end{array}$ \\
\hline $\mathbf{1}$ & 6,0 & 3,0 & $\mathbf{4 , 4 4 5}$ & $\mathbf{0 , 2 0 1 3}$ & $\mathbf{4 , 5 3 0}$ & $\mathbf{A}$ \\
\hline $\mathbf{2}$ & 12,0 & 1,5 & $\mathbf{5 , 6 9 4}$ & $\mathbf{0 , 2 4 3 9}$ & $\mathbf{4 , 2 8 3}$ & $\mathbf{B}$ \\
\hline $\mathbf{3}$ & 18,0 & 1,0 & $\mathbf{7 , 0 1 7}$ & $\mathbf{0 , 1 6 2 7}$ & $\mathbf{2 , 3 1 8}$ & $\mathbf{C}$ \\
\hline $\mathbf{4}$ & 24,0 & 0,75 & $\mathbf{8 , 2 6 1}$ & $\mathbf{0 , 2 8 1 6}$ & $\mathbf{3 , 4 0 8}$ & $\mathbf{D}$ \\
\hline $\mathbf{5}$ & 30,0 & 0,6 & $\mathbf{9 , 8 4 7}$ & $\mathbf{0 , 3 4 8 3}$ & $\mathbf{3 , 5 3 7}$ & $\mathbf{E}$ \\
\hline $\mathbf{6}$ & 36,0 & 0,5 & $\mathbf{1 1 , 1 4 0}$ & $\mathbf{0 , 3 3 3 6}$ & $\mathbf{2 , 9 9 4}$ & $\mathbf{F}$ \\
\hline
\end{tabular}

$n=10 ; p \leq 0,05$

* Letras diferentes indicam valores estatisticamente significantes. 
Tabela 06 - Análise de variância a um critério para comparação entre os grupos, em função do volume e do fator de configuração cavitária.

\begin{tabular}{c|c|c|c|c|c|}
\hline GI & QM & gl & QM & & \\
\hline Efeito & efeito & erro & erro & F & $\mathbf{p}$ \\
\hline $\mathbf{5}$ & 63,67885 & 54 & $\mathbf{0 , 0 7 3 1 7 7}$ & $\mathbf{8 7 0 , 2 0 7}$ & $\mathbf{0 , 0 0 0 *}$ \\
\hline
\end{tabular}

$p \leq 0,05$.

* Diferença estatisticamente significante entre os grupos.

Tabela 07 - Teste de Tukey para as comparações múltiplas entre os grupos.

\begin{tabular}{|c|c|c|c|c|c|c|}
\hline $\begin{array}{c}\text { Grupos: } \\
\text { Volume mm³ } \\
\text { ("Fator C") }\end{array}$ & $\{1\}$ & $\{2\}$ & $\{3\}$ & $\{4\}$ & $\{5\}$ & $\{6$ \\
\hline 1: $\quad 6(3,0)$ & & $0,000138^{*}$ & $0,000138^{\star}$ & $0,000138^{*}$ & $0,000138^{*}$ & $0,000138^{*}$ \\
\hline $2: 12(1,5)$ & $0,000138^{\star}$ & & $0,000138^{*}$ & $0,000138^{*}$ & $0,000138^{*}$ & $0,000138^{*}$ \\
\hline $3: 18(1,0)$ & $0,000138^{\star}$ & $0,000138^{*}$ & & $0,000138^{*}$ & $0,000138^{\star}$ & $0,000138^{*}$ \\
\hline $4: 24(0,75)$ & $0,000138^{*}$ & $0,000138^{*}$ & $0,000138^{*}$ & & $0,000138^{*}$ & $0,000138^{*}$ \\
\hline $5: 30(0,6)$ & $0,000138^{\star}$ & $0,000138^{\star}$ & $0,000138^{*}$ & $0,000138^{*}$ & & $0,000138^{*}$ \\
\hline $6: 36(0,5)$ & $0,000138^{*}$ & $0,000138^{*}$ & $0,000138^{*}$ & $0,000138^{\star}$ & $0,000138^{*}$ & \\
\hline
\end{tabular}

$\mathrm{p} \leq 0,05$.

${ }^{\star}$ Diferenças estatisticamente significantes entre os grupos.

A análise do gráfico da figura 18, onde estão apresentadas as curvas obtidas [força (N) $x$ tempo (s)] dos seis grupos avaliados, pode-se observar padrão semelhante no desenvolvimento das forças geradas durante a contração de polimerização. Com o início do ensaio, em sincronia com o início da fotoativação, foi observado que a resina composta fotoativada, independente do volume e do "fator C", começou rapidamente a gerar forças de contração de polimerização durante os 20 segundos de fotoativação. Após a ativação da resina composta, a mesma continuou a gerar forças em menor intensidade até fim do ensaio (120 segundos), quando os valores máximos obtidos foram registrados para análise (Anexos 1 a 6 ). Para as curvas obtidas de todos os grupos avaliados, observou-se pequena alteração na curva, em forma de " $S$ ", no momento da finalização da fotoativação em função da diminuição de temperatura da resina composta. 


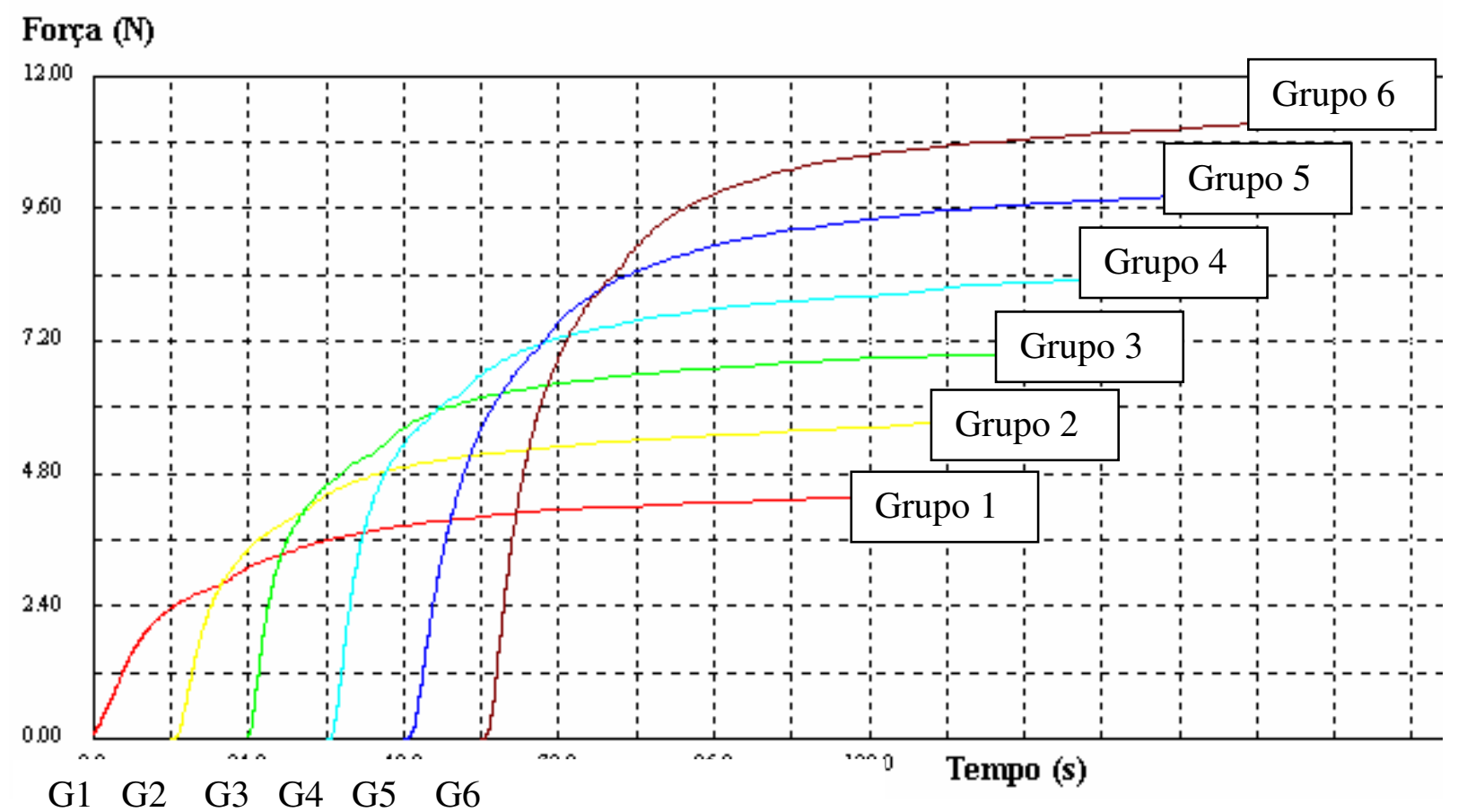

Figura 18- Gráfico das médias (N) das forças geradas durante contração de polimerização da resina composta Z-250, em função da variação do volume e do fator de configuração cavitária.

Por meio da análise dos resultados obtidos (Tabela 5) e dos gráficos das figuras 18, 19 e 20, pode-se constatar a influência direta na variação do volume empregado para a resina composta Z-250 (3M/ESPE) nas forças geradas durante a contração de polimerização. Diferentemente dos conceitos observados por FEILZER; DE GEE; DAVIDSON ${ }^{34}$ (1987), para as resinas compostas de ativação química em que o "Fator C" apresenta influência direta nas forças geradas durante a contração de polimerização, neste experimento o fator de configuração cavitária ("Fator C") não foi determinante para os resultados observados da resina Z-250 (3M/ESPE) com fotoativação convencional. Este fato pode ser constatado na observação dos resultados do grupo 6, com o maior volume $\left(36,0 \mathrm{~mm}^{3}\right)$ e o menor "Fator C" $(0,5)$, que apresentou os maiores valores de força de contração $(11,140 \mathrm{~N})$, enquanto o grupo 1 , com o menor volume $\left(6,0 \mathrm{~mm}^{3}\right)$ e o maior "Fator C" $(3,0)$, apresentou os menores valores $(4,445 \mathrm{~N})$. Pela análise do gráfico da figura 19 pode-se observar uma correlação positiva entre 0 volume e as forças geradas durante a contração de polimerização evidenciada pela reta apresentada no gráfico, enquanto a variação do "Fator C" (Figura 20) não influenciou decisivamente nos resultados para este ensaio. 


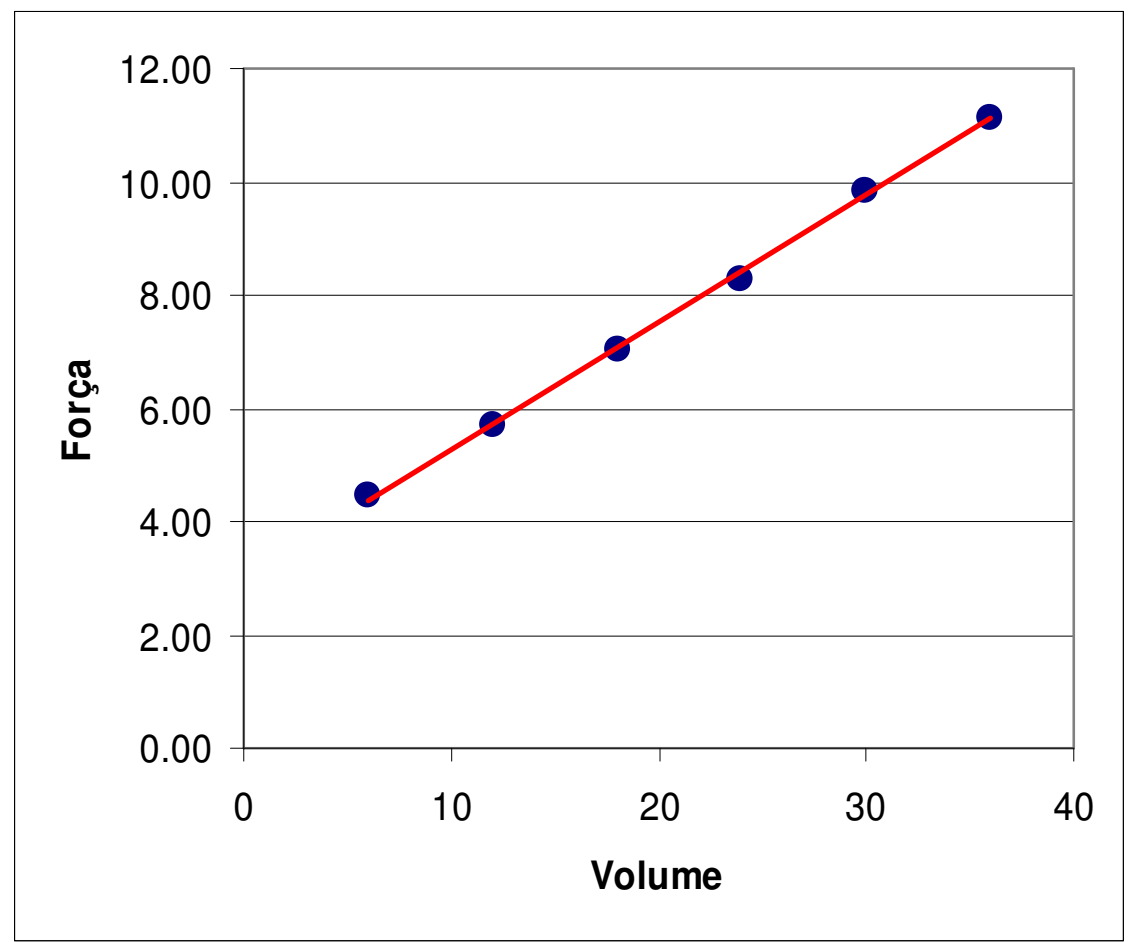

Figura 19 - Gráfico das médias $(\mathrm{N})$ das forças geradas durante a contração de polimerização da resina composta Z-250, em função da variação do volume $\left(\mathrm{mm}^{3}\right)$.

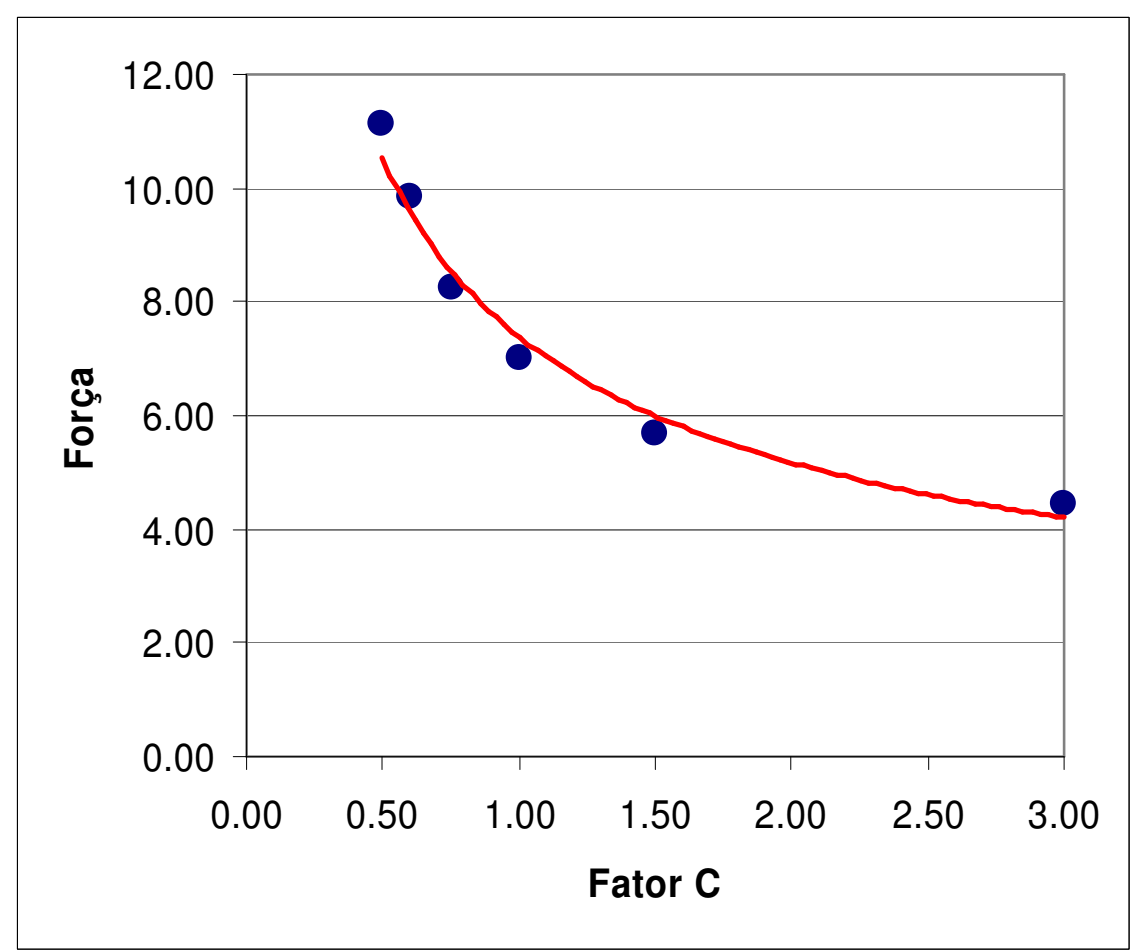

Figura 20- Gráfico das médias $(\mathrm{N})$ das forças geradas durante a contração de polimerização da resina composta Z-250, em função da variação do "Fator C". 
5.2 Influência da variação do fator de configuração cavitária na intensidade das forças geradas durante a contração polimerização de resinas compostas de ativação física e química

As forças geradas durante a contração de polimerização da resina composta Z-250 (3M/ESPE), de ativação física, e da resina composta de ativação química Concise (3M/ESPE), com volume constante de $12 \mathrm{~mm}^{3}$, variando-se o "Fator C" em 0,6 e 0,33 dos incrementos das resinas compostas inseridos entre as bases metálicas, podem ser observados na tabela 8. As médias obtidas foram submetidas à análise de variância a dois critérios (resina composta e "Fator C") (Tabela 9), onde foi constatada a ocorrência de diferenças significantes entre os grupos estudados $(p \leq 0,05)$, com interação positiva entre os dois fatores em estudo. O teste de Tukey para comparações múltiplas entre os grupos (Tabela 10) não acusou diferenças estatisticamente significantes $(p \leq 0,05)$ entre os grupos 7 e 8 da resina composta de ativação física (Z-250 3M/ESPE). Os grupos 9 e 10 da resina de ativação química (Concise 3M/ESPE) apresentaram diferenças estatisticamente significantes entre si e em relação aos grupos 7 e 8.

Tabela 08 - Médias, Desvio-Padrão, Coeficiente de Variação e Análise Estatística das forças geradas durante a contração de polimerização das resinas compostas Z-250 e Concise, com volume constante de $12 \mathrm{~mm}^{3}$, em função da variação do fator de configuração cavitária.

\begin{tabular}{c|c|c|c|c|c|c}
\hline Grupos & Resina & "Fator C" & $\begin{array}{c}\text { MÉDIA } \\
\text { FORÇA } \\
\text { MÁXIMA (N) }\end{array}$ & $\begin{array}{c}\text { DESVIO- } \\
\text { PADRÃO }\end{array}$ & $\begin{array}{c}\text { COEFICIENTE } \\
\text { VARIAÇÃO(\%) }\end{array}$ & $\begin{array}{c}\text { ANÁLISE } \\
\text { ESTATÍSTI } \\
\text { CA }\end{array}$ \\
\hline $\mathbf{7}$ & $\mathbf{Z}-250$ & 0,6 & $\mathbf{3 , 8 9 0}$ & $\mathbf{0 , 1 3 6 3}$ & $\mathbf{3 , 5 0 3}$ & $\mathbf{B}$ \\
\hline $\mathbf{8}$ & Z-250 & 0,33 & $\mathbf{4 , 0 7 4}$ & $\mathbf{0 , 1 2 2 3}$ & $\mathbf{3 , 0 0 1}$ & $\mathbf{B}$ \\
\hline $\mathbf{9}$ & Concise & 0,6 & $\mathbf{4 , 9 2 6}$ & $\mathbf{0 , 3 3 4 4}$ & $\mathbf{6 , 7 8 9}$ & $\mathbf{C}$ \\
\hline $\mathbf{1 0}$ & Concise & 0,33 & $\mathbf{2 , 1 9 7}$ & $\mathbf{0 , 3 1 9 8}$ & $\mathbf{1 4 , 5 5 0}$ & $\mathbf{A}$ \\
\hline
\end{tabular}

$n=10 ; p \leq 0,05$.

${ }^{*}$ Letras diferentes indicam valores estatisticamente significantes.

Tabela 09 - Análise de variância a dois critérios (resina composta e "Fator C").

\begin{tabular}{|ccc|c|c|c|c|}
\hline Efeito & gl & QM & gl & QM & & \\
\hline & efeito & efeito & erro & erro & $\mathbf{F}$ & $\mathbf{P}$ \\
\hline Resina & $\mathbf{1}$ & 1,77241 & 36 & $\mathbf{0 , 0 6 2 1 9 7}$ & $\mathbf{2 8 , 4 9 6 6 1}$ & $\mathbf{0 , 0 0 0 0 ^ { * }}$ \\
\hline "Fator C" & $\mathbf{1}$ & 16,17984 & 36 & $\mathbf{0 , 0 6 2 1 9 7}$ & $\mathbf{2 6 0 , 1 3 7 7}$ & $\mathbf{0 , 0 0 0 0 ^ { * }}$ \\
\hline Interação & $\mathbf{1}$ & 21,19936 & 36 & $\mathbf{0 , 0 6 2 1 9 7}$ & $\mathbf{3 4 0 , 8 4 0 9}$ & $\mathbf{0 , 0 0 0 0 ^ { * }}$ \\
\hline
\end{tabular}

$p \leq 0,05$. 
* Diferenças estatisticamente significantes entre os grupos.

Tabela 10 - Teste de Tukey para as comparações múltiplas entre os grupos.

\begin{tabular}{|c|c|c|c|c|}
\hline Grupos ("Fator C") & $\{7\}$ & $\{8\}$ & $\{9\}$ & $\{10\}$ \\
\hline 7: Z-250 $(0,6)$ & & 0,364712 & $0,000159^{\star}$ & $0,000159^{*}$ \\
\hline $8:$ Z-250 $(0,33)$ & 0,364712 & & $0,000159^{*}$ & $0,000159^{\star}$ \\
\hline 9: Concise $(0,6)$ & $0,000159^{*}$ & $0,000159^{\star}$ & & $0,000159^{\star}$ \\
\hline 10: Concise $(0,33)$ & $0,000159^{\star}$ & $0,000159^{\star}$ & $0,000159^{*}$ & \\
\hline
\end{tabular}

$p \leq 0,05$.

* Diferenças estatisticamente significantes entre os grupos.

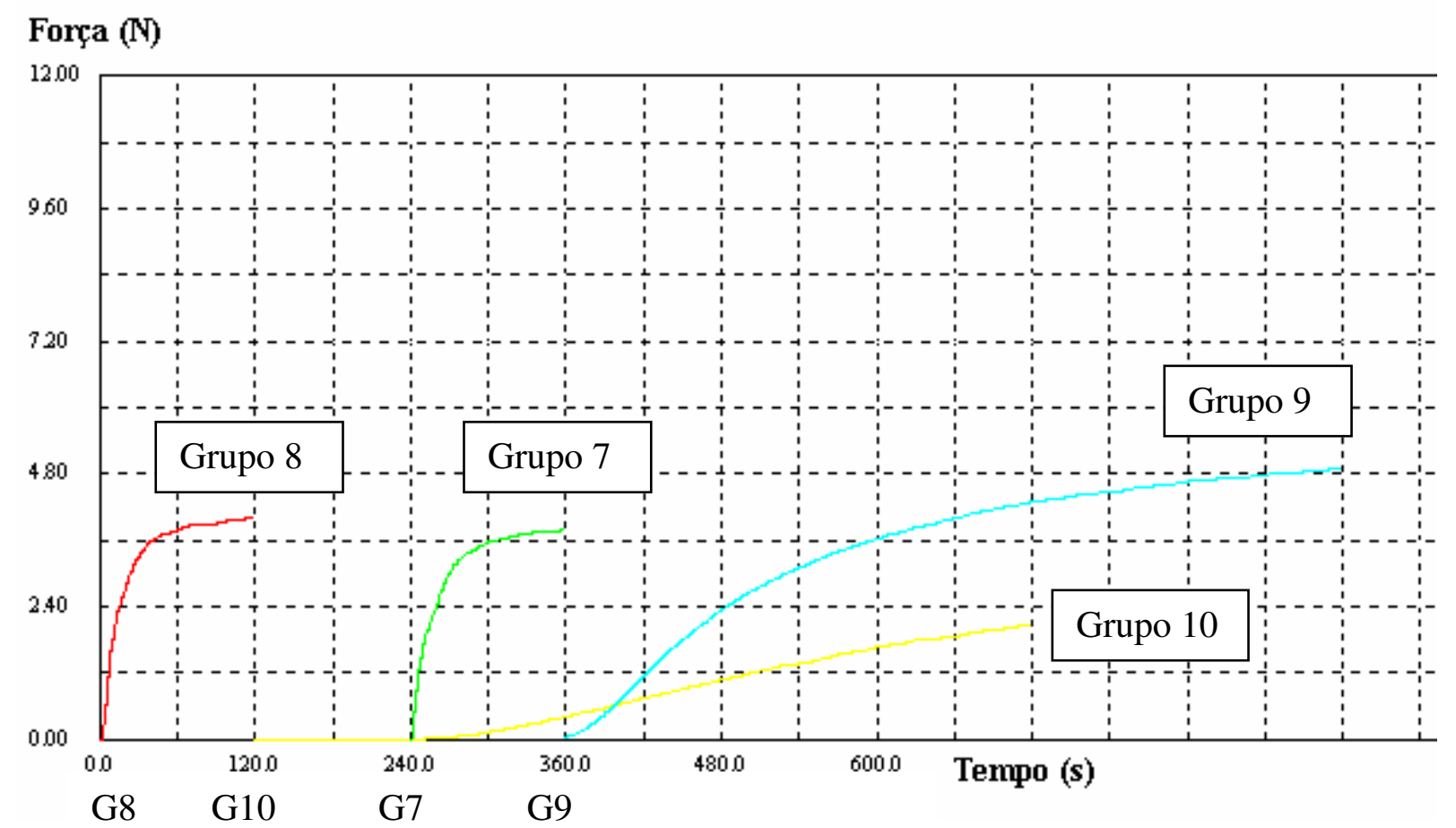

Figura 21- Gráfico das médias $(\mathrm{N})$ das forças geradas durante a contração de polimerização da resina composta Z-250 e Concise, com volume constante de $12 \mathrm{~mm}^{3}$, em função da variação do "Fator C".

No gráfico da figura 21, onde estão apresentadas as curvas obtidas [força $(\mathrm{N}) \times$ tempo (s)] dos quatro grupos avaliados, podem-se observar padrões diferentes no desenvolvimento das forças geradas durante a contração de polimerização em função do modo de ativação da resina composta. Para a resina de ativação física (Z-250 3M/ESPE), observou-se comportamento semelhante nas curvas e nas forças de contração independentemente do "Fator C", ou seja, com o início do ensaio, em sincronia com o início da fotoativação, a resina começou rapidamente a gerar forças de contração de polimerização durante os 20 segundos da fotoativação (Anexos 7 e 8), continuando em 
menor velocidade até o término do ensaio (120 segundos). As curvas obtidas destes dois grupos, em semelhança aos grupos 1, 2, 3, 4, 5 e 6, também apresentaram pequena alteração em forma de "S" (Figura 21). Em contra-partida, as curvas das forças geradas durante a contração de polimerização da resina composta quimicamente ativada (Concise 3M/ESPE) foram influenciadas diretamente pela variação do "Fator C", em acordo com os conceitos observados por FEILZER; de GEE; DAVIDSON ${ }^{34}$ (1987). O grupo 9 com "Fator C" de 0,6 apresentou os maiores valores de força de contração (4,926 N), enquanto o grupo 10, com "Fator C" de 0,33, os menores valores (2,197 N). As diferenças nas curvas obtidas para estes grupos é bastante nítida, o que indica a influência direta do "Fator C" no relaxamento das tensões geradas durante a contração de polimerização da resina química avaliada (Anexos 9 e 10). 
6 DISCUSSÃO 


\section{DISCUSSÃO}

Para facilitar o entendimento dos resultados observados nesta pesquisa, a discussão será dividida em tópicos e apresentada em ordem pertinente.

\subsection{Metodologia empregada}

A análise da contração de polimerização dos compósitos pode ser determinada por meio do emprego de diferentes técnicas e metodologias. A mais empregada utiliza ensaios mecânicos, enquanto a análise de elemento finito (VERSLUIS; TANTBIROJN; DOUGLAS ${ }^{72}$, 1998), emprego de extensores elétricos (stain gauge) (LOPES ${ }^{48}, 2003$ ) e fotoelasticidade (KINOMOTO, et al. ${ }^{44}$, 1999; LOPES $^{48}$, 2003), dentre outras metodologias, também podem ser empregados para o mesmo fim. Uma vez que as forças geradas durante a contração de polimerização dos compósitos não podem ser medidas diretamente nas cavidades (SAKAGUCHI ${ }^{60}$, 1999), métodos indiretos foram desenvolvidos. A utilização de ensaios mecânicos para determinar a tensão de contração das resinas compostas é a metodologia mais empregada para este fim e apresenta algumas variáveis que são objetos de críticas e discordâncias entre pesquisadores, tornando difícil a comparação dos resultados de diferentes trabalhos da literatura. A utilização de máquina de ensaio associada a uma célula de carga possibilitou que as tensões transmitidas pela contração de polimerização dos compósitos a um outro corpo fossem determinadas numericamente, além da obtenção das curvas do comportamento durante a polimerização dos mesmos (cinética de polimerização).

Os ensaios mecânicos existentes se distinguem basicamente pelo tipo de equipamento, utilização ou não de reposicionamento entre as bases durante a polimerização dos compósitos, forma destas bases e tipo de substrato utilizado para adesão dos compósitos. Os sistemas que utilizam sonda transdutora para 0 monitoramento, reposicionamento e manutenção constante da altura entre as bases e, conseqüentemente, da altura do corpo-de-prova de resina composta durante sua polimerização, são considerados totalmente rígidos e apresentam baixo "compliance" para o sistema de ensaio (BOWEN ${ }^{9}$, 1967; DAVIDSON; DE GEE ${ }^{29}$, 1984; CALHEIROS et 
al. $^{13}$, 2004; DAVIDSON; DE GEE; FEILZER ${ }^{30}$, 1984; FEILZER; DE GEE; DAVIDSON ${ }^{34}$, 1987; FEILZER; DE GEE; DAVIDSON ${ }^{35}$, 1990). Neste tipo de ensaio ocorre a somatória das forças: contração da resina e reposicionamento das bases, o que determina maiores valores de força de contração, geralmente expressos em MPa. DAVIDSON; FEILZER ${ }^{31}$ (1997) consideram que o equipamento utilizado no teste deve ser totalmente rígido para conseguir avaliar as forças de contração de polimerização, acrescentando que um teste não rígido (sem reposicionamento das bases) pode influir nos resultados de corpos-deprova de diversos tamanhos e proporções diferentes. Explicaram que nos sistemas sem reposicionamento a influência da deformação constante do equipamento (célula de carga) poderia ser maior para os corpos-de-prova de menor tamanho, podendo levar a interpretações erradas dos resultados de corpos-de-prova com diferentes alturas. Contrário a este ponto de vista, MIGUEL; DE LA MACORRA ${ }^{49}$ (2001) comenta que este tipo de ensaio não pode ser considerado totalmente rígido, uma vez que os discos opostos estão sempre se afastando quando a resina se contrai, mantendo uma distância constante entre eles. Estes autores comentam ainda que existe uma segunda limitação conceitual, ou seja, na natureza não existe um sistema totalmente rígido. $\mathrm{O}$ dente e a restauração inevitavelmente possuem certa capacidade de deformação, sendo capazes de relaxar parte da tensão produzida pela polimerização. Um terceiro fator é o volume empregado e as características específicas do material restaurador.

Durante a confecção de restaurações de resina composta pode ocorrer a deflexão das cúspides em função das forças de contração de polimerização (PALIN et al. ${ }^{53}$, 2005). Para as cavidades em dentes humanos que serão preenchidas com um sistema restaurador adesivo, não existe um sistema totalmente rígido e a deformação das paredes cavitárias permite, proporcionalmente, maior liberação de tensões para os incrementos pequenos, em comparação com incrementos maiores, enfatizando a importância do volume utilizado em cada incremento e não a necessidade de um reposicionador na montagem do teste $8,49,51,73$.

O método empregado neste estudo pode ser considerado como não rígido, pois não apresenta um sistema de reposicionamento das bases metálicas, fornecendo valores de tensão mais baixos. Isto ocorre porque, quanto menor for à oposição à contração de polimerização do compósito (“compliance” alto), menor será a força desenvolvida pelo mesmo. Durante os ensaios não era permitido ao braço superior móvel da máquina de 
ensaio se movimentar para compensar a contração de polimerização dos compósitos inseridos entre as bases metálicas. Desta maneira, as forças de contração de polimerização foram determinadas apenas pela deformação da célula de carga de $10 \mathrm{~kg}$ utilizada, além das curvas \{força $(N) X$ tempo (s)\} obtidas para cada corpo-de-prova. As curvas apresentadas no presente trabalho (Figuras 18 e 21) se assemelham muito com as curvas obtidas por diversos autores em trabalhos e metodologias distintas, como AZEVEDO et al. ${ }^{3}$, 2003 (Figura 07), BOUSCHLICHER; VARGAS; BOYER ${ }^{8}, 1997$ (Figura 02), ILIE et al. ${ }^{41}$ (2005), LOPES $^{48}$ (2003), MONDELLI; CASTAÑEDA-ESPINOSA; FRANCO ${ }^{50}$, em 2002 (Figura 06), SAKAGUCHI; WILTBANK; MURCHISON ${ }^{61}, 2004$ (Figura 10) e WATTS; MAROUF; Al-HINDI ${ }^{73}$ (2003), independe do sistema empregado apresentar ou não reposicionamento das bases.

As observações dos resultados apresentados nesta pesquisa sugerem que o sistema de ensaio utilizado foi capaz de captar as curvas e a magnitude das forças geradas durante a contração de polimerização das resinas de ativação física e química avaliadas, sem considerar o volume, geometria, área adesiva, altura dos corpos-de-prova, "Fator C" e os respectivos conjuntos de bases metálicas empregados (Tabelas 5 a 10). Além destas características, a precisão dos sistemas de encaixe da máquina, a célula de carga e as bases confeccionadas em aço proporcionaram um sistema com mínima deformação de todo o conjunto, possibilitando a captação dos resultados aqui observados. Outros trabalhos que empregaram a mesma metodologia, mas estudaram diferentes variáveis, como a energia, técnica e o modo de ativação, fonte de luz, tipo de resina composta e utilização de materiais intermediários (AZEVEDO et al. ${ }^{3}, 2003$; CASTAÑEDA-ESPINOSA; MONDELLI ${ }^{14}$, 2002; CASTAÑEDA-ESPINOSA et al. ${ }^{15}$, 2003; CAVALCANTI; CASTAÑEDA-ESPINOSA; MONDELLI ${ }^{17}$ 2003; CAVINA et al. ${ }^{18}$, 2003; CORTÉS et al. $^{25}$, 2003; MONDELLI; CASTAÑEDA-ESPINOSA; FRANCO50, 2002; MONDELLI et al. ${ }^{51}$, 2003; $\mathrm{PAN}^{54}$, 2002) demonstram o alcance e a precisão desta metodologia, sem influências significativas nos resultados, além das possíveis combinações para o estudo destas variáveis.

A afirmação de DAVIDSON; FEILZER ${ }^{31}$ (1997), de que existe influência da deformação da célula de carga nos sistemas sem reposicionamento (baixo "compliance"), para corpos-de-prova de menor tamanho e altura, é controverso, uma vez que estas observações foram determinadas quando do emprego das resinas químicas, onde 0 
"Fator C" apresenta papel fundamental no relaxamento das tensões (BOWEN ${ }^{9}, 1967$; CALHEIROS et al. $^{13}$, 2004; DAVIDSON; DE GEE ${ }^{29}$, 1984; DAVIDSON; DE GEE; FEILZER ${ }^{30}$, 1984; FEILZER; DE GEE; DAVIDSON ${ }^{34}$, 1987; FEILZER; DE GEE; DAVIDSON $^{35}$, 1990). O inverso também pode ser verdadeiro, ou seja, nos sistemas com reposicionamento entre as bases que apresentam alto "complaince" e corpos-de-prova com menor altura e, conseqüentemente, menor volume, a pequena magnitude da força de contração de polimerização do compósito pode ser igualada ou mesmo superada pela força proveniente do reposicionamento das bases, podendo levar a interpretações equivocadas, principalmente quando não se avaliam de forma distinta as resinas de ativação química e física.

\subsection{Influência do modo de ativação das resinas compostas nas forças de contração de polimerização}

Durante o processo de polimerização das resinas compostas, suas moléculas (monômeros) se situam mais perto uma das outras com a finalidade de formar cadeias de polímeros ${ }^{6,12,40}$. Como conseqüência deste reordenamento molecular, o material sofre contração volumétrica que, em certas condições, quando o material é impedido de se contrair (como em uma restauração adesiva), são desenvolvidas forças em decorrência da falta de deformação da superfície externa da restauração ${ }^{6,9,29,40}$. Essas forças transmitem tensão à interface dente-restauração e podem ser responsáveis pelas falhas adesivas que causam fendas marginais e microinfiltração, seguidas de sensibilidade dentária, irritação pulpar, pigmentações e cárie secundária ${ }^{29,31,38,71}$. Por outro lado, não havendo falha adesiva, as forças de contração podem causar movimento das cúspides (PALIN, et al. ${ }^{53}$, 2005), possível diminuição da resistência da estrutura dentária (DAVIDSON; FEILZER ${ }^{31}$, 1997) e até fraturas dentárias (SUH ${ }^{65}$, 1998; VERSLUIS; TANTBIROJN ${ }^{71}$, 1999). O entendimento do processo da contração de polimerização, das suas conseqüências e dos diferentes fatores que podem interferir nesse processo pode fazer a diferença na maior ou menor longevidade de uma restauração de resina composta (MONDELLI et al. ${ }^{51}$, 2003). 
A resina composta Concise empregada nos ensaios apresenta ativação química, tendo como catalisador da reação o peróxido de benzoíla e como ativador uma amina terciária do tipo dimetil-paratoluidine. A reação de polimerização se inicia no momento da espatulação e mistura das pastas base e catalisadora em partes iguais, onde o ativador imediatamente inicia a ativação do catalisador, proporcionando a formação de radicais livres. No presente estudo, as pastas base e catalisadora da resina Concise foram espatuladas em 30 segundos e inseridas entre as bases em 90 segundos, tempo necessário para este procedimento. A reação destes radicais com as moléculas de dimetacrilato da resina é temporariamente inibida, porque os radicais livres reagem primeiramente com os inibidores da reação (dióxido de titânio e óxidos férricos). Quando uma pequena porção dos inibidores é consumida, os radicais livres reagem então com a resina (monômeros) e a superfície silanizada das partículas de carga, formando a ligação entre as partículas de carga e as cadeias poliméricas, iniciando as ligações cruzadas entre as cadeias (fase pré-gel). Nesse período a velocidade de polimerização é rápida mas o material ainda se apresenta em estado líquido, permitindo a deformação das superfícies livres do corpo-de-prova, de forma a liberar parte das tensões de contração (BAUSCH et al. ${ }^{6}$, 1982; DAVIDSON; DE GEE ${ }^{29}$, 1984; FEILZER; DE GEE; DAVIDSON ${ }^{35}$, 1990; MONDELLI, CASTAÑEDA-ESPINOSA, FRANCO ${ }^{50}$, 2002). Quando o ponto de geleificação é atingido, o material começa a desenvolver forças de contração, primeiro em velocidade lenta, em função do baixo módulo de elasticidade do material e, logo após, com maior velocidade (BRAEM et al. ${ }^{11}$, 1987). Segundo estes autores, quando a reação de polimerização progride, o módulo de elasticidade da resina aumenta e a resina perde flexibilidade. Estas reações continuam durante a fase pós-gel, ocorrendo a ligação entre as partículas de carga e as moléculas de resina, formando um sistema de ligações cruzadas. No presente estudo, nos últimos 240 segundos dos ensaios dos grupos 9 e 10 da resina Concise (Anexos 9 e 10), ocorreu diminuição na velocidade em que as forças de contração eram geradas, possivelmente em função da velocidade de polimerização ter diminuído por existir menor quantidade de monômeros disponíveis (BAUSCH et al. ${ }^{6}$, 1982).

Este sistema de ativação promove uma polimerização uniforme em toda porção da reisna manipulada, obtendo o mesmo grau de conversão tanto na superfície quanto na base de uma determinada porção do material (FRANCO; LOPE ${ }^{37}$, 2003). Esta categoria de resina composta apresenta dois inconvenientes, limitação do tempo de trabalho e 
incorporação de bolhas durante a espatulação das pastas base e catalisadora. DAUVILLIER; AARNTS; FEILZER ${ }^{33}$ (2003) reportaram que, embora a composição química seja bastante distinta entre diferentes resinas compostas, em geral o aumento na velocidade de polimerização tem um efeito negativo na capacidade de fluxo de um material. Estes dados são largamente consubstanciados na literatura, onde vários autores afirmam que este tipo de resina apresenta uma fase pré-gel evidente, fase esta em que o material ainda não se encontra em um estágio rígido, permitindo que haja o escoamento da tensões provenientes da contração de polimerização $8,32,36,44$.

Em função destas características da resina química, DAVIDSON; DE GEE; FEILZER ${ }^{30}$ (1984) observaram que grande parte da força de contração de polimerização dos compósitos de ativação química poderia ser relaxada através do escoamento do material, durante a fase pré-gel, nas superfícies livres dos incrementos de resina. A partir destas observações, FEILZER; DE GEE; DAVIDSON ${ }^{34}$ (1987) estabeleceram uma relação entre o número de superfícies aderidas e livres, denominando de fator de configuração cavitária ou "Fator C".

Com a finalidade de contornar os problemas da resina de ativação química, foram desenvolvidas as resinas fotossensíveis (ativação física) em pasta única, sem a necessidade de manipulação de duas pastas, tendo sua polimerização iniciada por radiação proveniente de energia luminosa que ativa o agente fotossensível presente na resina. A molécula do fotoiniciador é capaz de absorver a energia dentro de um comprimento de onda específico e então iniciar o processo de polimerização. O produto mais empregado na fabricação dos compósitos é a canforoquinona, que absorve energia entre 450 - 500 nm, com pico máximo de absorção em 468 nm. Com a absorção pela canforoquinona dos fótons provenientes da fonte de luz, a mesma entra num estado mais reativo ou excitado, denominado estado tripleto. Quando a canforoquinona colide com o co-iniciador, no caso uma amina terciária, ocorre a transferência de elétrons, o que resulta na formação de radicais livres. Estes radicais, com extrema energia e com elétrons sem par, buscam se ligar com as unidades monoméricas $(\mathrm{C}=\mathrm{C})$, determinando a quebra da ligação dupla do monômero, formando um complexo radical-monômero. Estes complexos procuram fazer mais ligações com outros monômeros, determinando a formação de moléculas maiores, os polímeros (RUEGGEBERG ${ }^{58}, 1999$ ). 
A velocidade da reação de polimerização dos compósitos quando fotoativados de maneira convencional é muito mais rápida do que a reação das resinas químicas. Este fato pode ser observado claramente nas curvas [força $(N) X$ tempo (s)] obtidas para a resina Z-250, presentes nos gráficos das figuras 18 e 21 e anexos de 1 a 8 , quando comparada com as curvas obtidas para a resina Concise (Figura 21 e Anexos 9 e 10). Pode-se observar que, no momento do início do ensaio, em sincronia com o início da fotoativação, a resina iniciou a geração de forças de forma mais rápida e incisiva do que a resina Concise, com elevação abrupta da curva pela tensão desenvolvida nos períodos iniciais. Com a cinética de polimerização apresentada pela resina Z-250 fotoativada de forma convencional, a possibilidade desta em relaxar as forças de contração através do escoamento ou fluxo do material é diminuída consideravelmente devido à sua fase pré-gel apresentar duração extremamente curta.

Nesse sentido, sabe-se que a aplicação de uma energia luminosa de forma convencional (sem modulação) sobre a resina composta, propicia uma rápida reação de polimerização, ou seja, ocorrerá uma passagem instantânea de um estado menos viscoso (pré-gel) para um estado rígido (pós-gel), de forma a aumentar rapidamente o módulo de elasticidade (DAVIDSON; FEILZER ${ }^{31}$, 1997; SAKAGUCHI et al. ${ }^{59}$, 1992). Até o ponto gel, que define o momento em que a cadeia polimérica da resina composta não mais possibilita um escoamento para alívio das tensões, as forças de contração podem ser compensadas pelo rearranjo molecular desta rede polimérica ${ }^{31}$. Após o desenvolvimento da rigidez da resina (pós-gel), verificar-se-á uma grande redução no escoamento deste polímero, aumentando a concentração das tensões ${ }^{29,59}$.

Outras técnicas empregadas na fotoativação das resinas compostas foram estudadas no sentido de verificar a possibilidade de se aumentar a fase pré-gel da resina e, conseqüentemente, proporcionar maior alívio das tensões geradas pela contração de polimerização. De acordo com ASENJO-MARTINEZ et al. ${ }^{3}$ (2003), AZEVEDO et al. ${ }^{5}$ (2003), FRANCO; LOPES ${ }^{37}$ (2003), ILIE et al. ${ }^{41}$ (2005), LOPES ${ }^{48}$ (2003) e SAKAGUCHI; WILTBANK; MURCHISON ${ }^{61}$ (2004), a técnica que proporcionou aumento significativo da fase pré-gel foi a do pulso interrompido, diferentemente das técnicas convencional e gradual, que não permitiram este tipo de comportamento durante a fotopolimerização dos compósitos. Fato interessante também foi observado por SANTOS, et al. ${ }^{62}$ (2004), em que as técnicas de polimerização (convencional, convencional com alta densidade, rampa 
e pulso interrompido) de maneira geral não influenciaram significativamente na contração volumétrica das resinas compostas avaliadas (Suprafil, Z-100 e P-60).

A resina composta Z-250 apresentou comportamento semelhante em relação a outros trabalhos da literatura (BOUSCHLICHER; VARGAS; BOYER ${ }^{8}$, em 1997; CASTAÑEDA-ESPINOSA; MONDELLI ${ }^{14}$, em 2002; CAVINA $^{18}$, em 2003; CHEN et al. ${ }^{20}$, em 2001; DAVIDSON; DE GEE; FEILZER ${ }^{30}$, em 1984; FEILZER; DE GEE; DAVIDSON ${ }^{36}$, em 1993; LOPES $^{48}$, em 2004; MIGUEL; DE LA MACORRA ${ }^{49}$, em 2001; MONDELLI, CASTAÑEDA-ESPINOSA, FRANCO ${ }^{50}$, 2002; MONDELLI et al. ${ }^{51}$, em 2003; YAP et al. ${ }^{74}$, em 2002), onde resinas compostas de ativação física geraram e armazenaram forças de contração de polimerização mesmo depois de concluída a fotoativação, apesar da velocidade de geração das forças diminuir consideravelmente.

MONDELLI; CASTAÑEDA-ESPINOSA; FRANCO50 (2002) observaram que a cinética de polimerização apresentada pelos compósitos com formas diferentes de polimerização (física e química) é dependente de sua constituição e apresentam reações de polimerização com velocidades distintas (Figura 06). Semelhante a estas observações, o presente trabalho demonstra claramente que a cinética da reação de polimerização (Figura 21) e as forças geradas durante a contração de polimerização dos compósitos de ativação química é diferente dos de ativação física (Tabela 8), além do volume e o "Fator C" terem influenciado de maneira distinta os dois tipos de resina composta (Anexos 1 a 10).

\subsection{Geometria das bases para adesão dos compósitos}

A utilização de áreas de adesão em forma cilíndrica (bases), pela maioria dos trabalhos da literatura, determina algumas limitações em sua utilização e correlação com a clínica ${ }^{1,2,8,13,20,29,34,36,40,43,49}$. Corpos-de-prova cilíndricos não permitem a passagem uniforme da luz através dos compósitos, pois a espessura de material que os fótons atravessam diminui do centro do corpo-de-prova para os extremos laterais, podendo determinar menor grau de conversão em algumas áreas do espécime. Em função do volume de material a da forma cilíndrica das bases de vidro, alguns trabalhos utilizaram simultaneamente dois aparelhos de luz para a fotoativação do espécime (CALHEIROS et 
al. ${ }^{13}$, 2004; CHEN et al. ${ }^{20}, 2001$; BOUSCHLICHER; VARGAS; BOYER ${ }^{8}$, 1997; FEILZER; DE GEE; DAVIDSON ${ }^{34}$, 1987; FEILZER; DE GEE; DAVIDSON ${ }^{36}$, 1993). Mesmo assim, os vetores de força podem se formar em diferentes direções, permitindo alterar os valores de força de contração, além de também não apresentar correlação com a aplicação clínica diária em função do volume dos incrementos e a energia necessária para sua ativação. CALHEIROS et al. ${ }^{13}$ (2004) chamam a atenção para a diminuição da energia de ativação em função da distância e dispersão da luz apresentada quando da fotopolimerização através dos cilindros de vidro, afirmando que a real densidade de potência, que atinge o corpo-de-prova de resina, deveria ser determinada para a melhor avaliação do ensaio. Provavelmente este seja um dos motivos pelos quais vários autores testaram resinas compostas de ativação química onde a fotopolimerização não se faz necessária. Atualmente é mínima a utilização deste compósito como material restaurador estético direto, tornando difícil a correlação dos resultados observados por estes autores entre resinas de ativação química e física.

Algumas razões levaram os autores MONDELLI; CASTAÑEDA-ESPINOSA; FRANCO $^{50}$ (2002), CASTAÑEDA-ESPINOSA; MONDELLI' ${ }^{14}$ (2002) e MONDELLI et al. $^{51}$ (2003) a utilizarem bases metálicas retangulares com dimensões de 6,0 x 2,0 mm, altura entre as bases de $1,0 \mathrm{~mm}$ e, conseqüentemente, volume dos corpos-de-prova de $12,0 \mathrm{~mm}^{3}$ e "Fator C" de 1,5 das resinas compostas avaliadas nos primeiros experimentos realizados com a mesma metodologia empregada no presente estudo. CHEN et al. ${ }^{20}$ (2001) também utilizaram corpos-de-prova retangulares com volume de $32 \mathrm{~mm}^{3}$ para determinar a força de contração dos compósitos. Ao se empregar menor volume de resina nesta presente pesquisa em comparação aos maiores volumes utilizados nos trabalhos existentes na literatura, como de ALSTER et al. ${ }^{1}$ (1997a), BOUSCHLINCHER; VARGAS; BOYER $^{8}$ (1997), BOWEN ${ }^{9}$ (1967), CHEN et al. ${ }^{20}$ (2001), DAVIDSON; DE GEE; FEILZER $^{30}$ (1984), DAVIDSON; FEILZER ${ }^{31}$ (1997), FEILZER; DE GEE; DAVIDSON ${ }^{34}$ (1987), FEILZER; DE GEE; DAVIDSON ${ }^{35}$ (1990) e KEMP-SCHOLTE; DAVIDSON ${ }^{43}$ (1990), dentre outros, conseguiu-se maior aproximação das condições clínicas de aplicação (técnica incremental) destes materiais restauradores e, principalmente, por ser possível à utilização de apenas um aparelho de luz para a polimerização uniforme de todo o incremento de resina composta aplicado entre as bases em apenas único procedimento. Como o corpo-de-prova de resina composta, no caso específico dos trabalhos de MONDELLI; CASTAÑEDA-ESPINOSA; FRANCO ${ }^{50}$ (2002), CASTAÑEDA- 
ESPINOSA; MONDELLI ${ }^{14}$ (2002), MONDELLI et al. ${ }^{51}$ (2003) e também para o grupo 2, da presente pesquisa, apresentavam comprimento de $6,0 \mathrm{~mm}$, altura de $1,0 \mathrm{~mm}$ e profundidade

2,0 mm (Figuras 13, 14 e 15), qualquer aparelho de luz com ponta foto-transmissora de 6,0 $\mathrm{mm}$ de diâmetro e densidade de potência adequada para polimerização em profundidade de $2,0 \mathrm{~mm}$ (VERSLUIZ; TANTBIROJN; DOUGLAS ${ }^{72}$, 1998) é capaz de ativar uniformemente todo incremento do material restaurador com apenas um aparelho de fotopolimerização e num único procedimento, independente da altura dos corpos-deprova, que variou de 0,5 a $3,0 \mathrm{~mm}$ na presente pesquisa. Convém salientar que a polimerização dos incrementos de resina quando da utilização das bases com comprimento de $2 \times 2 \mathrm{~mm}$ e altura de $3 \mathrm{~mm}$ e comprimento de $3 \times 2 \mathrm{~mm}$ e altura de 2 $\mathrm{mm}$, o mesmo princípio é válido para a fotopolimerização dos corpos-de prova que apresentaram volume constante de $12 \mathrm{~mm}^{3}$.

O vidro silanizado, dentina hibridizada ou metal podem ser utilizados como substratos adesivos na determinação das forças de contração dos compósitos. Uma das vantagens na utilização de bases confeccionadas em aço, como as empregadas no presente trabalho, é a adesão direta dos compósitos ao metal, suprimindo a aplicação de adesivo previamente à inserção da resina composta, facilidade de remoção da resina, adequada adesão aos compósitos sem apresentar desunião durante os ensaios, alto módulo de elasticidade do aço, facilidade na confecção das bases e a utilização das mesmas bases metálicas para a realização de todos os ensaios para cada grupo avaliado. Neste presente trabalho a utilização de três conjuntos de bases metálicas retangulares e quadradas, com diferentes dimensões e confeccionadas em aço, permitiu maior facilidade no cálculo das áreas das superfícies livres e aderidas; polimerização uniforme em toda a extensão e altura do espécime com a mesma energia de ativação e emprego de apenas um único aparelho de luz para fotopolimerização; utilização de menores e variados volumes de resina; variação do "Fator C" com volume constante e variação conjunta do volume e do“Fator C". Estas características do experimento não inviabilizam a utilização de outro substrato adesivo para a realização dos ensaios; seriam necessárias algumas pequenas alterações no sistema de encaixe das bases, permitindo a adaptação de fragmentos de dentina ou de esmalte como substratos adesivos, como exemplo. 
A maneira encontrada pelos pesquisadores para determinar a força de contração dos compósitos se restringe à utilização de duas bases opostas. Clinicamente esta disposição dos incrementos de resina seria como de duas paredes paralelas e opostas, ou seja, o incremento de resina estaria aderido às paredes vestibular e lingual, como exemplo, sem interferências de outras áreas adesivas. Clinicamente esta disposição deve ser evitada para não determinar maior deflexão das cúspides do dente a ser restaurado (NIKOLAENKO et al. ${ }^{52}$, 2004; PALIN et al. ${ }^{53}$, 2005), causando elevado estresse na área adesiva dente-restauração. Uma opção seria a utilização de bases para adesão posicionadas de forma oblíqua, em semelhança ao incremento de resina aplicado às paredes pulpar e vestibular. Até o momento os sistemas existentes para medição destas forças não permitem este tipo de disposição, apenas de duas paredes opostas e paralelas.

\subsection{Volume dos incrementos de resina composta}

Um fator que contribui para a obtenção de altos valores de força de contração na maioria dos estudos é a utilização de amostras com grande volume do material, o que não apresenta relação direta com as situações clínicas ${ }^{1,8,9,10,20,29,30,34,35}$.

Na presente pesquisa os resultados apresentados nas tabelas 5 e 8 e nos gráficos das figuras 18 e 21 permite observar que, independente da altura ajustada $(0,5 ; 1,0 ; 1,5 ; 2,0$; 2,5 e $3,0 \mathrm{~mm}$ ) entre as bases metálicas de $6 \times 2 \mathrm{~mm}$, do volume empregado (6; 12; 18; 24; $30 \mathrm{e}$ $\left.36 \mathrm{~mm}^{3}\right)$ e do "Fator C" (3,0; 1,5; 1,0; 0,75; 0,6 e 0,5), o sistema de ensaio foi capaz de registrar as forças de contração de polimerização (N) com muita precisão $(4,445 ; 5,694 ; 7,017$; $8,261 ; 9,847 ; 11,40)$, com baixo desvio padrão e baixo coeficiente de variação. Estes achados apontam para uma relação direta entre o volume e a força de contração da resina Z-250 polimerizada convencionalmente, sendo constatada esta relação no gráfico da figura 19, sem influência incisiva do "Fator C" (Figura 20). Resultados semelhantes foram observados por BOUSCHLINCHER; VARGAS; BOYER ${ }^{8}$ (1997), MIGUEL; DE LA MACORRA $^{49}$ (2001) e WATTS; MAROUF; AL-HINDI ${ }^{73}$ (2003), utilizando sistemas sem reposicionamento, em que o "Fator C" apresentou relação inesperada com a tensão máxima. Esta relação não foi linear, em semelhança aos resultados apresentados no presente trabalho (Figura 20), onde a relação foi inversa, ou seja, as maiores tensões 
foram determinadas para o menor "Fator C". Estes resultados estão diretamente relacionados com o volume do incremento e o modo de ativação dos compósitos e não com a espessura e/ou o "Fator C", independente do sistema empregado apresentar reposicionamento entre as bases.

De acordo com os resultados observados nesta pesquisa, que empregou a metodologia sem reposicionamento entre as bases, para se determinar a influência do volume ou do "Fator C" nas forças de contração das resinas compostas, estas variáveis devem ser estudadas de forma distinta e/ou em associação, a fim de observar o comportamento que estes materiais devem apresentar quando de sua utilização clínica, contribuindo para o aumento da longevidade das restaurações adesivas. Os resultados aqui apresentados pela resina composta Z-250 de ativação física evidenciam a importância do emprego de incrementos com pequeno volume durante a confecção das restaurações de resina composta fotoativada, além, é claro, da disposição destes incrementos na cavidade dentária. Convém salientar que esta categoria de resina (fotoativada) não seguiu a teoria do "Fator C" com esta delineação experimental, ou seja, a força de contração não foi influenciada pela área livre do corpo-de-prova num sistema de bases paralelas (duas paredes opostas), mas sim pelo volume empregado.

\subsection{Influência do fator de configuração cavitária na determinação das forças de contração dos compósitos}

O "Fator C" também tem sido motivo de controvérsias, principalmente quando é citado como sendo o motivo principal de falhas de restaurações adesivas. Na realidade, 0 "Fator C" não deve ser analisado isoladamente, mas sim em associação com outros fatores, como as características de cada substrato (dentina ou esmalte), técnica de aplicação do sistema adesivo, tipo de material restaurador, técnica operatória relacionadas à inserção do material, sua polimerização, bem como aspectos referentes ao acabamento e tratamento do ângulo cavosuperficial. O "Fator C", como observado por FRANCO et al. ${ }^{38}$ (2003) e NIKOLAENKO et al. ${ }^{52}$ (2004), pode influenciar de maneira significativa na resistência à infiltração marginal e na resistência adesiva, respectivamente, das restaurações confeccionadas com resina composta. 
Interpretações equivocadas ou a falta de informações fidedignas em relação ao real comportamento dos compósitos durante sua contração de polimerização ainda causa dúvidas e confusões na comunidade científica, principalmente em função do sistema de ensaio utilizado apresentar baixo ou alto "compliance". Algumas características relacionadas com a contração de polimerização dos compósitos observadas em trabalhos da literatura que, na maioria das vezes, utilizaram bases cilíndricas para adesão, variando o diâmetro, a altura, o volume e o "Fator C" dos incrementos do material, levaram a interpretações incorretas do comportamento das resinas durante a contração de polimerização. Este problema está muito mais relacionado com as diferenças entre o modo de ativação dos compósitos do que o sistema apresentar ou não reposicionamento entre as bases. A maior parte dos trabalhos da literatura utilizaram resinas de ativação química para determinar alguns conceitos que, inadvertidamente, foram estendidos para as resinas compostas de ativação física, como o "Fator C", descrito por FEILZER; DE GEE; DAVIDSON ${ }^{34}$, em 1987. Um exemplo comum é a utilização de resina de ativação química e bases com diâmetro constante (área adesiva), onde a altura entre as bases é variada e, conseqüentemente, o volume e o "Fator C". A realização de um experimento com estas características e a utilização de uma resina de ativação química proporciona, para os corpos-de-prova com menor altura e, conseqüentemente, menor volume e maior "Fator C", maiores valores de força de contração, correspondendo à teoria do "Fator C" (ALSTER, et al. ${ }^{1,2}$, 1997a, 1997b; BOWEN ${ }^{9}$, 1967; CALHEIROS et al. ${ }^{13}$, 2004; DAVIDSON; DE GEE ${ }^{29}$, 1984; DAVIDSON; DE GEE; FEILZER ${ }^{30}$, 1984; FEILZER; DE GEE; DAVIDSON ${ }^{34}, 1987$; FEILZER; DE GEE; DAVIDSON $\left.{ }^{35}, 1990\right)$.

Independentemente do sistema de ensaio empregado apresentar ou não reposicionamento entre as bases, o controle de um destes fatores, volume ou "Fator C", na determinação das forças geradas durante a contração de polimerização das resinas compostas de ativação física ou química, como o empregado no presente trabalho, proporcionou a observação de algumas características do comportamento destes materiais durante o processo de polimerização.

Quando o volume empregado foi constante $\left(12,0 \mathrm{~mm}^{3}\right)$ mas o "Fator C" era variado em 0,6 e 0,33, o sistema de ensaio foi capaz de apontar a influência deste fator nas forças geradas durante a polimerização química da resina Concise, diferentemente da 
resina Z-250, que não foi influenciada por esta variável (Tabela 8 e Figura 21). Os resultados observados para a resina Z-250 permitem concluir que, quando ativada de forma convencional, o "Fator C" não apresentou influência significativa na geração das forças durante sua contração. Apesar de não terem ocorrido diferenças estatisticamentes significantes entre os grupos 7 e 8 , o grupo 8 da resina Z-250 com maior altura (3,0 mm), maior área livre e menor "Fator C" $(0,33)$ apresentou resultados numericamente superiores $(4,074 \mathrm{~N})$ em relação ao grupo $7(3,890 \mathrm{~N})$. Este fato leva à suposição de que a contração linear das resinas compostas fotoativadas também pode ter influência incisiva na determinação das forças de contração, quando do emprego destas relações entre áreas livres e aderidas. As curvas obtidas para os grupos da resina Z-250 apresentaram a mesma cinética de polimerização, ou seja, rápida elevação das forças de contração no momento do início da fotoativação, seguindo sempre o mesmo padrão quando fotoativadas de maneira convencional (Figuras 18 e 21 e Anexos 1 ao 8).

Contrariando estas observações, a resina composta Concise apresentou comportamento oposto à resina Z-250, sendo influenciada de maneira significativa pelo "Fator C". A observação dos resultados do grupo 9, que empregou altura de 2,0 mm, "Fator C" de 0,6 e menor área livre, demonstrou força de contração de 4,926 N, enquanto o grupo 10, com altura de 3,0 mm, "Fator C" de 0,33 e maior área livre, apresentou força de contração de 2,197 N. Desta forma, quando a resina composta apresenta reação de polimerização lenta, as superfícies livres têm papel fundamental na liberação do estresse desenvolvido em função da contração de polimerização dos compósitos, confirmando a teoria do "Fator C" proposta por FEILZER; DE GEE; DAVIDSON³4, em 1987. A influência do "Fator C" na geração das forças de contração da resina Concise pode ser observada nos gráficos da figura 21 e anexos 9 e 10. O grupo 10, com menor "Fator C" $(0,33)$, além da menor intensidade das forças de contração apresentou maior liberação das tensões nos períodos iniciais dos ensaios, determinando curvas com menor altura e maior inclinação para a direita. Comportamento diferente apresentou o grupo 9 ("Fator C" de $0,6)$, com os maiores valores de força de contração de polimerização, o que determinou curvas com maior altura e menor inclinação para a direita. A observação das curvas da cinética de polimerização apresentadas pela resina Concise (Anexos 9 e 10) evidencia que o grupo 9, com maior "Fator C", começou a gerar forças desde os períodos iniciais dos ensaios, apresentando menor capacidade de relaxar as tensões provenientes da contração de polimerização. 
Em vista do exposto e discutido na presente pesquisa, alguns aspectos e orientações pertinentes à utilização clínica das resinas compostas fotoativadas devem ser observados, como a importância do emprego de volumes pequenos do material durante sua inserção e fotopolimerização; os incrementos devem ser aplicados de forma oblíqua, com maior área livre, nunca unindo duas paredes opostas; evitar incrementos longos em função da contração linear dos compósitos; modulação da fotoativação com a finalidade de aumentar a fase pré-gel da resina; utilização do cimento de ionômero de vidro como forrador cavitário para absorção de parte da força de contração de polimerização da resina composta; conhecimento da magnitude das forças geradas durante a contração de polimerização dos compósitos em função da porcentagem e tipo de partículas de carga, dos monômeros, diluentes e fotoiniciadores empregados, marca comercial e densidade da resina; energia necessária para a fotopolimerização dos incrementos da resina. Além de outros fatores envolvidos na realização de uma restauração de resina composta direta, como o preparo cavitário, proteção pulpar, hibridização, adaptação de matriz e cunha, técnica de inserção e polimerização, ajuste oclusal e procedimentos de acabamento e polimento, todas as considerações feitas acima devem nortear o procedimento restaurador, para a obtenção de sucesso clínico com as restaurações estéticas diretas. 
7 CONCLUSÕES 


\section{CONCLUSÕES}

Em função do delineamento experimental empregado e dos resultados obtidos na presente pesquisa, a hipótese nula apresentada deve ser recusada, pois o volume e 0 "Fator C" influenciaram de forma distinta a intensidade das forças geradas durante a contração de polimerização das resinas compostas avaliadas.

- O sistema de ensaio, sem reposicionamento das bases metálicas, foi capaz de captar com bastante precisão as forças geradas durante a realização dos experimentos.

- A cinética de polimerização da resina de ativação física, polimerizada de forma convencional, é diferente da resina química.

- A resina Z-250 (ativação física) foi influenciada diretamente pelo volume dos corpos-de-prova, demonstrando relação direta entre o volume e a força de contração, sem influência do "Fator C".

- A resina Concise (ativação química), diferentemente da resina de ativação física, foi influenciada pelo "Fator C". 
ANEXOS 


\section{ANEXOS}

Anexo 01 - Forças máximas (Newton) e curvas [força $(\mathrm{N}) \mathrm{X}$ tempo (s)] obtidas para 0 grupo 1 (bases 6x2 mm; volume 6,0 $\mathrm{mm}^{3}$; "Fator C" 3,0).

CORPO DE PROVA

CP1
CP2
CP3
CP4
CP5
CP6
CP7
CP8
CP9
CP10
MÍNIMO
MÁXIMO
MÉDIA

FORÇA MÁXIMA (N)
4,34
4,62
4,29
4,38
4,30
4,63
4,39
4,72
4,11
4,66
4,111
4,724
4,445

FORÇA MÁXIMA (N)

4,34

4,30

4,72

4,11

4,66

4,111

4,445

Resina composta Z-250 (3M/ESPE).

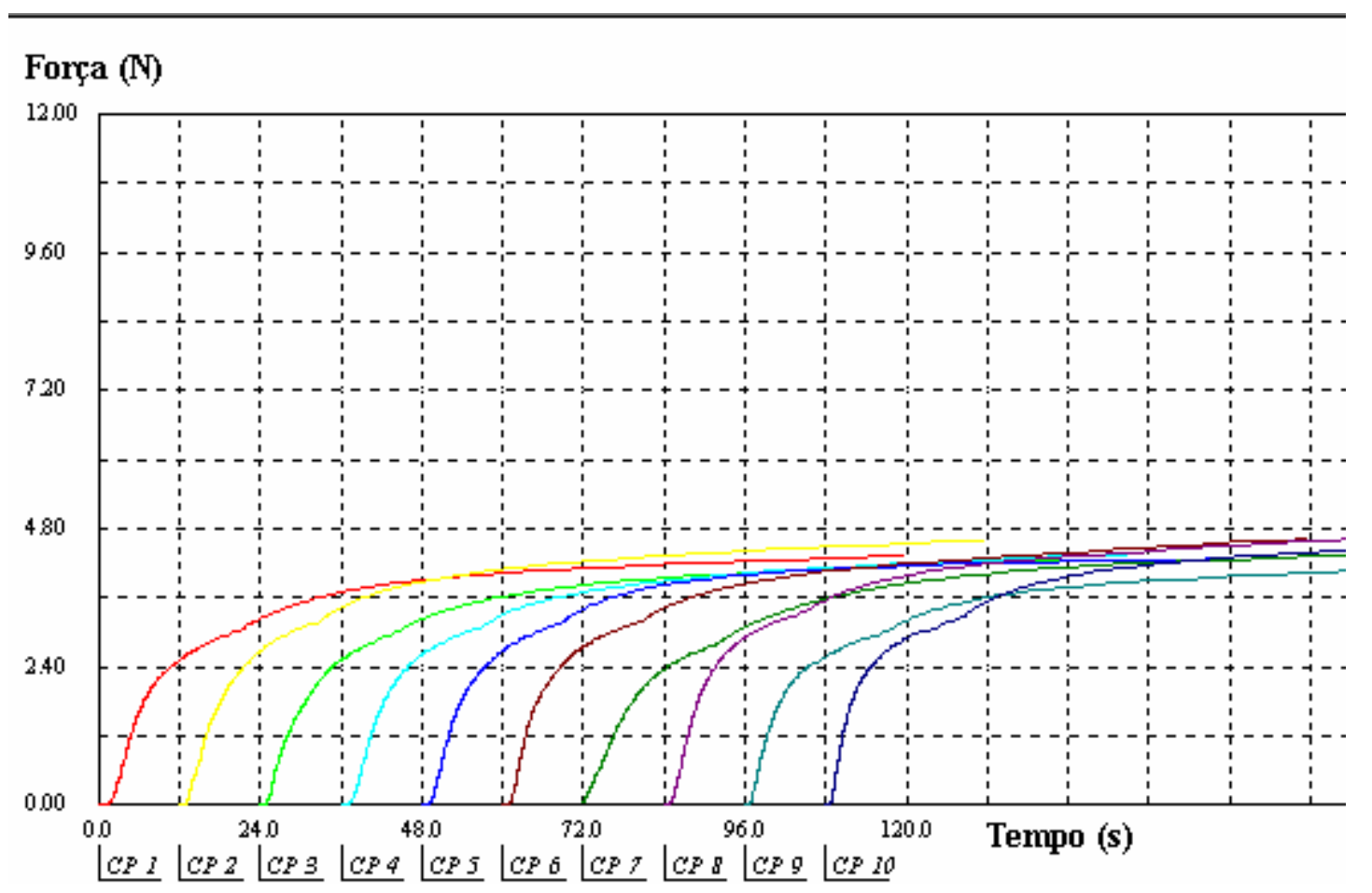


Anexo 02 - Forças máximas (Newton) e curvas [força (N) X tempo (s)] obtidas para o grupo 2 (bases 6x2 mm; volume 12,0 $\mathrm{mm}^{3}$; "Fator C" 1,5).

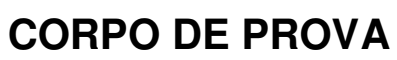

CP1
CP2
CP3
CP4
CP5
CP6
CP7
CP8
CP9
CP10
MÍNIMO
MÁXIMO
MÉDIA

\section{FORÇA MÁXIMA (N)}

5,51

6,01

5,73

5,48

5,60

5,32

5,51

5,96

5,90

5,93

5,322

6,012

5,694

Resina composta Z-250 (3M/ESPE).

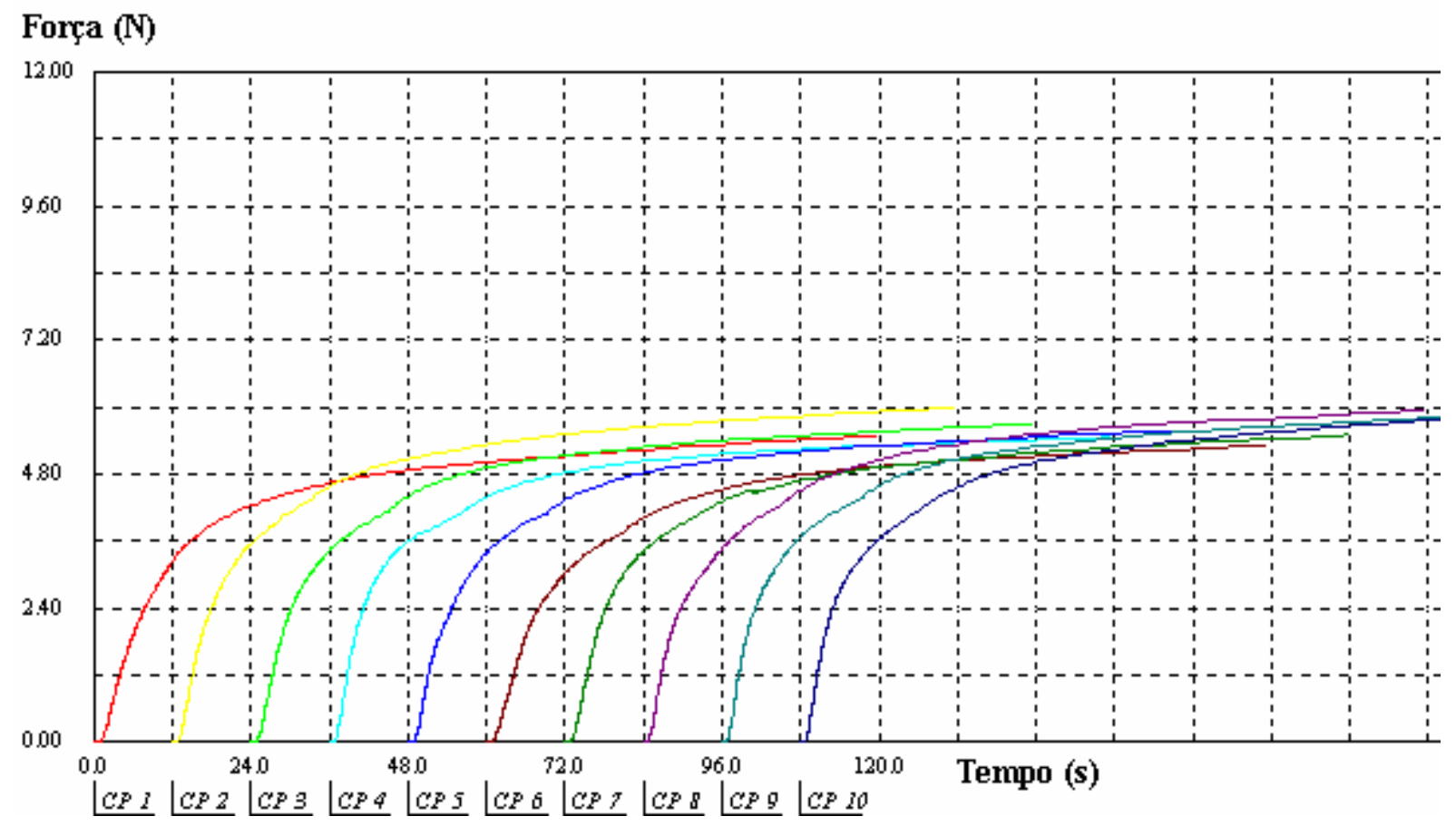


Anexo 03 - Forças máximas (Newton) e curvas [força (N) X tempo (s)] obtidas para o grupo 3 (bases 6x2 mm; volume 18,0 $\mathrm{mm}^{3}$; "Fator C" 1,0).

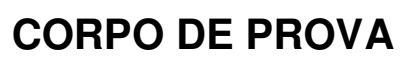

CP1
CP2
CP3
CP4
CP5
CP6
CP7
CP8
CP9
CP10
MÍNIMO
MÁXIMO
MÉDIA

\section{FORÇA MÁXIMA (N)}

7,11

6,98

7,14

7,13

7,23

6,97

6,83

6,81

6,79

7,17

6,794

7,234

7,017

Resina composta Z-250 (3M/ESPE).

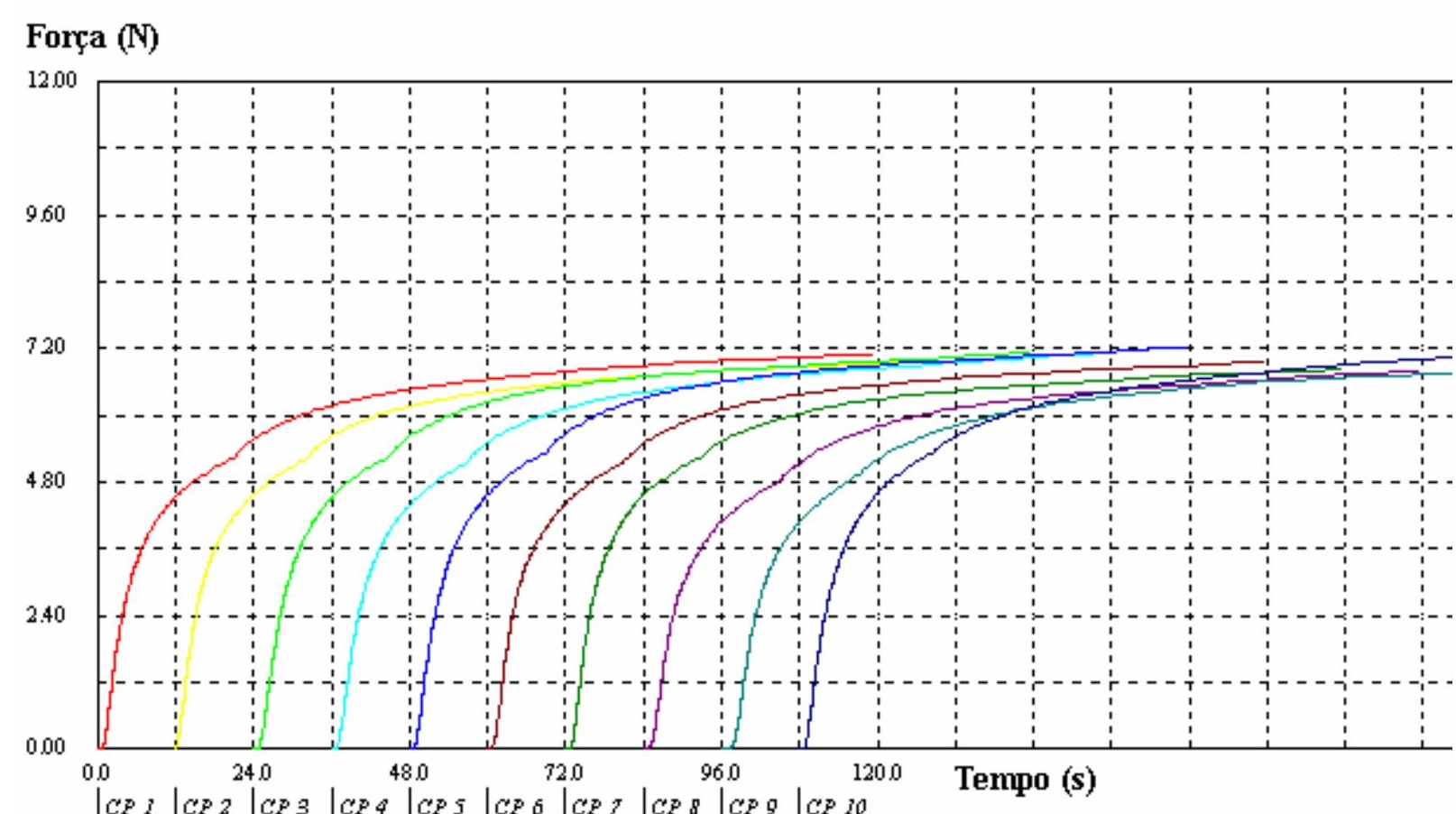

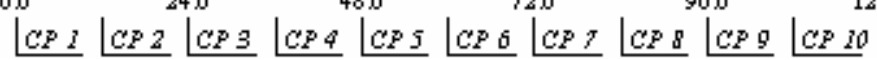


Anexo 04 - Forças máximas (Newton) e curvas [força (N) X tempo (s)] obtidas

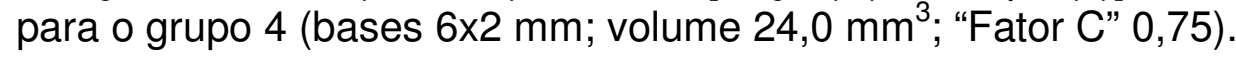

$\begin{array}{cc}\text { CORPO DE PROVA } & \text { FORÇA MÁXIMA (N) } \\ \text { CP1 } & 7,91 \\ \text { CP2 } & 8,09 \\ \text { CP3 } & 7,78 \\ \text { CP4 } & 8,10 \\ \text { CP5 } & 8,53 \\ \text { CP6 } & 8,32 \\ \text { CP7 } & 8,68 \\ \text { CP8 } & 8,41 \\ \text { CP9 } & 8,43 \\ \text { CP10 } & 8,35 \\ \text { MÍNIMO } & 7,781 \\ \text { MÁXIMO } & 8,677 \\ \text { MÉDIA } & \mathbf{8 , 2 6 1}\end{array}$

Resina composta Z-250 (3M/ESPE).

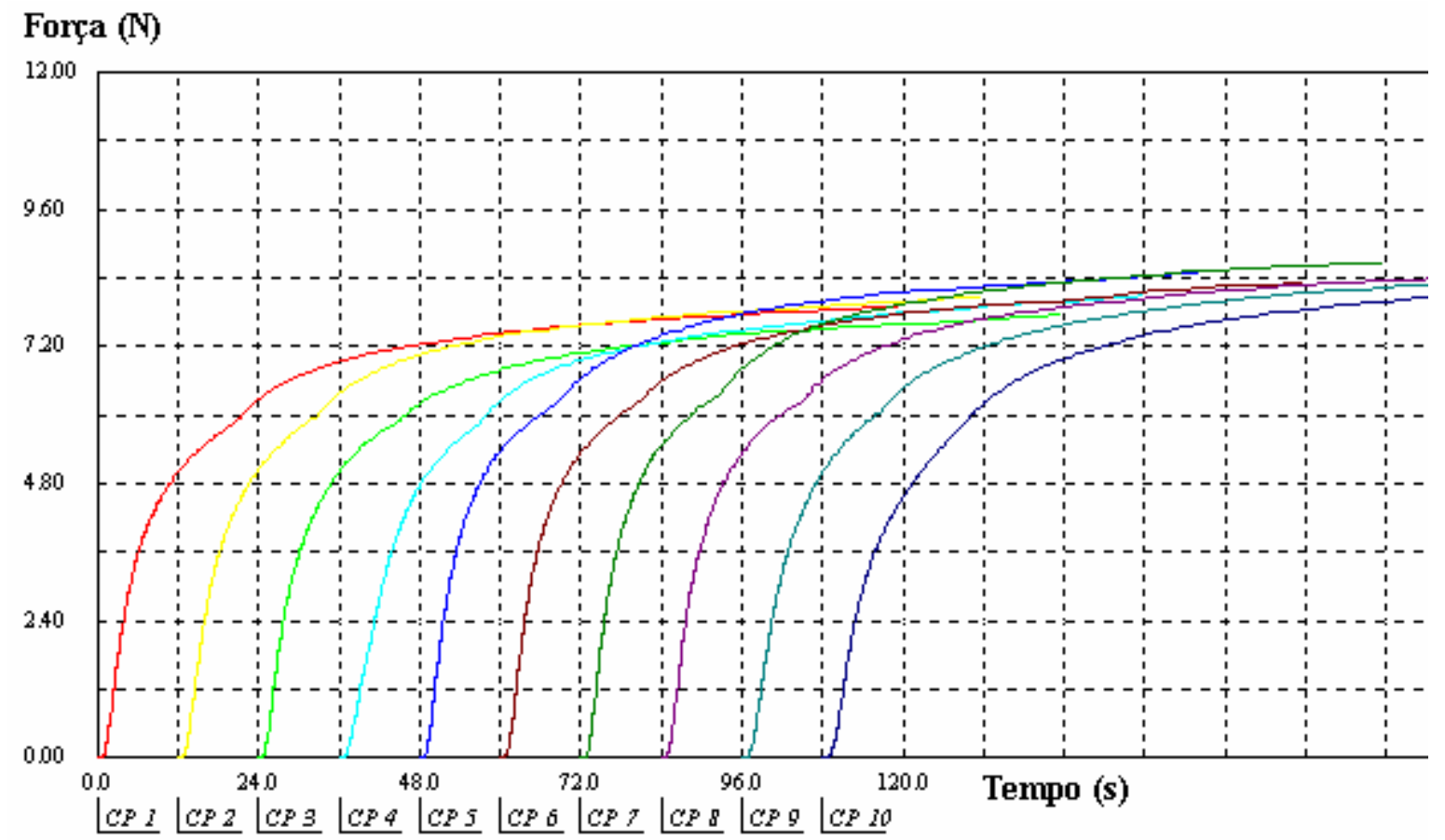


Anexo 05 - Forças máximas (Newton) e curvas [força (N) X tempo (s)] obtidas para o grupo 5 (bases $6 \times 2 \mathrm{~mm}$; volume $30,0 \mathrm{~mm}^{3}$; "Fator C" 0,6).

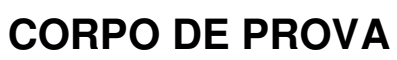

CP1
CP2
CP3
CP4
CP5
CP6
CP7
CP8
CP9
CP10
MÍNIMO
MÁXIMO
MÉDIA

FORÇA MÁXIMA (N)
$\begin{gathered}9,88 \\ 10,01 \\ 9,54 \\ 9,20 \\ 9,96 \\ 10,01 \\ 9,98 \\ 10,49 \\ 9,57 \\ 9,83 \\ 9,201 \\ 10,490 \\ 9,847\end{gathered}$

Resina composta Z-250 (3M/ESPE).

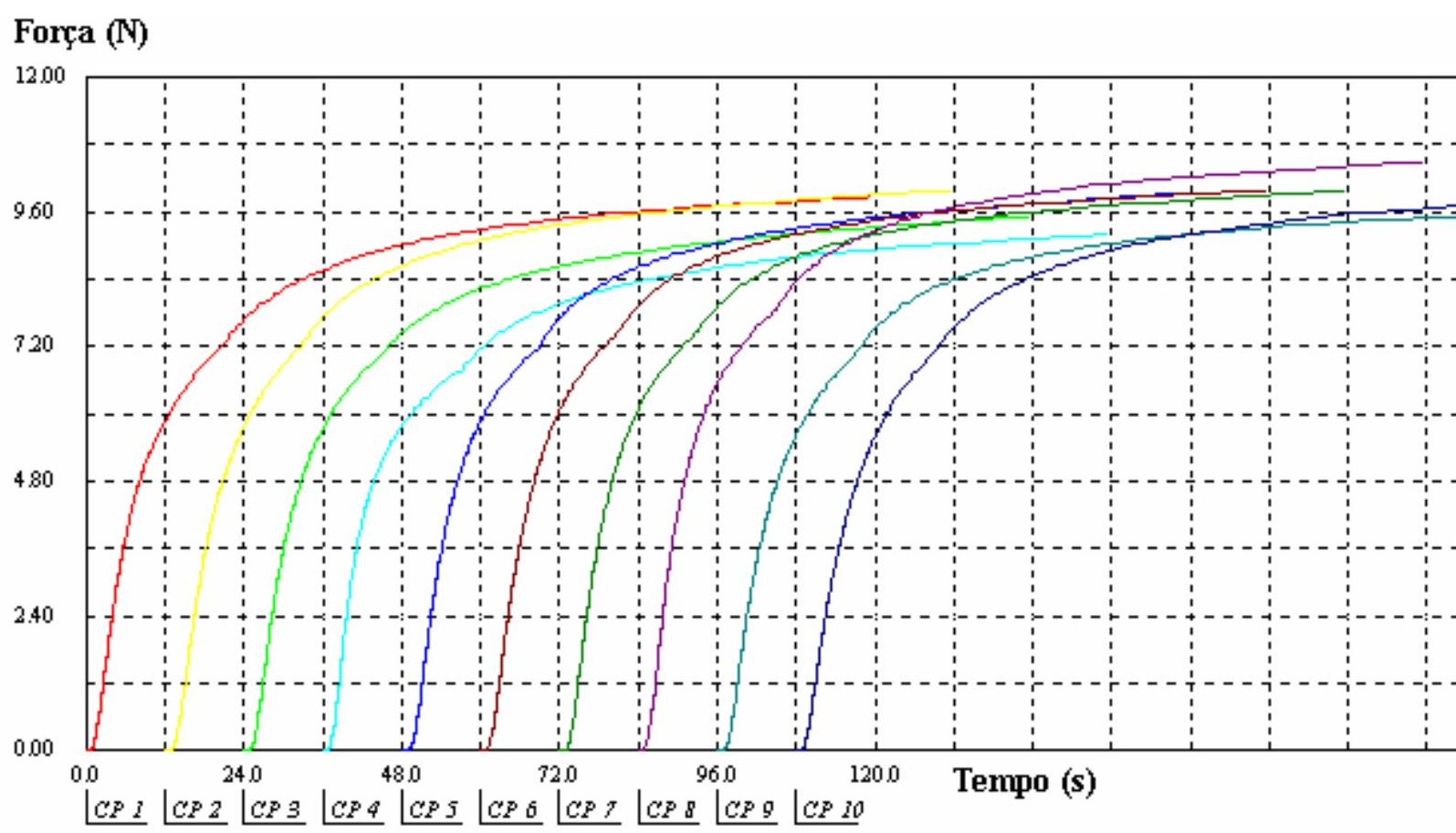


Anexo 06 - Forças máximas (Newton) e curvas [força (N) X tempo (s)] obtidas

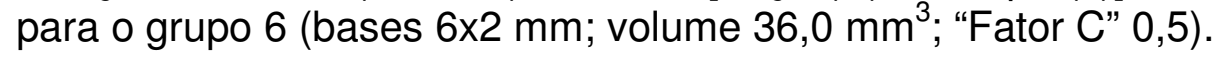

\section{CORPO DE PROVA}

CP1

CP2

CP3

CP4

CP5

CP6

CP7

CP8

CP9

CP10

MÍNIMO

MÁXIMO

MÉDIA

\section{FORÇA MÁXIMA (N)}

11,26

11,61

11,32

11,02

10,68

11,18

11,14

11,30

10,49

11,40

10,49

11,61

11,14

Resina composta Z-250 (3M/ESPE).

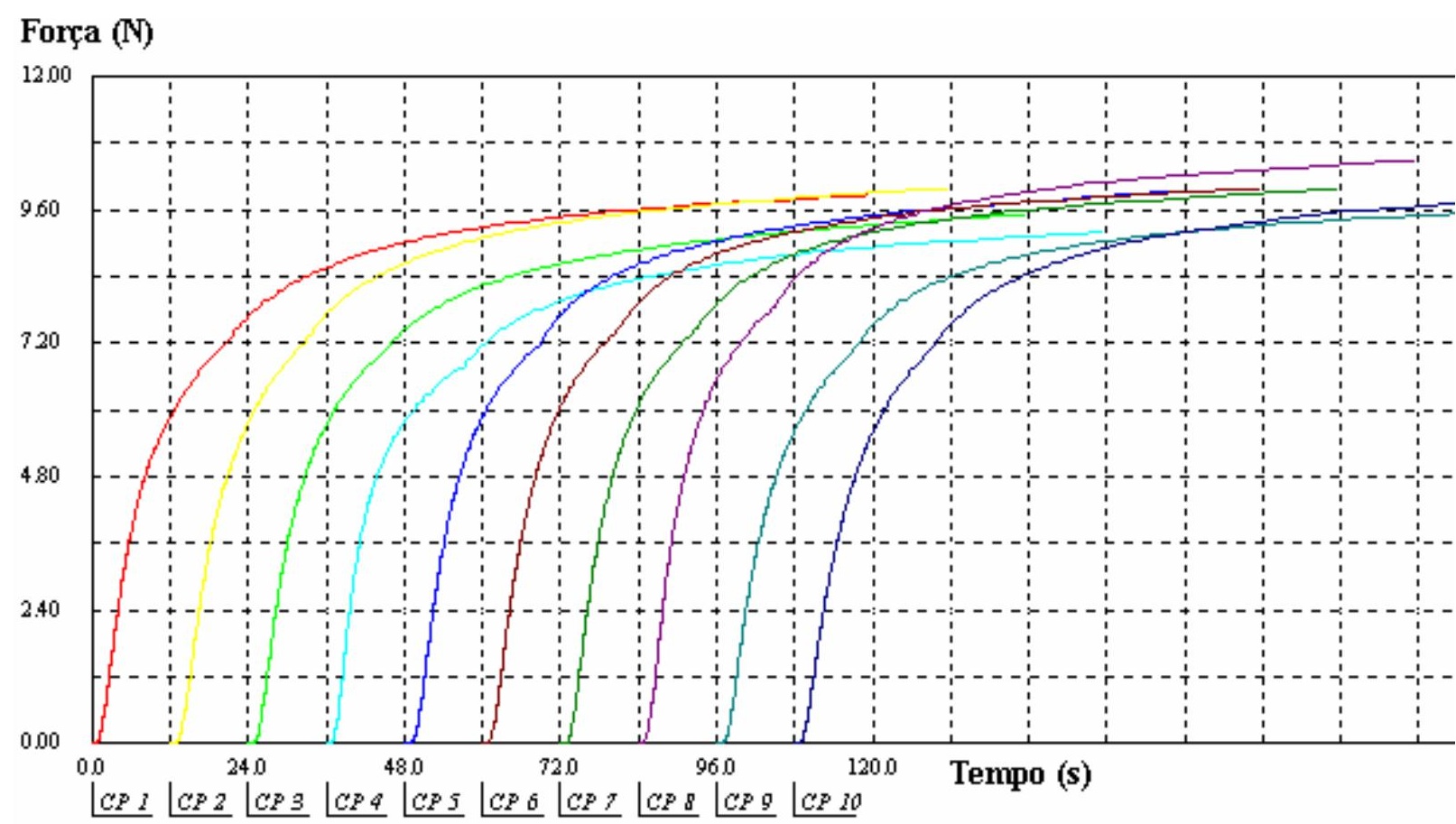


Anexo 07 - Forças máximas (Newton) e curvas [força (N) X tempo (s)] obtidas para o grupo 7 (bases 3x2 mm; volume 12,0 mm³; "Fator C" 0,6; resina composta Z-250 (3M/ESPE).

CORPO DE PROVA

CP1
CP2
CP3
CP4
CP5
CP6
CP7
CP8
CP9
CP10

MÍNIMO

MÁXIMO

MÉDIA
FORÇA MÁXIMA (N)

3,76

3,97

3,96

4,04

3,75

4,13

3,78

3,81

3,75

3,95

3,747

4,125

3,890

Resina composta Z-250 (3M/ESPE).

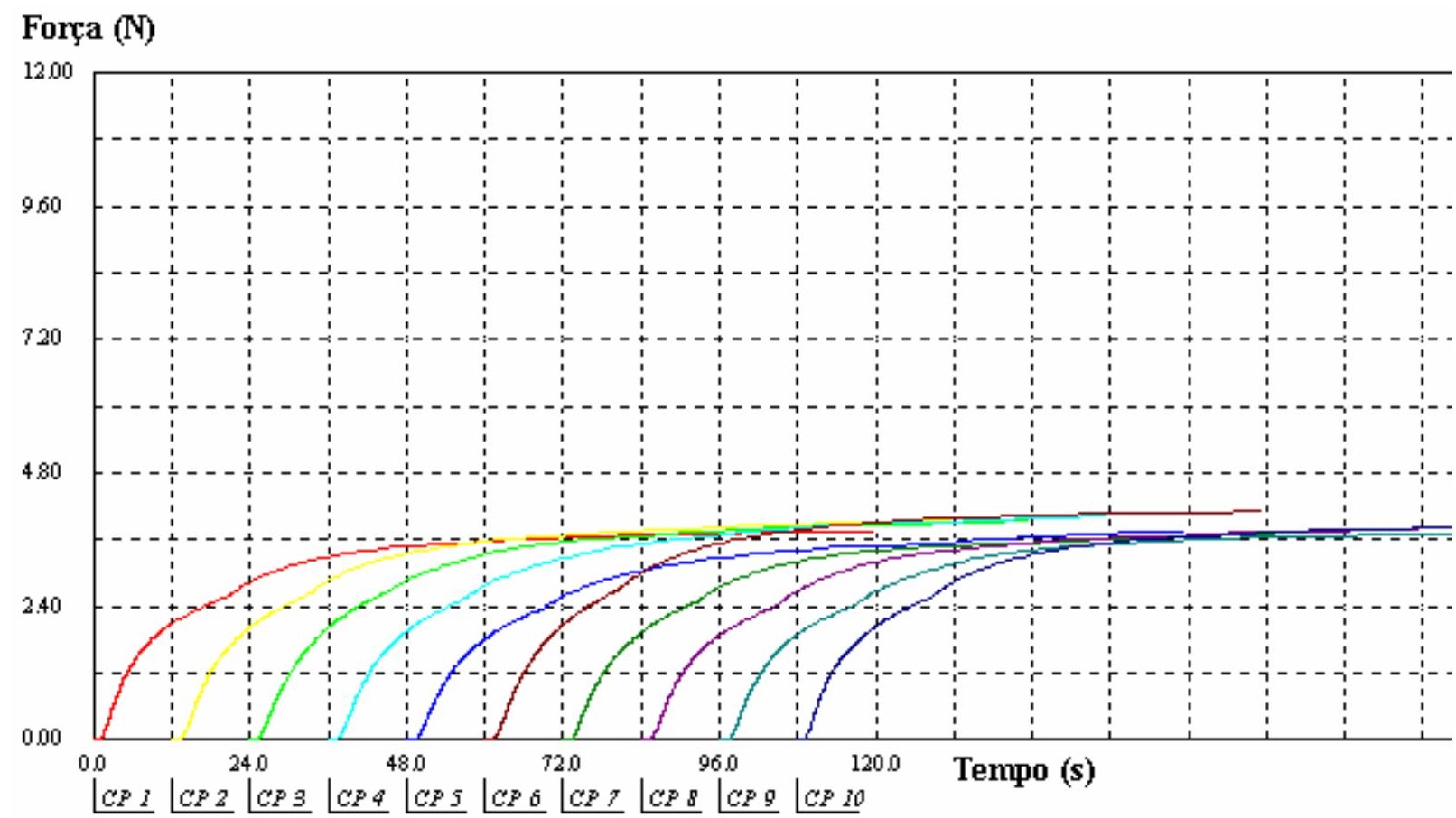


Anexo 08 - Forças máximas (Newton) e curvas [força (N) X tempo (s)] obtidas para o grupo 8 (bases 2x2 mm; volume 12,0 $\mathrm{mm}^{3}$; "Fator C" 0,33; resina Z-250 3M/ESPE).

CORPO DE PROVA

CP1
CP2
CP3
CP4
CP5
CP6
CP7
CP8
CP9
CP10
MíNIMO
MÁXIMO
MÉDIA

\section{FORÇA MÁXIMA (N)}

3,98

4,20

3,96

4,23

3,88

4,09

4,01

4,19

4,01

4,19

3,880

4,228

4,074

Resina composta Z-250 (3M/ESPE).

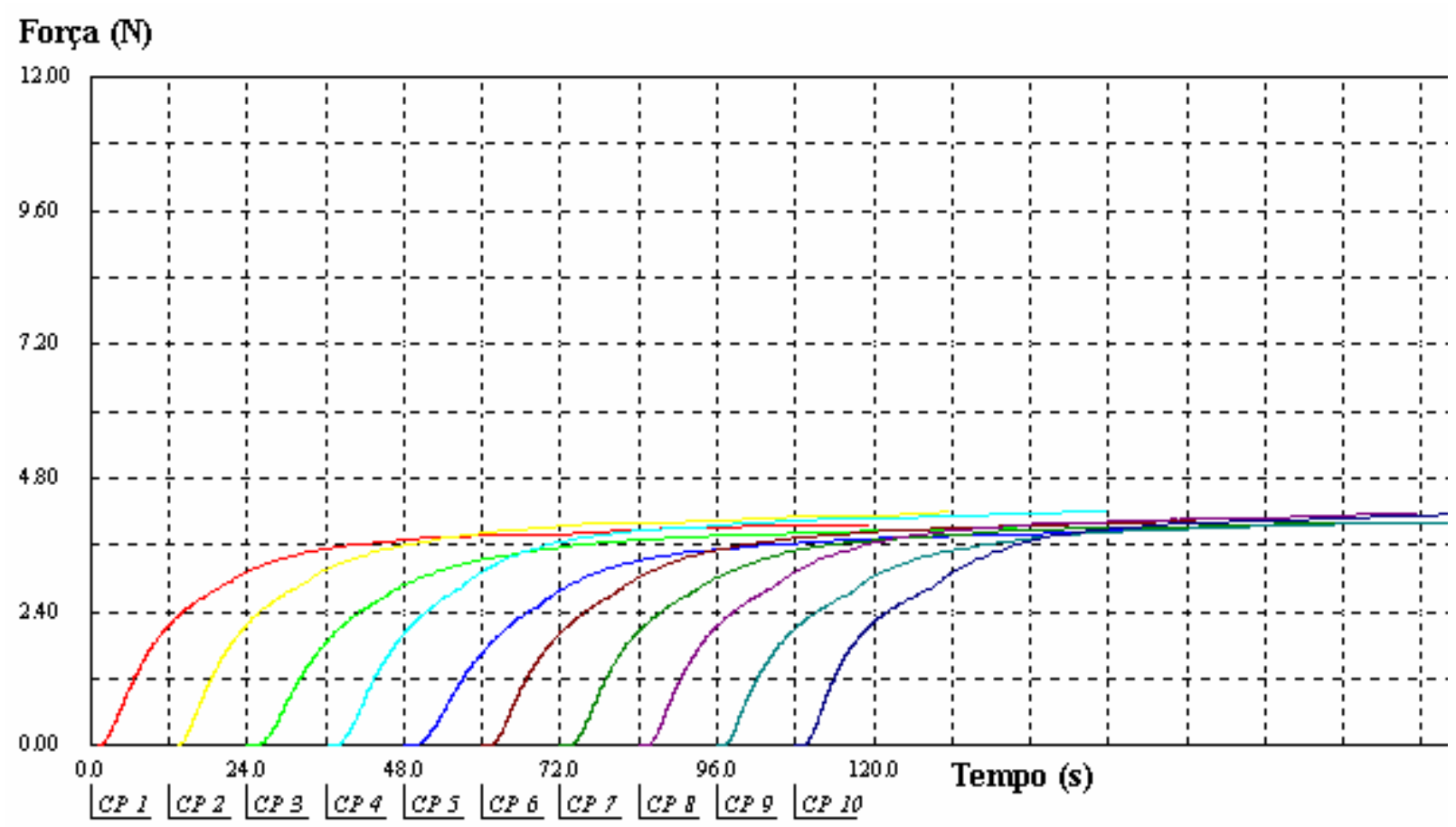


Anexo 09 - Forças máximas (Newton) e curvas [força (N) X tempo (s)] obtidas para o grupo 9 (bases $3 \times 2 \mathrm{~mm}$; volume 12,0 $\mathrm{mm}^{3}$; "Fator C" 0,6; resina composta Concise 3M/ESPE).

CORPO DE PROVA

CP1
CP2
CP3
CP4
CP5
CP6
CP7
CP8
CP9
CP10
MÍNIMO
MÁXIMO
MÉDIA

\section{FORÇA MÁXIMA (N)}

4,90

4,84

5,11

4,76

5,07

5,36

4,89

4,73

4,22

5,37

4,225

5,373

4,926

Resina composta Concise (3M/ESPE).

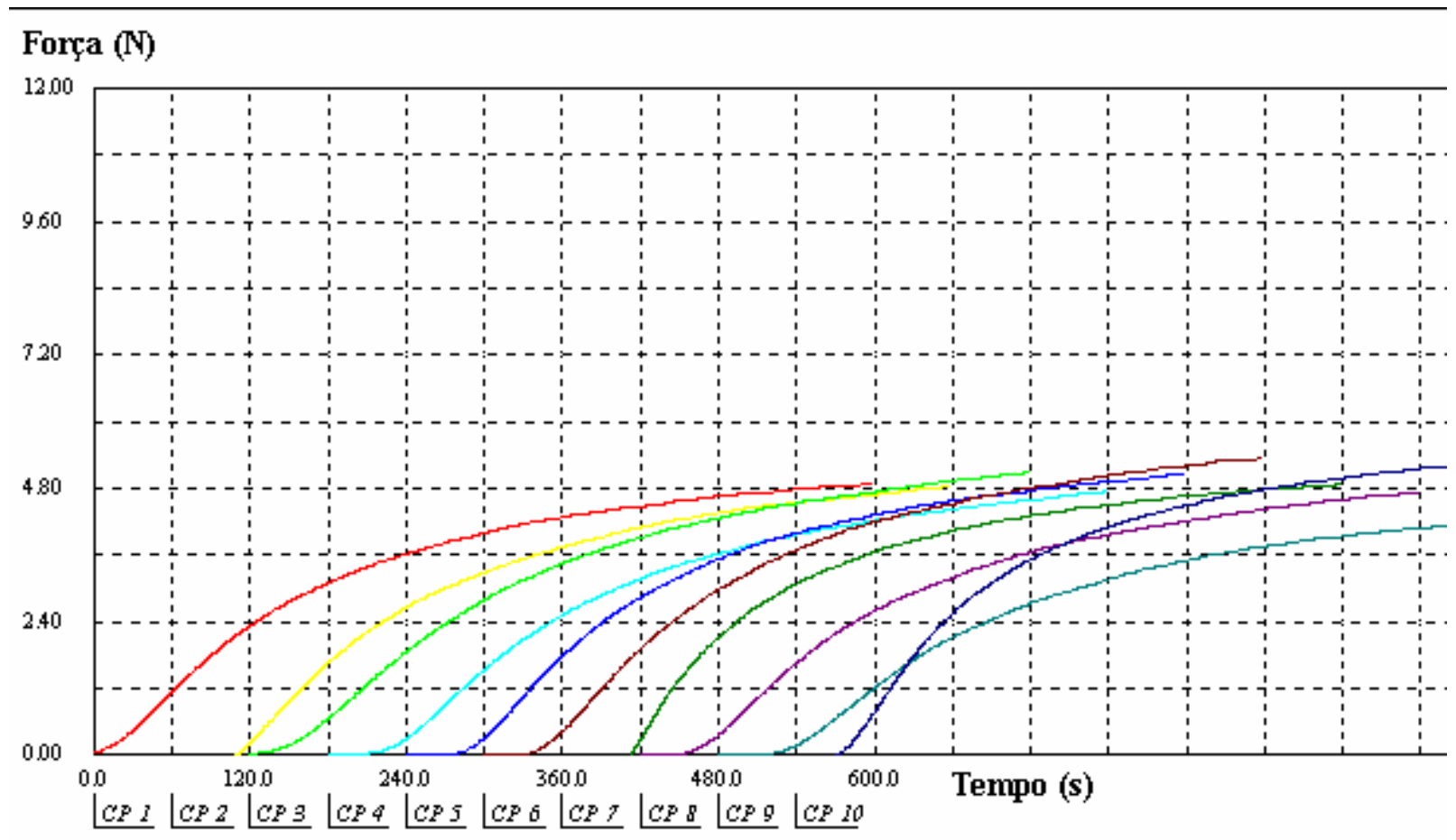


Anexo 10 - Forças máximas (Newton) e curvas [força (N) X tempo (s)] obtidas para o grupo 10 (bases $2 \times 2 \mathrm{~mm}$; volume 12,0 $\mathrm{mm}^{3}$; "Fator C" 0,33; resina composta Concise 3M/ESPE).

\section{CORPO DE PROVA}

CP1

CP2

CP3

CP4

CP5

CP6

CP7

CP8

CP9

CP10

MÍNIMO

MÁXIMO

MÉDIA
FORÇA MÁXIMA (N)

1,90

2,28

1,96

1,92

2,79

2,06

1,93

2,63

2,08

2,42

1,896

2,789

2,197

Resina composta Concise (3M/ESPE).

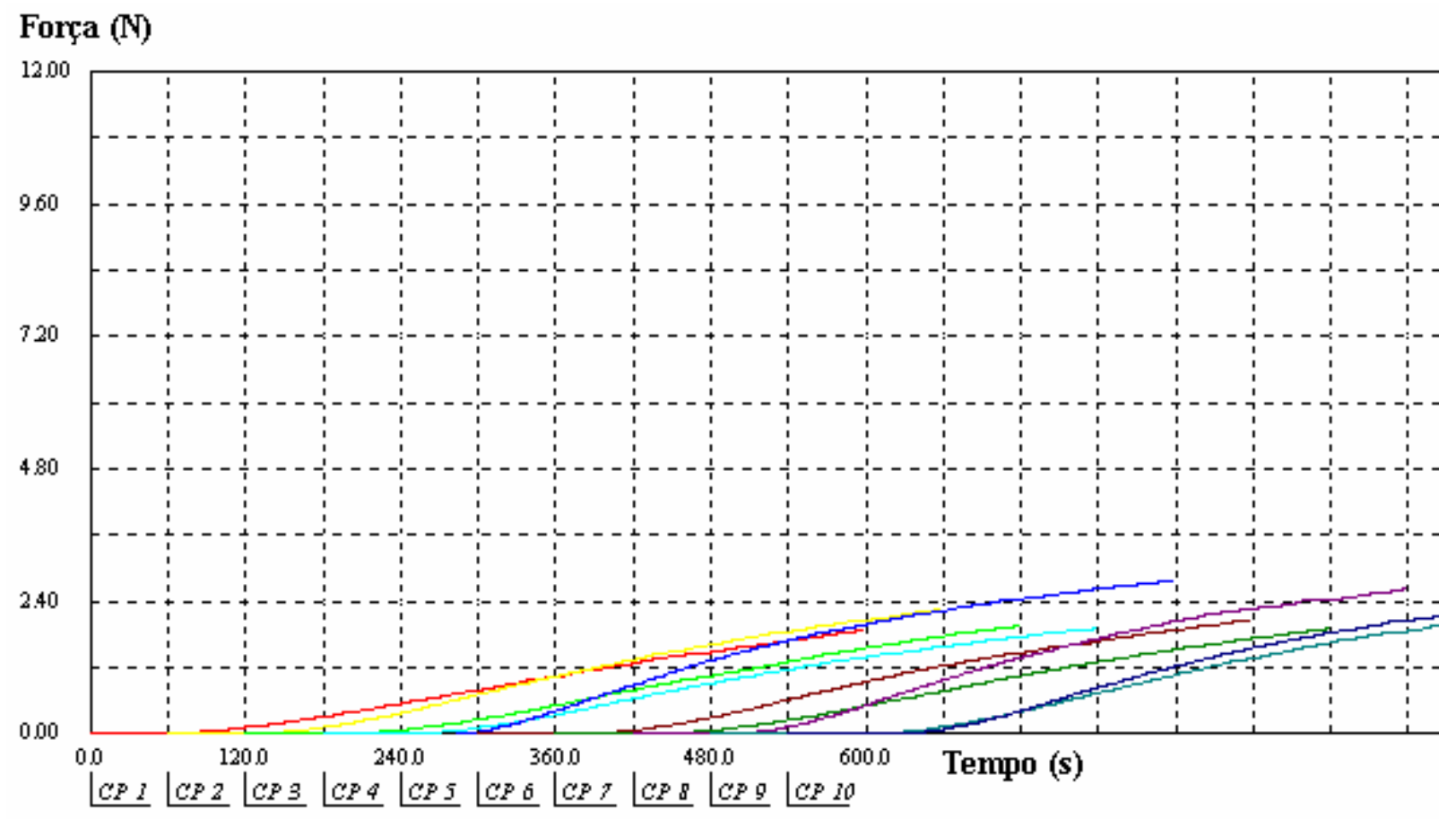


REFERÊNCIAS BIBLIOGRÁFICAS 


\section{REFERÊNCIAS BIBLIOGRÁFICAS}

1 ALSTER, D.; FEIZER, A. J.; DE GEE, A. J.; DAVIDSON, C. L. Polymerization contraction stress in thin resin composite layers as a function of layer thickness. Dent Mater, Copenhagen, v. 13, n. 3, p. 146-150, May 1997a.

2 ALSTER, D.; VENHOVEN, B. A. M.; FEIZER, A. J.; DAVIDSON, C. L. Influence of compliance of the substrate materials on polymerization contraction stress in thin resin composite layers. Biomaterials, Oxford, v. 18, n. 4, p. 337-341, 1997b.

3 ASENJO-MARTINEZ, M. A. J., CASTAÑEDA-ESPINOSA, J. C., FRANCO, E. B., MONDELLI, R.F.L. Avaliação da contração de polimerização de uma resina composta utilizando a técnica em rampa. Pesq. Odontol Bras, São Paulo , v. 17, p. 190, ago./ 2003. Resumo n. Pb253. Suplemento 2. Trabalho apresentado na 20ª Reunião Anual da Sociedade Brasileira de Pesquisa Odontológica, ago./2003.

4 ASMUSSEN, E. Composite restorative resins: composition versus wall-to-wall polymerization contraction. Acta Odontol Scand, Stockholm, v. 16, n. 4, p. 337344, June 1975.

5 AZEVEdo, J. F. D. G., CASTAÑEdA-ESPINOSA, J. C., FRANCO, E. B., MONDELLI, R. F. L.; Avaliação da força de contração de polimerização utilizando a técnica do pulso tardio com fonte de luz VIP. Pesq. Odontol Bras, São Paulo, v.17, p. 191, ago./2003. Resumo n. Pb262. Suplemento 2. Trabalho apresentado na 20 a Reunião Anual da Sociedade Brasileira de Pesquisa Odontológica, ago./2003.

6 BAUSCH, J. R.; de LANGE, K.; DAVIDSON, C. L.; PETERS, A.; de GEE, A. J. Clinical significance of polymerization shrinkage of composite resins. J Prosthet Dent, St. Louis, v. 48, n. 1, p. 59-67, July 1982.

7 BOUSCHLICHER, M. R.; RUEGGEBERG, F. A.; BOYER, D. B. Effect of stepped light intensity on polymerization force and conversion in a photoactivated composite. J Esthet Dent, Philadelphia, v. 12, n. 1, p. 23-32, 2000.

8 BOUSCHLINCHER, M. R.; VARGAS, M.; BOYER, D. Effect of composite type, light intensiy, configuration factor and laser polymerization on polymerization contraction forces. J Dent Bristol, v. 10, n. 2, p. 88-96, Apr. 1997.

9 BOWEN, R. Adhesive bonding of various materials to hard tooth tissues. Forces development in direct-filling materials during hardening. J Am Dent Assoc, Chicago, v. 74, p. 439-445, Feb. 1967.

10 BOWEN, R. L.; NEMOTO, K.; RASPON, J. E. Adhesive bonding of various materials to hard tooth tissues: forces developing in composite materials during hardening. J Am Dent Assoc, Chicago, v. 106, n. 4, p. 475-477, Apr. 1983. 
11 BRAEM, M.; LAMBRECHTS, P; VANHERLE, G.; DAVIDSON, C.L. Stiffnes Increase During the Setting of Dental Composite Resins. J Dent Res, Chicago, v. 66, n. 12, p.1713-1716, Dec.1987.

12 BRAGA, R. R.; FERRACANE, J. L. Contraction stress related to degree of conversion and reaction kinetics. J Dent Res, Chicago, v. 81, n. 2, p. 114-118, Feb. 2002.

13 CALHEIROS, F. C.; BRAGA, R. R.; KAWANO, Y.; BALLESTER, R.Y. Relationship between contraction stress and degree of conversion in restorative composites. Dent Mater, Copenhagen, v. 20, n. 10, p. 939-946, Dec. 2004.

14 CASTAÑEDA-ESPINOSA, J. C.; MONDELLI, R. F. L. Avaliação das forças de contração na polimerização de resinas compostas ativadas com luz halógena e LED. In: REUNIÃO ANUAL DA SOCIEDADE BRASILEIRA DE PESQUISA ODONTOLÓGICA, 19., 2002, Águas de Lindóia Anais... Águas de Lindóia: Ed. Científica, 2002. p.15.

15 CASTAÑEDA-ESPINOSA, J. C.; MONDELLI, R. F. L.; FRANCO, E. B.; CAVALCANTI, A. P. Alteração na força de contração de uma resina composta em função da utilização de diferentes materiais intermediários. Pesqui Odontol Bras, São Paulo, v.17, p. 191, ago./2003. Resumo n. Pb259. Suplemento 2. Trabalho apresentado na 20 a Reunião Anual da Sociedade Brasileira de Pesquisa Odontológica, ago./2003.

16 CARVALHO, R. M.; PEREIRA, J. C.; YOSHIMA, M.; PASHLEY, D. H. A review of polymerization contraction: the influence of stress development versus stress relief. Oper Dent, Seattle, v. 21, n. 1, p.17-24, Jan./Feb. 1996.

17 CAVAlCANTI, A. P.; CASTAÑEDA-ESPINOSA, J. C.; MONDELLI, R. F. L. Avaliação das forças de contração de polimerização em diferentes técnicas com a mesma energia de irradiação. In: REUNIÃO ANUAL DA SOCIEDADE BRASILEIRA DE PESQUISA ODONTOLÓGICA, 20., 2003, Águas de Lindóia. Anais... Águas de Lindóia: Ed. Científica, 2003. p. 95.

18 CAVINA, D. A.; MONDELLI, R. F. L.; CASTAÑEDA-ESPINOSA, J. C.; GOMES, J. C.; CORTÉS, M. J. V.; VIRGENS FILHO, J. S. D. Análise das forças geradas durante a contração de polimerização de resinas compostas ativadas utilizando LED com diferentes tempos. In: REUNIÃO ANUAL DA SOCIEDADE BRASILEIRA DE PESQUISA ODONTOLÓGICA, 20., 2003, Águas de Lindóia. Anais... Águas de Lindóia: Ed. Científica, 2003. p. 184.

19 CHAIN, M. C. Como polimerizar uma resina composta. Guia de compras Dental Gaúcho., 2001.

20 CHEN, H. Y.; Manhart, J.; Hickel, R.; Kunzelmann, K. H. Polymerization contraction stress in light-cured packable composite resins. Dent Mater, Copenhagen, v. 17, n. 3, p. 253-259, May 2001. 
$21 \mathrm{CHO}$, B.H.; DICKENS, S. H.; BAE, J. H.; CHANG, C. G.; SON, H. H.; UM, C. M. Effect of interfacial bond quality on the direction of polymerization shrinkage flow in resin composite restorations. Oper Dent, Seattle, v. 27, n. 3, p. 297-304, May/June 2002.

$22 \mathrm{CHOI}$, K. K.; CONDON, J. R.; FERRACANE, J. L. The effects of adhesive thickness on polymerization contraction stress of composite. J Dent Res, Chicago, v. 79, n. 3; p. 812-823, Mar. 2000.

23 CONDON, J. R.; FERRACANE, J. L. Reduction of composite contraction stress through non-bonded microfiller particle. Dent Mater, Copenhagen, v. 14, n. 6, p. 256-260, July 1998.

24 CONDON, J. R.; FERRACANE, J. L. Assessing the effect of composite formulation on polymerization stress. J Am Dent Assoc, Chicago, v. 131, n. 4; p. 335-341, Apr. 2000.

25 CORTÉS, M. J. V., GOMES, J. C., CASTAÑEDA-ESPINOSA, J. C, CAVINA, D. A., VIRGENS FILHO, J. S. D., RIBEIRO, J. P. F., MONDELLI, R. F. L. Comparação das forças de contração de polimeriação de uma resina composta utilizando aparelho halógeno e a base de LEDs. Pesqui Odontol Bras, v.17, p. 187, Resumo n. Pb227, ago./ 2003. Suplemento 2. Trabalho apresentado na 20ª Reunião Anual da Sociedade Brasileira de Pesquisa Odontológica, ago./2003.

26 DAVIDSON, C. L. Handling of polymerization stresses in composite restorations. In: INTERNATIONAL SYMPOSIUM, 2nd., 1998. [S.I.], 1998. p. 22-25.

27 DAVIDSON, C. L. Resisting the curing contraction with adhesive composites. J Prosthet Dent, St. Louis, v. 55, n. 4, p. 446-447, Apr. 1986.

28 DAVIDSON, C. L. Activation energy, light sources and depth of cure. In: SIMPOSIO ITERNAZIONALE DE ODONTOIARIA ADESIVA E RICONSTRUTIVA, 4., 2000, S. Margherita Ligure, 2000. Atti... [S.I.]: Probagonsti in Odontoiatria, 2000. p. 68-72.

29 DAVIDSON, C. L., DE GEE, A. J. Relaxation of polimerization contraction stresses by flow in dental composites. J Dent Res, Chicago, v. 63, n. 2, p. 146-148, Feb.1984.

30 DAVIDSON, C. L.; DE GEE, A. J.; FEILZER, A. J. The Competition between the composite-Dentin bond Stregth and the Polimerization Contraction Stress. J Dent Res, Chicago, v. 63, n. 12, p. 1396-1399, Dec.1984.

31 DAVIDSON, C. L.; FEILZER, A. J. Polymerization shrinkage and polymerization shrinkage stress in polymer-based restoratives. J Dent Bristol, v. 25, n. 6, p. 435440, Nov.1997.

32 DE GEE, A. J.; DAVIDSON, C. L.; SMITH, A. A modified dilatometer for continuous recording of volumetric polymerization shrinkage of composite restorative materials. J Dent Bristol, v. 9, n. 1, p. 36-42, Mar. 1981. 
33 DAUVILLIER, B. S.; AARNTS, M. P.; FEILZER, A. J. Developments in shrinkage control of adhesive restoratives. J Esthet Dent, Philadelphia, v. 12, n. 6, p. 291299, 2000.

34 FEILZER, A. J.; DE GEE, A.J.; DAVIDSON, C. L. Setting stress in composite resin in relation to configuration of the restoration. J Dent Res, Chicago, v. 66, n. 11, p.1636-1639, Nov. 1987.

35 FEILZER, A. J., DE GEE, A. J., DAVIDSON, C. L. Relaxation of polimerization contraction shear stress by hygroscopic expansion. J Dent Res, Chicago, v. 69, n. 1, p.36-39, Jan. 1990.

36 FEILZER, A. J.; DE GEE, A.J.; DAVIDSON, C. L. Setting stresses in composites for two different curing modes. Dent Mater, Copenhagen, v. 9, n. 1, p. 2-5, Jan. 1993.

37 FRANCO, E. B; LOPES, L. G. Conceitos atuais na polimerização de sistemas restauradores resinosos. BioOdonto, Maringá, v.1, n.2, p.10-59, mar./abr. 2003.

38 FRANCO, E. B., LOPES, L. G., MONDELLI, R. F. L., SOUZA Junior, M. H. S.; LAURIS, J. R. P. Effect of the cavity configuration factor on the marginal microleakage of esthetic restorative materials. Am J Dent, San Antonio, v. 16, n. 3, p. 211-214, June, 2003.

39 HANSEN, E. K.; ASMUSSEN, E. Marginal adaptation of posterior resins: Effect of dentin-bonding agent and hygroscopic expansion. Dent Mater, Copenhagen, v. 5, n. 2, p. 122-126, Mar. 1989.

40 HEGHDAHL, T.; GJERDET, N.R. Contraction stresses of composite resin filling materials. Acta Odontol Scand, Stockholm, v. 35, n. 4, p.191-195, 1977.

41 ILIE, N.; FELTEN, K.; TRIXNER, R. H.; KUNZELMANN, K. Shirinkage behavior of a resin-based composite irradiated with modrn curing units. Dent Mater, Copenhagen, v. 21, n. 5, p.483-489, May 2005.

42 KEMP-SCHOLTE, CH. M.; DAVIDSON, C. L. Marginal Sealing of Curing Contraction Gaps in class V Composite Resin Restorations. J Dent Res, Chicago, v. 67, n. 5 , p. $841-845$, May 1988.

43 KEMP-SCHOLTE, CH.M.; DAVIDSON, C.L. Marginal integrity related to bond strength and strain capacity of composite resin restorative systems. J Prosthet Dent, St. Louis, v. 64, n. 6, p. 658-664, Dec.1990.

44 KINOMOTO, Y.; TORII, M.; TAKESHIGE, F.; EBISU, S. Comparison of polymerization contraction stresses between self- and light-curing composites. $\mathbf{J}$ Dent, Bristol, v. 27, n. 5, p. 383-389, July 1999.

45 KORAN, P.; KÜRSCHNER, R. Effect of sequential versus continuous irradiation of light-cure resin composite on shrinkage, viscosity, adhesion, and degree of polymerization. Am J Dent, San Antonio, v.11, n.1, Feb. 1998. 
46 LABELLA, R.; LAMBRECHTS, P.; VAN MEERBEEK, B.; VANHERLE, G. Polymerization shrinkage and elasticity of flowable composites and filled adhesives. Dent. Mater, Chicago, v. 15, n. 2, p. 128-137, Mar. 1999.

47 LIM, B.S.; FERRACANE, J. L.; SAKAGUCHI, R. L.; CONDON, J. R. Reduction of polymerization contraction stress for dental composites by two-step light-activation. Dent Mater, Copenhagen, v. 18, n. 6, p. 436-444, Sept. 2002.

48 LOPES, L. G. Avaliação da contração de polimerização e das tensões promovidas em função de diferentes sistemas de polimerização e de materiais. Bauru, 2003. 134 f. Tese (Doutorado) - Faculdade de Odontologia de Bauru, Universidade de São Paulo, Bauru, 2003.

49 MIGUEL, A.; De LA MACORRA, J. C. A predictive formula of the contraction stress in restorative and luting materials attending to free and adhered surfaces. Dent Mater, Copenhagen, v. 17, n. 3, p. 241-246, May 2001.

50 MONDELLI, R. F. L; CASTAÑEDA-ESPINOSA, J. C; FRANCO, E. B. Avaliação das forças de contração geradas na polimerização segundo o tipo de resina composta e modo de ativação. In: REUNIÃO ANUAL DA SOCIEDADE BRASILEIRA DE PESQUISA ODONTOLÓGICA, 19., 2002, Águas de Lindóia. Anais... Águas de Lindóia: Ed. Científica, 2002. p. 241.

51 MONDELLI, R. F. L., CAVINA, D. A., CASTAÑEDA-ESPINOSA, J. C., FRANCO, E. B., MONDELLI, J. Avaliação das forças geradas durante a contração de polimerização de resinas compostas híbridas. JBD J Bras Dent Estet, Curitiba, v. 2, n. 7, p.238-245, jul./set, 2003.

52 NIKOLAENKO, S. A.; LOHBAUER, U., ROGGENDORF, A. P.; DASCH, W.; FRANKENBERGER, R. Influence of $c$-fator and layering technique on microtensile bond strength to dentin. Dent Mater, Copenhagen, v. 20, n. 6, p. 579-585, July 2004.

53 PALIN, W. M.; FleMinG, G. J. P.; NATHWANI, H.; TREVOR BURKE, F. J.; RANDALL, R. C. In vitro cuspal deflection and microleakage of maxillary premolars restored with novel low-shirink dental composites. Dent Mater, Copenhagen, v. 21, n. 4, p. 324-335, Apr. 2005.

54 PAN, L. C. P. Avaliação das forças geradas durante a contração de polimerização de resinas compostas microparticuladas. 2002. $142 \mathrm{f}$. Dissertação (Mestrado) - Centro de Pós-Graduação São Leopoldo Mandic, Campinas.

55 PEUTZFELDT, A. Resin composites in dentistry: the monomer systems. Eur J Oral Sci, Copenhagen, v. 105, n. 2, p. 97-116, Abr. 1997. 
56 RENGO, S. et al. Problems concerning composite material polymerization. In: SIMPOSIO ITERNAZIONALE DE ODONTOIARIA ADESIVA E RICONSTRUTIVA, 5., 2000, S. Margherita Ligure. Atti... [S.I.]: Probagonsti in Odontoiatria, 2001. p. 6670.

57 RUEGGEBERG, F. A.; CAUGHMAN, W. F.; CURTIS JUNIOR., J. W. Effect of light intensity and exposure duration on cure of resin composite. Oper Dent, Seattle, v. 19, n. 1, p. 26-32, Jan./Feb. 1994.

58 RUEGGEBERG, F. Contemporary Issues in photocuring. Compendium, Newtown, v. 20, n. 25, p. 4-15, Nov. 1999.

59 SAKAGUCHI, R. L.; PETERS, M. C.; NELSON, S. R.; DOUGLAS, W. H.; POORT, $\mathrm{H}$. W. Effects of polymerization contraction in composite restorations. J Dent Bristol, v. 20, n. 3, p.178-182, June 1992.

60 SAKAGUCHI, R. L. A Review of the Curing Mechanism of Composites and their Significance in Dental Applications. Compendium, Newtown, v. 20, n. 25, p. 16-23, Nov. 1999.

61 SAKAGUCHI, R.L.; WILTBANK, B.D.; MURCHISON, C.F. Contraction force rate of polymer composites is linearly correlated with irradiance. Dent Mater, Copenhagen, v. 20 , p. $402-407,2004$.

62 SANTOS, M.J.M.C., SANTOS JR.G.C., NAGEM FILHO, H., MONDELLI, R.F.L., EL MOWAFI, O. Effect of light curing method on volumetric polymerization shrinkage of resin composites. Oper Dent, Seattle, v. 29, n. 2, p. 157-161, Mar./Apr. 2004.

63 SANTOS, M. J. C. M.; SILVA e SOUZA JUNIOR, M. H.; MONDELLI, R. F. L. Novos conceitos relacionados à fotopolimerização das resinas compostas. JBD J Bras Dent Estet,, Curitiba, v. 1, n. 1, p. 14-21, jan./mar. 2002

64 SUH, B. I.; CINCIONE, F. A.; SANDRIK, J. L. Examination of experimental cavity substrate as a function of modulus of elasticity during polimerization of composite. $\mathbf{J}$ Dent Res, Chicago, v. 77, p. 261, 1998. Special Issue. Abstract n.1242.

$65 \mathrm{SUH}, \mathrm{B}$. I. Composite shrinkage stress and its relaxation by the pulse cure technique. In: International Symposium, 2., 1998, [S.I.]:, 1998. p. 26-32.

$66 \mathrm{SUH}, \mathrm{B}$. I. Controlling and understanding the polymerization shrinkage - induced stresses in light-cured composites. Compend Contin Educ Dent, Lawrenceville, v. 20, n. 1, p. 34-41, Nov. 1999.

67 SUH, B. I.; WANG, Y. Determining the direction of shrinkage in dental composite by changes in surface contour for different bonding configurations. Am J Dent, San Antonio, v. 14, n. 2, p. 109-113, Apr. 2001. 
68 TESSORE, G.; TRINCHERO, A. Post-operative sensitivity consequent to composite restorations in posterior sectors. In: SIMPOSIO ITERNAZIONALE DE ODONTOIARIA ADESIVA E RICONSTRUTIVA, 5., 2001, S. Margherita Ligure. Atti... [S.I.]: Probagonsti in Odontoiatria, 2001. p. 62-65.

69 UNO, S.; ASMUSSEN, E. Marginal adaptation of a restorative resin polymerized at reduced rate. Scan J Dent Res, Copenhagen, v. 99, n. 6, p. 440-444, Dec. 1991.

70 UNTERBRINK, G.; LIEBENBERG, W. Flowable resin composites as "filled adhesives": Literature review and clinical recommendations. Quintessence Int, Berlin, v. 30, n. 4, p. 249-257, Apr. 1999.

71 VERSLUIS, A.; TANTBIROJN, D. Theoretical considerations of contraction stress. Compend Contin Educ Dent, Lawrenceville, v. 20, n. 1, p. 24-32, Nov. 1999.

72 VERSLUIS, A.; TANTBIROJN, D.; DOUGLAS, W. H. Do dental composite always shrink toward the light? J Dent Res, Chicago, v. 77, n. 6, p. 1435-1445, June 1998.

73 WATTS, D. C.; MAROUF, A. S.; AL-HINDI, A. M. Photo-polymerization shirinkagestress kinetics in resin-composites: methods development. Dent. Mater, v.19, n.1, p.1-11, Jan. 2003.

74 YAP, A. U. J.; SOH, M. S.; SIOW, K. S. Effectiveness of composite cure with pulse activation and soft-start polymerization. Oper Dent, Seattle, v. 27, n. 1, p. 44-49, Jan./Feb. 2002a.

75 YAP, A.U.J.; SOH, M.S.; SIOW, K.S. Post-gel shrinkage with pulse activation and soft-start polymerization. Oper Dent, Seattle, v. 27, n. 1, p. 81-87, Jan./Feb. 2002b.

76 OSHIKAWA, T.; BURROW, M.F.; TAGAMI, J. The effects of bonding system and light curing method on reducing stress of different C-factor cavities. J Adhesive Dent, New Malden, v. 3, n. 2, p. 177-183, Summer 2001. 
ABSTRACT 


\section{ABSTRACT}

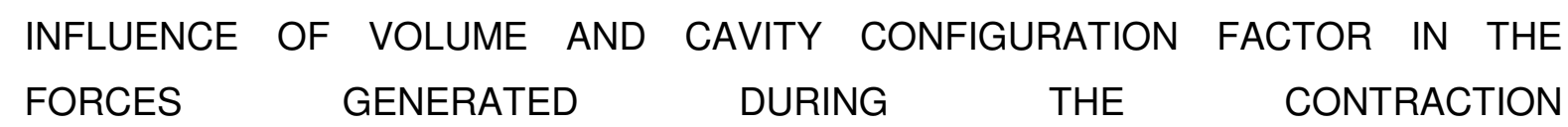
POLYMERIZATION OF COMPOSITE RESIN

The aim of this study was to evaluate "in vitro" the volume and cavity configuration factor ("C Factor") influence on chemical and photo activated resin composite polymerization contraction forces. The null hypothesis tested was that there would be no influence of the volume and " $\mathrm{C}$ Factor" on the resin composite contraction forces during polymerization. The experimental set up consisted of two identical and parallel steel bases one of them connected to the cross head of a Universal Testing Machine and the other to a transversal base. First, two rectangular steel bases ( $6 \mathrm{~mm} \times 2 \mathrm{~mm}$ ) were used with the distance between them adjusted to $0.5,1.0,1.5,2.0,2.5,3.0 \mathrm{~mm}$ for a total of 6 groups; the resin composite (Z-250 3M/ESPE) configuration factor was adjusted to 3.0, 1.5, 1.0, $0.75,0.6,0.5$ and its volume adjusted to $6,12,18,24,30,36 \mathrm{~mm}^{3}$, respectively. The resin composite was inserted into the space between bases and light cured with an halogen lamp for $20 \mathrm{~s}$ (Dentsply $\left.500 \mathrm{~mW} / \mathrm{cm}^{2} ; \mathrm{E}=10 \mathrm{~J} / \mathrm{cm} 2\right)$. During polymerization, a force $(\mathrm{N}) \mathrm{x}$ time (s) curve was obtained for a total of 10 samples for each group. Secondly, the forces generated during Z-250 resin composite polymerization contraction (polymerized for 20s; Dentsply $500 \mathrm{~mW} / \mathrm{cm}^{2} ; \mathrm{E}=10 \mathrm{~J} / \mathrm{cm}^{2}$ ) and the chemically cured resin composite Concise (3M/ESPE) were calculated. In this experiment, the resin composites " $C$ Factor" varied and their volumes were constantly maintained $\left(12 \mathrm{~mm}^{3}\right)$. Here, two thicknesses steel bases $(2 \mathrm{~mm} \times 2 \mathrm{~mm}$ and $2 \mathrm{~mm} \times 3 \mathrm{~mm}$ ) were used with the distance between them adjusted to 3.0 and $2.0 \mathrm{~mm}$ and the "C Factor" adjusted to 0.33 and 0.6 , respectively. A total of 4 groups and 10 samples for each were tested. The manipulation of Concise resin composite was carried out for 30s, it was then inserted between the bases for $90 \mathrm{~s}$, after which the test started and extended for 600s. During polymerization the force $(\mathrm{N}) \times$ time (s) curve was obtained. The means were compared using the Analysis of Variance and Tukey test $(p \leq 0.05)$. The null hypothesis was not accepted once the volume had influenced the physically activated resin composite contraction forces and the "C Factor" on the chemically activated composite. The conventionally activated Z-250 results showed 
that the volume variation, independently from "C Factor", had direct influence on the generated forces, differently from Concise, which was influenced by "C factor".

UNITERMS: Composite Resin; Polymerization; Contraction. 